Comprehensive Summaries of Uppsala Dissertations

from the Faculty of Science and Technology 706

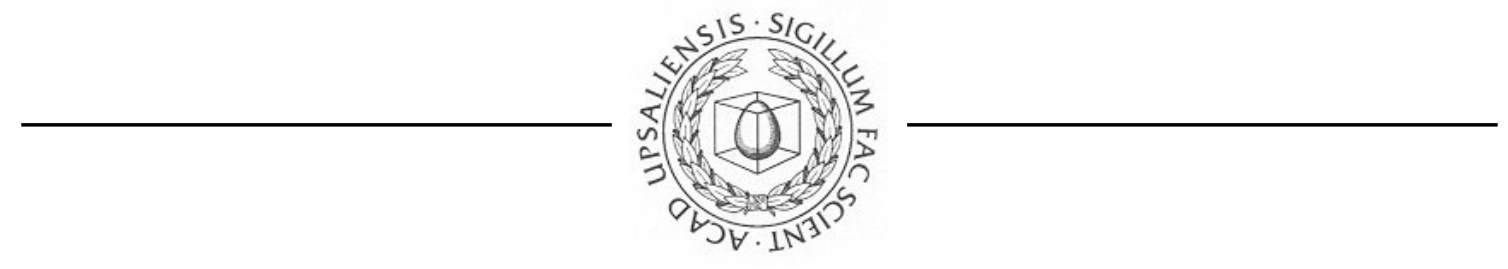

\title{
Identification and Characterization of Peptides and Proteins using Fourier Transform Ion Cyclotron Resonance Mass Spectrometry
}

BY

MAGNUS PALMBLAD

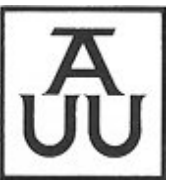

ACTA UNIVERSITATIS UPSALIENSIS UPPSALA 2002 
Dissertation for the Degree of Doctor of Philosophy in Molecular Biotechnology presented at Uppsala University 2002

\begin{abstract}
Palmblad, M. 2002. Identification and Characterization of Peptides and Proteins using Fourier Transform Ion Cyclotron Resonance Mass Spectrometry. Acta Universitatis Upsaliensis. Comprehensive Summaries of Uppsala Dissertations from the Faculty of Science and Technology 706. 76 pp. Uppsala. ISBN 91-554-5296-5.
\end{abstract}

Mass spectrometry has in recent years been established as the standard method for protein identification and characterization in proteomics with excellent intrinsic sensitivity and specificity. Fourier transform ion cyclotron resonance is the mass spectrometric technique that provides the highest resolving power and mass accuracy, increasing the amount of information that can be obtained from complex samples. This thesis concerns how useful information on proteins of interest can be extracted from mass spectrometric data on different levels of protein structure and how to obtain this data experimentally. It was shown that it is possible to analyze complex mixtures of protein tryptic digests by direct infusion electrospray ionization Fourier transform ion cyclotron resonance mass spectrometry and identify abundant proteins by peptide mass fingerprinting. Coupling on-line methods such as liquid chromatography and capillary electrophoresis increased the number of proteins that could be identified in human body fluids. Protein identification was also improved by novel statistical methods utilizing prediction of chromatographic behavior and the non-randomness of enzymatic digestion. To identify proteins by short sequence tags, electron capture dissociation was implemented, improved and finally coupled on-line to liquid chromatography for the first time. The combined techniques can be used to sequence large proteins de novo or to localize and characterize any labile post-translational modification. New computer algorithms for the automated analysis of isotope exchange mass spectra were developed to facilitate the study of protein structural dynamics. The non-covalent interaction between HIV-inhibitory peptides and the oligomerization of amyloid $\beta$-peptides were investigated, reporting several new findings with possible relevance for development of anti-HIV drug therapies and understanding of fundamental mechanisms in Alzheimer's disease.

Keywords: Peptide, protein, peptide mass fingerprinting, identification, sequencing, protein structure, non-covalent interaction, modification, electrospray ionization, liquid chromatography, capillary electrophoresis, electron capture dissociation, Fourier transform ion cyclotron resonance mass spectrometry, cerebrospinal fluid, amyloid $\beta$-peptide, Alzheimer's disease.

Magnus Palmblad, Division of Ion Physics, The Angström Laboratory, Uppsala University, Box 534, SE-751 21, Uppsala, Sweden

(C) Magnus Palmblad 2002

ISSN 1104-232X

ISBN 91-554-5296-5

Printed in Sweden by Uppsala University, Tryck \& Medier, Uppsala 2002 

This thesis is based on the following publications, which are referred to in the text by the Roman numerals I-IX:

I A 9.4 T Fourier Transform Ion Cyclotron Resonance Mass Spectrometer Description and Performance

Palmblad M, Håkansson K, Håkansson P, Feng X, Cooper HJ, Giannakopulos AE, Green PS and Derrick PJ

Eur. Mass Spectrom. 6, 267-275 (2000)

II Electron Capture Dissociation of Substance-P using a Commercially Available Fourier Transform Ion Cyclotron Resonance Mass Spectrometer Axelsson J, Palmblad M, Håkansson K and Håkansson P Rapid Commun. Mass Spectrom. 13, 474-477 (1999)

III Liquid Chromatography and Electron Capture Dissociation in Fourier Transform Ion Cyclotron Resonance Mass Spectrometry Palmblad M, Tsybin YO, Ramström M, Bergquist J and Håkansson P Rapid Commun. Mass Spectrom. 16, in press (2002)

IV Analysis of Enzymatically Digested Proteins and Protein Mixtures using a 9.4 Tesla Fourier Transform Ion Cyclotron Resonance Mass Spectrometer Palmblad M, Wetterhall M, Markides KE, Håkansson P and Bergquist J Rapid Commun. Mass Spectrom. 14, 1029-1034 (2000)

V Peptide Mapping of Proteins in Human Body Fluids using Electrospray Ionization Fourier Transform Ion Cyclotron Resonance Mass Spectrometry Bergquist J, Palmblad M, Wetterhall M, Håkansson P and Markides KE Submitted to Mass Spectrom. Rev. (2002)

VI Analysis of Tryptically Digested Cerebrospinal Fluid using Capillary Electrophoresis Electrospray Ionization Fourier Transform Ion Cyclotron Resonance Mass Spectrometry Wetterhall M, Palmblad M, Håkansson P, Markides KE and Bergquist J Manuscript (2002)

VII Prediction of Chromatographic Retention and Protein Identification in Liquid Chromatography Mass Spectrometry

Palmblad M, Ramström M, Markides KE, Håkansson P and Bergquist J Manuscript (2002) 
VIII Oxidation of Methionine-35 Attenuates Formation of Amyloid $\beta$-Peptide (1-40) Oligomers

Palmblad M, Westlind-Danielsson A and Bergquist J

J. Biol. Chem. 277, in press (2002)

IX Automatic Analysis of Hydrogen/Deuterium Exchange Mass Spectra of Peptides and Proteins using Calculations of Isotopic Distributions

Palmblad M, Buijs J and Håkansson P.

J. Am. Soc. Mass. Spectrom. 12, 1153-1162 (2001)

(C) IM Publications (I)

(C) John Wiley \& Sons Inc. (II-IV)

(C) The American Society for Biochemistry and Molecular Biology, Inc. (VIII)

(C) The American Society for Mass Spectrometry (IX)

All published or accepted papers are reprinted with permission from the journals in which they were originally published or accepted for publication.

I have produced experimental results for and written paper I. I was involved in the electron capture dissociation projects from the beginning and I wrote the computer software and performed experiments for paper II. I am accountable for original ideas, planning and performing experiments and writing of papers III and IV, and share significant responsibility for the same in papers V and VI. I am accountable also for original ideas and concepts in and writing of papers VII and IX, and the experiments, primary conclusions and writing of paper VIII. 
Related publications and manuscripts not included in thesis:

1 A Method to Significantly Lessen the Sample Contamination of the Vacuum Interface of an On-axis Electrospray Ion Source by Adding a Mechanical Shutter Axelsson J, Håkansson K, Palmblad M and Håkansson P Rapid Commun. Mass Spectrom. 13, 1550 (1999)

2 Analysis of the Native Lignin Structure using Fourier Transform Ion Cyclotron Resonance Mass Spectrometry Önnerud H, Palmblad M, Eriksson T and Gellerstedt G $10^{\text {th }}$ International Symposium on Wood and Pulping Chemistry, 11, I-166-I-171 (1999)

3 Mechanistic Studies of Multipole Storage Assisted Dissociation Håkansson K, Axelsson J, Palmblad $\mathbf{M}$ and Håkansson P J. Am. Soc. Mass. Spectrom. 11, 210-217 (2000)

4 Micro-Liquid Chromatography Fourier Transform Ion Cyclotron Resonance Mass Spectrometry - A Useful Tool for Peptide Identification Ramström M, Palmblad M, Amirkhani A, Tsybin YO, Markides KE, Håkansson $\mathrm{P}$ and Bergquist $\mathrm{J}$ Acta Biochim. Pol. 48, 1101-1104 (2002)

5 Investigation of Lignin Oligomer Structures using Electrospray Ionisation Mass Spectrometry Önnerud H, Palmblad M and Gellerstedt G Holzforsch. 56, in press (2002)

$6 \quad$ Strong Interaction Between Short Linear Peptides van der Spoel D, Raber J and Palmblad M Manuscript (2002)

7 Analysis of Cerebrospinal Fluid Proteins using Liquid Chromatography and Fourier Transform Ion Cyclotron Resonance Mass Spectrometry Ramström M, Palmblad M, Markides KE, Håkansson P and Bergquist J Manuscript (2002) 


\section{CONTENTS}

1. INTRODUCTION 9

$\begin{array}{ll}1.1 \text { Biological Macromolecules } & 9\end{array}$

$\begin{array}{ll}1.2 \text { Mass Spectrometry } & 13\end{array}$

1.2.1 Mass Analyzers 13

1.2.2 Ionization Techniques $\quad 15$

2. PROTEIN IDENTIFICATION 17

$\begin{array}{ll}2.1 \text { Methods } & 17\end{array}$

$\begin{array}{ll}\text { 2.1.1 Overview } & 17\end{array}$

2.1.2 Sample Purification 18

$\begin{array}{ll}\text { 2.1.3 Liquid Chromatography } & 18\end{array}$

2.1.4 Capillary Electrophoresis $\quad 20$

2.1.5 Electrospray lonization $\quad 21$

2.1.6 Fourier Transform Ion Cyclotron Resonance Mass Spectrometry 24

$\begin{array}{ll}\text { 2.1.7 Data Analysis } & 29\end{array}$

2.2 Results and Discussion $\quad 34$

2.2.1 Direct Infusion Electrospray lonization $\quad 34$

2.2.2 Liquid Separations and Mass Spectrometry 41

3. CHARACTERIZATION OF PEPTIDES AND PROTEINS

3.1 Methods $\quad 49$

3.2 Results and Discussion $\quad 50$

4. PEPTIDE AND PROTEIN STRUCTURE AND INTERACTIONS 54

4.1 Methods $\quad 54$

4.2 Results and Discussion $\quad 55$

4.2.1 Amyloid $\beta$-Peptides, Structure and Aggregation $\quad 55$

4.2.2 Non-covalent Interaction between HIV-Inhibitory Tripeptides $\quad 60$

4.2.3 Hydrogen/Deuterium Exchange Mass Spectrometry 62

5. CONCLUSIONS 66

6. ACKNOWLEDGEMENTS 67

7. REFERENCES $\quad 69$ 


\section{ABBREVIATIONS}

$\begin{array}{ll}\text { 2D } & \text { two-dimensional } \\ \text { AD } & \text { Alzheimer's disease } \\ \text { A } \beta & \text { amyloid } \beta \text {-peptide } \\ \text { BFPDB } & \text { body fluid protein database } \\ \text { BSA } & \text { bovine serum albumin } \\ \text { CE } & \text { capillary electrophoresis } \\ \text { CGE } & \text { capillary gel electrophoresis } \\ \text { CID } & \text { collision induced dissociation } \\ \text { CZE } & \text { capillary zone electrophoresis } \\ \text { DNA } & \text { deoxyribonucleic acid } \\ \text { ECD } & \text { electron capture dissociation } \\ \text { ESI } & \text { electrospray ionization } \\ \text { FFT } & \text { fast Fourier transform } \\ \text { FTICR } & \text { Fourier transform ion cyclotron resonance } \\ \text { FTNMR } & \text { Fourier transform nuclear magnetic resonance } \\ \text { HDX } & \text { hydrogen/deuterium exchange } \\ \text { HIV } & \text { human immunodeficiency virus } \\ \text { HSA } & \text { human serum albumin } \\ \text { ICR } & \text { ion cyclotron resonance } \\ \text { LC } & \text { liquid chromatography } \\ \text { MALDI } & \text { matrix assisted laser desorption/ionization } \\ \text { MAPTAC } & \text { [3-(methacryloylamino)-propyl]trimethylammonium chloride } \\ \text { MS } & \text { mass spectrometry } \\ \text { PAGE } & \text { polyacrylamide gel electrophoresis } \\ \text { PMF } & \text { peptide mass fingerprinting } \\ \text { Q } & \text { quadrupole } \\ \text { RF } & \text { radiofrequency } \\ \text { RNA } & \text { ribonucleic acid } \\ \text { RPC } & \text { revesed-phase chromatography } \\ \text { SDS } & \text { sodium dodecyl sulfate } \\ \text { SIMS } & \text { secondary ion mass spectrometry } \\ \text { TEMED } & \text { N,N,N',N'-tetramethylethylenediamine } \\ \text { TOF } & \text { time-of-flight } \\ \text { HA } & \end{array}$




\section{INTRODUCTION}

\subsection{Biological Macromolecules}

Three of the key macromolecular players in what we call life are deoxyribonucleic acid, DNA, ribonucleic acid, RNA, and proteins. The DNA contains the genes and the genes are the instructions, or blueprints, that are used to make proteins. Each protein performs its own specific tasks in the cell or body. RNA is the carrier of information between genes in the DNA and proteins. We say that genetic information is encoded in the DNA, transcribed into RNA (or mRNA for messenger RNA) and finally translated into the amino acid sequence of proteins (Figure 1). This unidirectional flow of information is often referred to as "the Central Dogma of molecular biology", stated by Crick in 1958 [1, 2]. There are four "letters" or bases in DNA and RNA, adenine (A), guanine $(\mathrm{G})$, cytosine $(\mathrm{C})$ and thymine (T). In RNA, thymine is replaced by uracil (U). These bases form triplets, or codons, and each codon corresponds to one out of 20 amino acids.

The Central Dogma states that the information (or more specifically the sequential information of nucleic or amino acid residues in nucleic acids and proteins respectively) is transferred from nucleic acids to protein, from DNA to RNA to protein, and not in the reverse direction, from protein to nucleic acid. There are a few but notable exceptions to the unidirectional flow of information from DNA to RNA. In retroviruses, such as the HIV (Human Immunodeficiency Virus), this information is transcribed from the viral RNA to the host organism DNA.

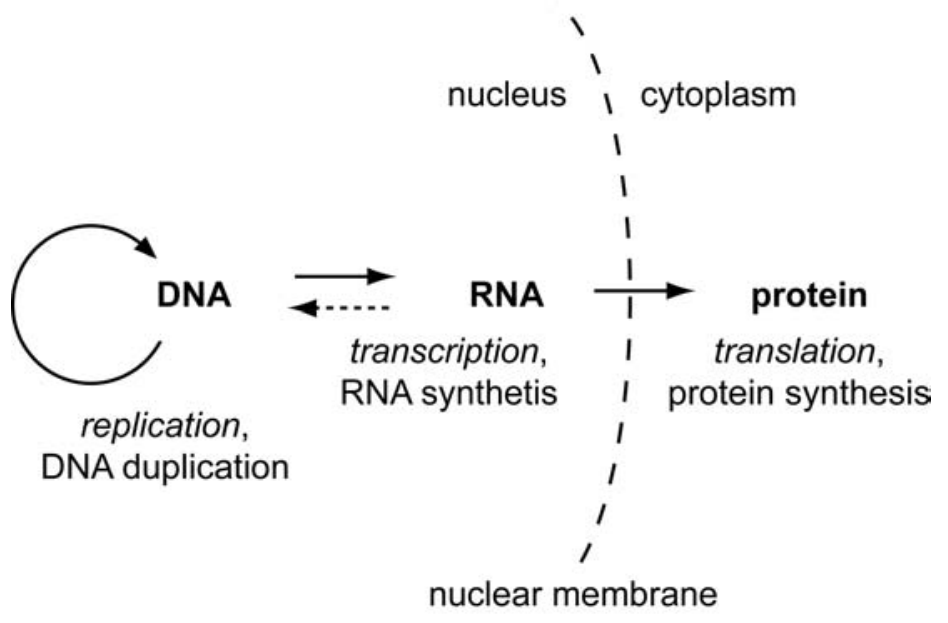

Figure 1. The Central Dogma of molecular biology with arrows depicting the flow of residue sequential information. The dashed arrow represents the rare occasions where DNA is synthesized from an RNA template. 
The translation of nucleic acid sequence to the amino acid sequence of proteins is defined by the genetic code (Figure 2). If the DNA (or RNA) sequence is known, the genetic code will give the protein sequence, or at least a prediction of this. The point of mentioning these fundamental facts here is that it has been, and still is, much less cumbersome to determine the oligonucleotide sequence of DNA than the amino acid sequence of proteins. The DNA is all there in the chromosomes in the cell nucleus (and a few other places, such as the mitochondria or chloroplast) and is easily extracted. Proteins are everywhere, inside and outside the cell, and they can have very different physiochemical properties. Their concentrations range from less than one to millions of molecules per cell. In fact, most proteins that we know anything about, at least with respect to sequence or function, are predictions from DNA and RNA sequences, essentially using the genetic code, some knowledge on what genes look like and comparison with similar proteins that have been characterized biochemically.

\begin{tabular}{|c|c|c|c|}
\hline $\begin{array}{l}\text { TTT Phe } \\
\text { TTC Phe } \\
\text { TTA Leu } \\
\text { TTG Leu }\end{array}$ & $\begin{array}{l}\text { TCT Ser } \\
\text { TCC Ser } \\
\text { TCA Ser } \\
\text { TCG Ser }\end{array}$ & $\begin{array}{ll}\text { TAT } & \text { Tyr } \\
\text { TAC } & \text { Tyr } \\
\text { TAA } & \text { Ter } \\
\text { TAG } & \text { Ter } \\
\end{array}$ & $\begin{array}{l}\text { TGT Cys } \\
\text { TGC Cys } \\
\text { TGA Ter } \\
\text { TGG Trp }\end{array}$ \\
\hline $\begin{array}{l}\text { CTT Leu } \\
\text { CTC Leu } \\
\text { CTA Leu } \\
\text { CTG Leu }\end{array}$ & $\begin{array}{l}\text { CCT Pro } \\
\text { CCC Pro } \\
\text { CCA Pro } \\
\text { CCG Pro } \\
\end{array}$ & $\begin{array}{l}\text { CAT His } \\
\text { CAC His } \\
\text { CAA GIn } \\
\text { CAG GIn }\end{array}$ & $\begin{array}{l}\text { CGT Arg } \\
\text { CGC Arg } \\
\text { CGA Arg } \\
\text { CGG Arg }\end{array}$ \\
\hline $\begin{array}{ll}\text { ATT } & \| l \\
\text { ATC } & \| l e \\
\text { ATA } & \| e \\
\text { ATG } & \text { Met } \\
\end{array}$ & $\begin{array}{l}\text { ACT Thr } \\
\text { ACC Thr } \\
\text { ACA Thr } \\
\text { ACG Thr } \\
\end{array}$ & $\begin{array}{l}\text { AAT Asn } \\
\text { AAC Asn } \\
\text { AAA Lys } \\
\text { AAG Lys }\end{array}$ & $\begin{array}{l}\text { AGT Ser } \\
\text { AGC Ser } \\
\text { AGA Arg } \\
\text { AGG Arg }\end{array}$ \\
\hline $\begin{array}{l}\text { GTT Val } \\
\text { GTC Val } \\
\text { GTA Val } \\
\text { GTG Val }\end{array}$ & $\begin{array}{l}\text { GCT Ala } \\
\text { GCC Ala } \\
\text { GCA Ala } \\
\text { GCG Ala }\end{array}$ & $\begin{array}{l}\text { GAT Asp } \\
\text { GAC Asp } \\
\text { GAA Glu } \\
\text { GAG Glu }\end{array}$ & $\begin{array}{l}\text { GGT Gly } \\
\text { GGC Gly } \\
\text { GGA Gly } \\
\text { GGG Gly }\end{array}$ \\
\hline
\end{tabular}

Figure 2. The genetic code defines the mapping of the DNA sequence into protein sequence where a code word of three nucleic bases, or a codon, is translated into one amino acid residue in a protein. One codon (ATG) defines the starting point of translation (always a methionine, Met), and one of three alternative codons terminates (Ter) translation (TAA, TAG, and TGA).

The picture is complicated by the fact that in eukaryotes, such as humans, the transcribed RNA sequence is often edited, or spliced, generating a protein sequence that is not a straightforward translation of the DNA sequence. Proteins are also modified post-translationally in a way that is not trivial to predict from the DNA sequence. Examples of such modifications are phosphorylations $\left(-\mathrm{O}-\mathrm{PO}_{3}\right)$ of serine, 
threonine and tyrosine, often involved in regulation of biological activity on the protein level, and glycosylation, carbohydrates bound to serine and threonine $(\mathrm{O}-$ glycosidic linkage) or asparagine (N-glycosidic). Regardless of the modifications, and this is an important point, there are always stretches of the protein whose sequences are correctly predicted and these stretches are sufficiently long to uniquely identify (trace back to the gene) the protein among all other proteins in the organism. This can be done by looking at a small part of the protein sequence, or alternatively, the patterns, or fingerprints, resulting from enzymatic digestion of the protein. Both the sequence "tags" (typically six amino acid residues or more) and fingerprints of enzymatic digestion can be routinely generated using mass spectrometry and are specific enough to uniquely identify any protein. This thesis partly concerns how mass spectrometry can be used to generate both of these types of information for the purpose of identifying and characterizing proteins.

For a deeper look into the foundations of molecular biology, the textbook "Molecular Biology of the Cell" [3] is highly recommended.

The first complete DNA sequence of an "organism", the bacteriophage $\phi X 174$, was completed in 1977, soon followed by the human mitochondrial genome and phage $\lambda$. The first bacterial genome, Haemophilus influenzae, was completed in 1995 [4] and the first eukaryotic genome, Saccaromyces cerevisiae, or baker's yeast, was completed in 1996 [5]. Rapid advances in automated, multiplexed, DNA sequencing machines in the 1990's made it possible to complete the entire human genome by the year 2000 [6, 7].

Sanger successfully sequenced the first protein by determining the amino-acid sequence of insulin, a work completed in 1953 [8]. Today, many methods are available for sequencing proteins, some of which are based on mass spectrometry. A general problem in protein sequencing is sensitivity - the amount of protein necessary to obtain a complete protein sequence. Mass spectrometric methods can provide excellent sensitivity, but have difficulties generating the complete sequence of even a small protein. Often, several techniques have to be combined in a procedure that is far from routine.

In the post-genomic era, focus has shifted to find methods to approach the other molecular "datasets", such as the proteome (the set of all proteins in an organism) and the metabolome (all other small, organic molecules in an organism). The systematic studies of these molecular datasets all bear the "ics" suffix, such as "proteomics", the study of the proteome. Table 1 summarizes the four principal molecular datasets, how they are approached today and to what degree of success. Other important parameters are the time and space dependence of these sets. The genome is (with just a few exceptions) constant throughout the organism and its lifetime. The other "omes" vary from cell to cell and from one moment to the next. 
Table 1. The molecular datasets in biology, what they mean and how they are studied (P. Kraulis, personal communication).

\begin{tabular}{|c|c|c|c|}
\hline dataset & definition & measurement & time-dependence \\
\hline genome & $\begin{array}{l}\text { The complete DNA } \\
\text { sequence of the genetic } \\
\text { material in the organism. }\end{array}$ & $\begin{array}{l}\text { routine, } \\
\text { completeness (CGE, } \\
\text { DNA arrays) }\end{array}$ & generation \\
\hline transcriptome & $\begin{array}{l}\text { The complete set and } \\
\text { levels of mRNA transcripts } \\
\text { in a cell or tissue of the } \\
\text { organism. }\end{array}$ & $\begin{array}{l}\text { routine, near- } \\
\text { completeness } \\
\text { (arrays) }\end{array}$ & seconds-minutes \\
\hline proteome & $\begin{array}{l}\text { The complete set and } \\
\text { levels of proteins in a cell } \\
\text { or tissue, including } \\
\text { modifications and } \\
\text { complexes. }\end{array}$ & $\begin{array}{l}\text { not quite routine }(2 \mathrm{D}- \\
\text { PAGE, MS, protein } \\
\text { arrays, fusions with } \\
\text { tag- or reporter } \\
\text { proteins, ...) }\end{array}$ & seconds-years \\
\hline metabolome & $\begin{array}{l}\text { All metabolites and their } \\
\text { concentrations. } \\
\text { Metabolites are here } \\
\text { defined as small organic } \\
\text { molecules, not protein, } \\
\text { RNA or DNA. }\end{array}$ & $\begin{array}{l}\text { hard (MS, NMR, } \\
\text { specific chemical } \\
\text { reagents, ...) }\end{array}$ & $<$ second-years \\
\hline
\end{tabular}

Gene expression is routinely analyzed on the RNA level by microarray techniques [9, 10], but protein abundance cannot simply be predicted from the corresponding mRNA abundance [11]. Much effort is now spent on developing analogous techniques for proteome analysis (for a review, see Stoll et al. [12]). Still, twodimensional isoelectric focusing and size separation in sodium dodecyl sulfate (SDS) in a polyacrylamide gel electrophoresis (2D-PAGE) $[13,14]$ is the workhorse for protein expression analysis. The proteins on a 2D-PAGE gel can be identified through in-gel tryptic digestion and mass spectrometry, also called peptide mass fingerprinting, or PMF [15-20], possibly using partial sequence tags from tandem mass spectrometry [21-24]. Proteins in simple mixtures, such as proteins comigrating in 2D-PAGE can also be identified by PMF if the mass accuracy is sufficiently high [25].

What kind of information are we looking for and what tools do we need? Primarily, we need a general method to detect and identify the proteins. We may wish to quantify the expression of the proteins to correlate levels of a specific protein or proteins to a particular physiological phenomenon that we are studying. We also wish to characterize the proteins themselves in greater detail, for example determining their amino acid sequences and localizing, characterizing and 
quantifying post-translational modifications important for structure and function. Proteins are folded in intricate two- and three-dimensional structures that strongly correlate with their function. Standard techniques to get structural and dynamical information on proteins include X-ray crystallography, electron diffraction, nuclear magnetic resonance (NMR) and circular dichroism (CD). There are also ways in which mass spectrometry can be used to indirectly generate such information, often complementary to other techniques. A general advantage of mass spectrometry is the inherent sensitivity - particularly in comparison to the above techniques.

We may also be interested in protein/protein interaction, and "charting the protein complexome", i.e. the protein/protein interaction networks [26-28]. Mass spectrometry has played a central role in these efforts so far. The second topic of this thesis deals with mass spectrometry as a tool to probe protein structure and noncovalent interactions.

\subsection{Mass Spectrometry}

\subsubsection{Mass Analyzers}

Mass spectrometry (MS) is the analysis or separation of charged particles, such as atoms and molecules, based on their mass-to-charge ratios. Most mass spectrometers are comprised by three principal parts. Ions are produced in an ion source and subsequently separated or analyzed in a mass analyzer before detection by a detector (Figure 3). All of these, or at least the analyzer and detector, are inside a vacuum system. The history of mass spectrometry can be traced back a little more than a century. In March 1897 J. J. Thomson at Cambridge's Cavendish Laboratory discovered the electron and determined its mass-to-charge ratio (to $5.69 \times 10^{-9} \mathrm{~g} / \mathrm{C}$ ). The results were announced a month later at the April $30^{\text {th }}$ Friday Evening Meeting of the Royal Institution in London [29]. Thomson went on to construct the first mass spectrometer, or a "parabola spectrograph", for the determination of mass-to-charge ratios of ions created by electrical discharges through gases. In this instrument, ions generated in discharge tubes were passed into electric and magnetic fields, which made the ions move through parabolic trajectories. The rays were then detected on a photographic plate or fluorescent screen. For these "investigations on the conduction of electricity by gases", Thomson received the Nobel Prize in Physics in 1906. In the decades that followed, mass spectrometers were greatly improved in terms of resolution (the performances of the first mass spectrometers were very poor by today's standards). 


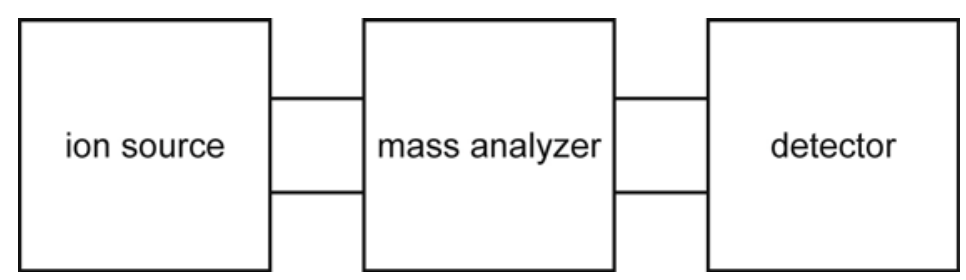

Figure 3. A generic mass spectrometer can be divided in three principal parts an ion source, a mass analyzer and a detector. A modern instrument also includes a computer to retrieve and analyze data.

The cyclotron principle, the core of Fourier transform ion cyclotron resonance mass spectrometry, was introduced by E. O. Lawrence in the early 1931 [30] and in 1936, F. M. Penning added an electrostatic confinement perpendicular to the magnetic field [31], a construction that later became known as the "Penning trap". As part of the Manhattan project during World War II, Lawrence converted a cyclotron into a mass spectrograph (or a $180^{\circ}$ magnetic sector) and used this in a preparative mode to separate ${ }^{235} \mathrm{U}$ from ${ }^{238} \mathrm{U}$.

The 1940's also saw the first commercial mass spectrometer enter the market [32]. These early commercial mass spectrometers were primarily used by the petroleum industry to analyze the composition of gases. New types of mass analyzers were introduced, like the time-of-flight (TOF) mass spectrometers in the mid-1940's [33, 34]. Paul and co-workers invented two types of mass analyzers in the early 1950's the quadrupole mass filter and the quadrupole ion trap, later also called the "Paul ion trap" [35]. The use of ion cyclotron resonance for mass measurements was pioneered by Hipple, Sommer and Thomas already in the late 1940's [36, 37] as a precise method to determine the Faraday constant. Over the following 15 years, ICRMS instrumentation was greatly improved, rapidly expanding its applications. High resolution and sensitivity became hallmarks of ICR and the technique was used with particular success in studies of gas-phase ion chemistry. Varian Associates introduced the first commercial ICR-MS in 1965 [38]. The next major step was taken in 1970 by R. T. McIver with the introduction of the "trapped ion analyzer cell", combining trapping and measurement in one cell (trap).

In 1974, Comisarow and Marshall significantly improved ICR mass spectrometry by building the first Fourier transform ion cyclotron resonance (FTICR) mass spectrometer [39], analogously to previous FT spectroscopies, particularly FTNMR $[40,41]$. Marshall, Comisarow and others have since continuously improved FTICR mass spectrometry, increasing the mass range, mass resolving power and sensitivity of the technique $[42,43]$.

In later years, hybrid mass spectrometers, such as the quadrupole-time-of-flight (QTOF) [44-46], have become popular instruments, especially for protein identification 
and proteomics research. The recently introduced TOF-TOF technique [47] promises to fulfill similar tasks as the Q-TOF.

For structural characterization and identification, tandem mass spectrometry (MS/MS) techniques have proved very efficient. In a typical MS/MS experiment, a precursor ion is selected and subjected to conditions sufficient to induce fragmentation of the molecule. The fragments are then analyzed in the mass spectrometer. There are several means to provide the conditions for fragmentation, the most commonly employed being collision-induced dissociation (CID) [48]. Recently, electron-capture dissociation (ECD) [49], a method particularly suitable for peptides and small proteins has attracted much attention and been applied to sequence polypeptides and characterize post-translational modifications [50-61].

\subsubsection{Ionization Techniques}

In addition to new mass-to-charge analyzers, novel means to produce ions were also discovered during the post-war decades. Desorption of positive ions from a surface in a strong electrostatic field gradient was first observed by Müller in 1951 [62]. Inghram and Gomer investigated the nature of such ions and the mechanism of their production using mass spectrometry in 1954 [63]. Beckey later developed field desorption as an ionization technique in mass spectrometry [64]. Techniques based on field desorption made it possible to study non-volatile and thermally unstable molecules by mass spectrometry. Chemical ionization (CI) was described and put to use in the mid-1960's by Field and Munson [65], but in fact, the phenomenon itself had been observed in hydrogen gas already by Thomson in 1913. In chemical ionization, a reagent gas is ionized by electrical discharges (electron impact) and the reagent gas ions then reacts with and ionizes the volatized analyte molecules. CI is a more gentle ionization method than electron impact (EI).

A range of desorption techniques for mass spectrometry were developed during the 1960's and the following decades. Several groups pioneered secondary-ion mass spectrometry (SIMS), where an ion beam with ion energies in the $\mathrm{keV}$ range is used to desorb and ionize molecules from a sample deposited on a surface [66]. SIMS is used with great success in materials science and other fields [66]. Plasma desorption mass spectrometry (PDMS) was developed by Macfarlane and coworkers at Texas A\&M University in the 1970's [67]. In PDMS, MeV ions from an accelerator or nuclear fission is used to desorb and ionize molecules. PDMS was the first ionization method that successfully produced mass spectra of high-molecular weight molecules such as peptides and proteins [68].

Posthumus, Kistemaker and Meuzelaar at the FOM Institute for Atomic and Molecular Physics in Amsterdam developed laser desorption mass spectrometry (LDMS) in 1978 [69]. As the name implies, a laser beam was used to desorb and 
ionize molecules. In 1981 Barber and coworkers at the University of Manchester Institute of Science \& Technology in England developed the technique of fast atom bombardment (FAB) [70]. In FAB, a beam of neutral atoms is used to gently desorb and ionize molecules from the surface of a liquid matrix, typically glycerol, making it possible to obtain spectra of large, non-volatile organic molecules. FAB was also used to couple capillary liquid chromatography and capillary electrophoresis to mass spectrometry [71].

Two breakthroughs that proved to have a major impact on biological mass spectrometry came in the 1980's with the development of matrix assisted laser desorption/ionization (MALDI) and the application of electrospray to what was named electrospray ionization (ESI). MALDI was discovered by Karas and Hillenkamp at the University of Frankfurt, Germany [72]. A related concept was developed independently by Tanaka and co-workers at the Shimadzu Corporation in Kyoto, Japan [73]. These techniques were significant improvements in sensitivity over LD methods. MALDI is also a very "soft" ionization method.

In electrospray ionization, pioneered by Fenn and coworkers at Yale university [74] and independently by Aleksandrov et al. in Leningrad [75], charged droplets are dispersed from a capillary, or needle, in a high electric field. As solvent evaporates, the Coulombic repulsion overcomes the surface tension and droplets fission [76, 77]. Eventually, gas phase ions are produced, although some of the details in this process remain to be unveiled. ESI is a very gentle ionization method, capable of transferring even large non-covalent complexes such as ribosomes [78, 79] and viral particles [80] intact into the gas phase.

Electrospray ionization was successfully coupled to FTICR mass spectrometry by Henry and co-workers in 1989 [81]. Although many other ion sources, including MALDI, have been coupled to FTICR mass spectrometers, the combination of ESI and FTICR mass spectrometry is particularly powerful due to the generation of multiply charged ions inherent in the electrospray process and that trapping efficiency and resolving power increases with charge (of a given mass) in an FTICR mass spectrometer.

Vestal has recently reviewed ionization techniques in mass spectrometry [82]. For further reading on mass spectrometry in biology, the recent reviews by Burlingame [83] and Matsuo and Seyama [84] are recommended. 


\section{PROTEIN IDENTIFICATION}

\subsection{Methods}

\subsubsection{Overview}

The mass spectrometric analysis of a biological sample, or any sample, does not start or end with the acquisition of a mass spectrum. In fact, this is often the easiest and fastest step in the analysis using modern commercial instruments. Samples in the real world are often complex and as rich in contaminants as they are in substances of interest. These contaminations can for one reason or another interfere with ionization or mass spectrometric measurements. Different ionization techniques have different spectra of sensitivities to such contaminants. Electrospray ionization, for instance, is notoriously sensitive to surfactants and salts. One or more stages of sample preparation or purification are often necessary to remove unwanted contaminants or to reduce the complexity of the sample to facilitate the mass spectrometric analysis. In this chapter sample purification and liquid separation techniques are briefly described in sections 2.1.2 to 2.1.4 followed by a more detailed account of electrospray ionization in section 2.1.5. The principle of Fourier transform ion cyclotron resonance (FTICR) is reviewed and the instrument used in this thesis is described in 2.1.6.

The successful acquisition of a mass spectrum does not mark the end of any analysis. Even a single mass spectrum contains an enormous amount of information, usually counted in megabytes. Still, this number diminishes in comparison with twodimensional, or time-series, of spectra whose information contents are in the gigabyte range. It is evident that efficient computer algorithms are as an important tool as any of the preceding physiochemical techniques in order to get useful information out of mass spectrometric measurements. Section 2.1.7 describes automatic methods for the analysis of raw data as well as partially novel statistical methods for peptide identification.

The protocols used for sample acquisition and tryptic digestion of proteins are described in the methods section of paper IV.

Figure 4 illustrates a minimal flow scheme from biological sample to final computerassisted analysis. 


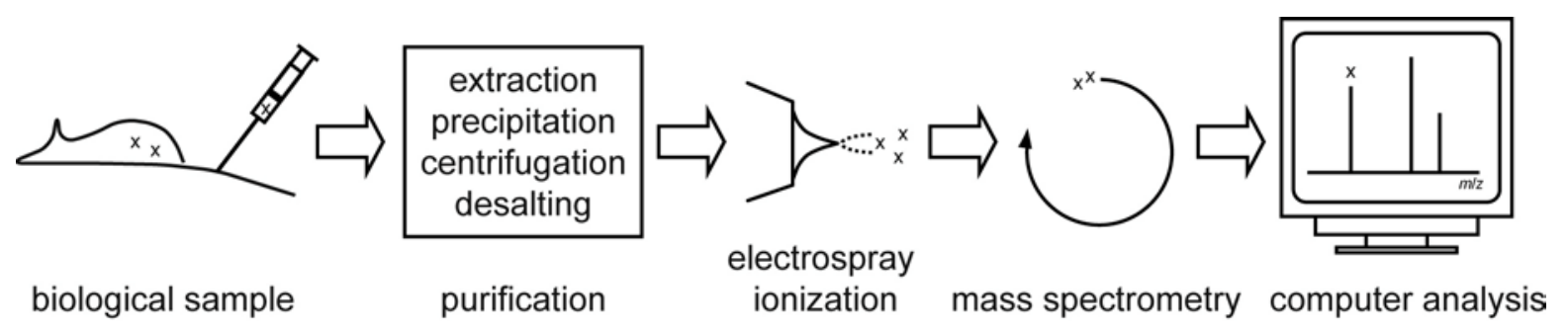

Figure 4. Flow scheme view of the analysis of a biological sample by electrospray ionization mass spectrometry. The purification is more or less elaborative depending on the tissue or fluid sampled. Liquid separation methods such as LC or CE can be conveniently used on-line with the electrospray mass spectrometer.

\subsubsection{Sample Purification}

One of the simplest and most commonly used sample purifications is the removal of salts from solutions of peptides or proteins. This can be achieved with high efficiency ( $99 \%$ or better) and good recovery ( $80 \%$ or more) using a micro-column packed into the tip of a disposable plastic pipette tip, such as the ZipTipc18 ${ }^{\circledR}$ (Millipore Corp., Marlborough, MA, USA) with a bed volume of $0.2 \mu \mathrm{L}$. The tips were first wetted using $50 \%$ acetonitrile $(\mathrm{ACN})(\mathrm{v} / \mathrm{v})$ in $\mathrm{H}_{2} \mathrm{O}$ and a micropipette. The column was equilibrated using $1 \%$ acetic acid ( $\mathrm{HAc}$ ) in $\mathrm{H}_{2} \mathrm{O}$. Each of these steps was repeated three times. The sample was loaded by filling and emptying the tip 10 times in the sample, then desalted by washing with $1 \% \mathrm{HAc}$ in $\mathrm{H}_{2} \mathrm{O} 3-5$ times. Finally, the sample analyte bound to the $\mathrm{C}_{18}$-column was eluted using $50 \% \mathrm{ACN}, 1 \% \mathrm{HAc}(\mathrm{v} / \mathrm{v})$ in $\mathrm{H}_{2} \mathrm{O}$ to the desired volume (typically 10-20 $\mu \mathrm{L}$, sufficient for most types of experiments) and transferred to electrospray ionization.

\subsubsection{Liquid Chromatography}

Reversed-phase chromatography (RPC) not only removes salts and contaminants from a biological sample but also separate the analytes from each other according to their hydrophobicity, thereby reducing the complexity of sample introduced to the electrospray and presented to the mass spectrometer at any given time. Analytes are separated according to their hydrophobic interaction with the column packing material, the more hydrophobic, the longer is the retention time in the column [85]. Liquid chromatography (LC) was first coupled to FTICR for the analysis of peptides by Stacey et al. [86]. For a general description of RPC, see Frenz et al. [87]. Voyksner has reviewed the combination of liquid chromatography with electrospray mass spectrometry [88] and Tomer has recently written an review on liquid separations coupled to mass spectrometry [89]. 
For the experimental results included in this thesis, a commercial JASCO 1580 microLC system (JASCO, Tokyo, Japan) was used with 8-10 cm $200 \mu \mathrm{m}$ i.d., $360 \mu \mathrm{m}$ o.d. fused silica (Polymicro Technologies, Tucson, AZ, USA) column packed in-house with $\mathrm{C}_{18}$-reversed-phase material ( $5 \mu \mathrm{m}$ ODS-AQ, YMC Europe GmbH, Schermbeck, Germany). The electrospray end of the capillaries were mechanically tapered [90] and the exposed bare fused silica was coated with polyimide (Alltech, Deerfield, IL, USA) and $2 \mu \mathrm{m}$ particle-size gold (Goodfellow, Cambridge, UK) or 1-2 $\mu \mathrm{m}$ particle-size graphite (Aldrich, Milwaukee, WI, USA) according to the "fairy dust" [91] or "black dust" [92] technique respectively, producing electrochemically stable and mechanically robust conductive layers (Figure 9). These tips were connected to ground, and a negative potential $(2-4 \mathrm{kV})$ was applied to the electrospray interface (see below). Mobile phase flow was typically $250 \mu \mathrm{L} / \mathrm{min}$, i.e. the minimum flow from the JASCO system, splitted approximately 1:1000 in a Valco T-connector [VICI AG (Valco International), Schenkon, Switzerland] mounted before the injector and column. For a schematic view of the JASCO LC-system coupled to the electrospray source, see Figure 5 below.

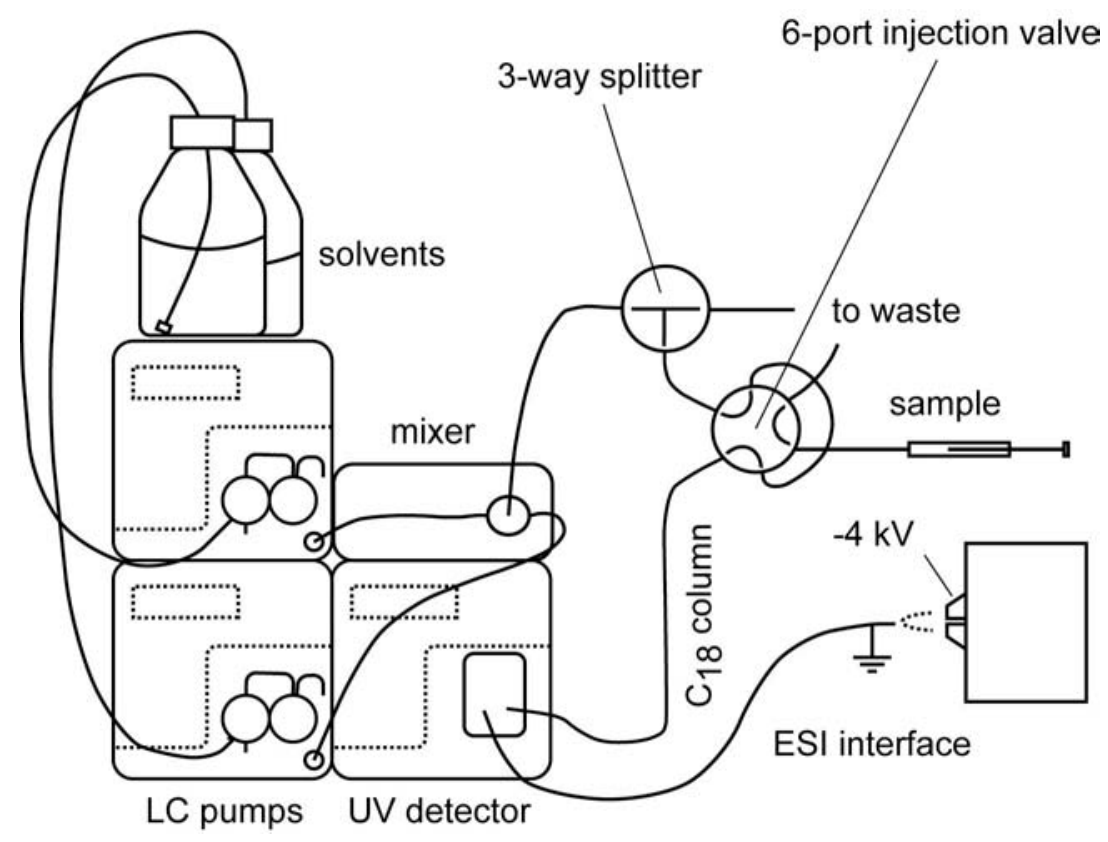

Figure 5. JASCO 1580 micro-LC system. Buffer and organic solvent from the two pumps are mixed in a dynamic mixer before splitting in a Valco Tconnector. The sample is loaded and injected manually at a 6-port injection valve. The eluent passes a UV detector before introduction into the electrospray interface.

The columns were equilibrated for a minimum of $30 \mathrm{~min}$ before each sample injection. A sample volume $10 \mu \mathrm{L}$ was injected through a loop connected to a 6-port 
manual injection valve. Gradients ramped from $0-20 \%$ to $80-100 \%$ organic solvent (95\% ACN, 0.5\% HAc) versus $0.5 \% \mathrm{HAc}$ in $\mathrm{H}_{2} \mathrm{O}$. UV data was acquired using the BORWIN software supplied with the LC system.

\subsubsection{Capillary Electrophoresis}

Capillary electrophoresis (CE) is a rapid means to separate analytes and is easily interfaced with electrospray ionization [93, 94]. In capillary zone electrophoresis, species are separated according to their charge and size while the electroosmotic flow drives the liquid through the capillary. For a general account on CE, see [95].

Capillary electrophoresis experiments were conducted using a home-built device allowing pressurized injections (Figure 6) and in-house coated $25 \mu \mathrm{m}$ i.d., $360 \mu \mathrm{m}$ o.d fused silica capillaries (Polymicro Technologies, Tucson, AZ, USA) cut into $100 \mathrm{~cm}$ lengths. Inner surface capillary coating reagent [3-(methacryloylamino)propyl]trimethylammonium chloride (MAPTAC) was obtained from Aldrich (Milwaukee, WI, USA) and the reagent 7-oct-1-enyltrimethoxysilane was purchased from Fluka (Buchs, Switzerland). N,N, $\mathrm{N}^{\prime}, \mathrm{N}^{\prime}$-tetramethylethylenediamine (TEMED) was purchased from Bio-Rad (Hercules, CA, USA). Bare fused silica capillaries were obtained from Polymicro Technologies (Phoenix, AZ, USA). The MAPTAC coating generates a constant positive inner capillary surface, thus reversing the electroosmotic flow [96]. The electrospray end of the capillary was tapered [90] and coated with polyimide and particular gold [91] or graphite [92] as described in the previous section.

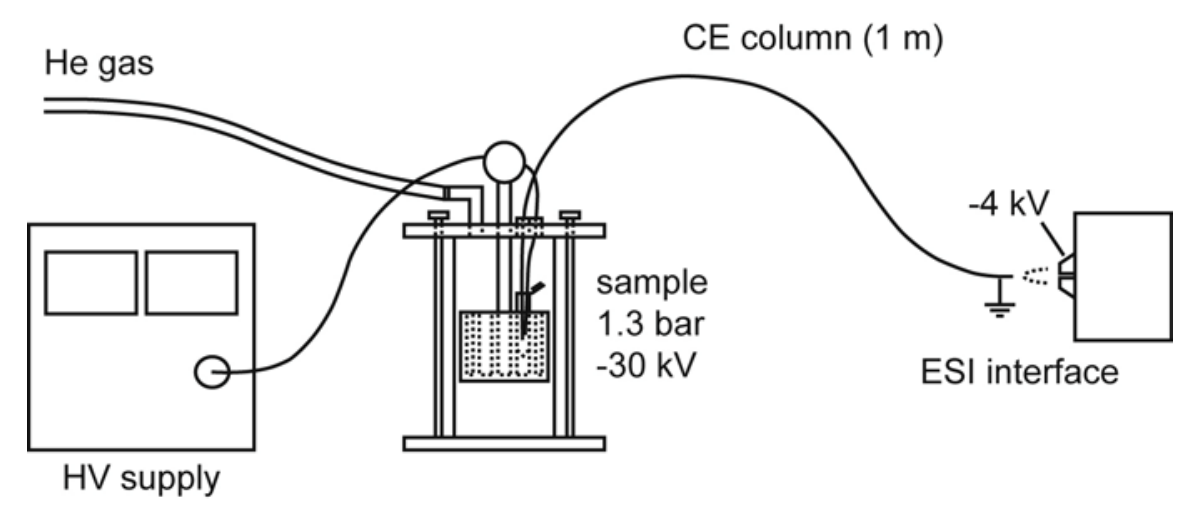

Figure 6. The home-built pressurized injection capillary electrophoresis apparatus. Negative high voltage is applied at the sample inside a pressurized container. The sample is driven by electroosmotic flow to an electrospray interface at ground potential. 
The CE instrumentation was assembled in-house and consisted of a high voltage power supply (Bertan, Hicksville, NY, USA) operated in constant negative voltage mode. The CE separation voltage was set at $-30 \mathrm{kV}$ relative to the grounded electrospray end of the capillary. The current was $\sim 40 \mu \mathrm{A}$ during the separation. The CE buffer used for the experiments consisted of $12.8 \mathrm{mM} \mathrm{HAc}, 0.2 \mathrm{mM}$ ammonium acetate $\left(\mathrm{NH}_{4} \mathrm{Ac}\right)$ in 25:75 (v/v) ACN/deionized $\mathrm{H}_{2} \mathrm{O}$ at $\mathrm{pH} 3.0$ [97]. The buffer was filtered and degassed by ultrasonication. The capillary was equilibrated with 4-5 capillary volumes of buffer prior to sample injection. The sample was injected using hydrodynamic injection at a pressure of 1.7 bar for 56 seconds, injecting $40 \mathrm{~nL}$ onto the capillary, followed by injection of buffer (1.7 bar, 56 seconds). The migration times for the last eluting components in the samples were 10-15 minutes under these conditions [Paper VI].

\subsubsection{Electrospray lonization}

Electrospray ionization, pioneered by Fenn et al. [74], is one of the most gentle and efficient means to ionize macromolecules and macromolecular complexes. The fundamental principles of electrospray is still a matter of investigation but it has been shown that charged droplets formed by electrospray undergo a recursive asymmetric fission process, where smaller and smaller droplets are formed [76, 77]. Charged droplets rupture when the charge approaches the Rayleigh limit [98], where Coulomb repulsion equals the surface tension,

$$
q^{2}=8 \pi^{2} \varepsilon_{0} \gamma d^{3}
$$

where $q$ is the charge, $\varepsilon_{0}$ the electrical permittivity of the surrounding, $\gamma$ the liquid surface tension and $d$ the diameter of the droplet.

A pictorial view of an electrospray ion source is shown in Figure 7. High voltage, typically a few kilovolts over a distance of a few millimeters, is applied between the electrospray liquid and the orifice of the mass spectrometer. An electrospray ion source is a constant-current electrochemical cell, causing redox reactions and ionization of neutral electroactive molecules in the electrosprayed solution. This makes the study of redox chemistry intrinsically difficult. The formed ions may hinder or assist the detection of the analyte species, depending on properties of the analyte and solution.

Since the sample is at atmospheric pressure and the liquid flow is not neglectable, instruments coupled to ESI sources need larger vacuum pumps than instruments with vacuum ion sources. The first successful combination of ESI and FTICR mass spectrometry was reported by Henry et al. in 1989 [81]. When combining an ion source such as ESI with a mass analyzer requiring ultrahigh vacuum it is beneficial to use as low flow rate as possible to reduce the gas load. A lower flow rate also reduces 
contamination of the interface. The ion yield is only flow-sensitive at very low (increasing with flow) [99] or very high (decreasing) flow rates. In the common operating range, the yield depends mostly on the concentration of analyte (and presence of interfering contaminants). For a review of the central concepts related to electrospray ionization, see a recent paper by Cole [100].

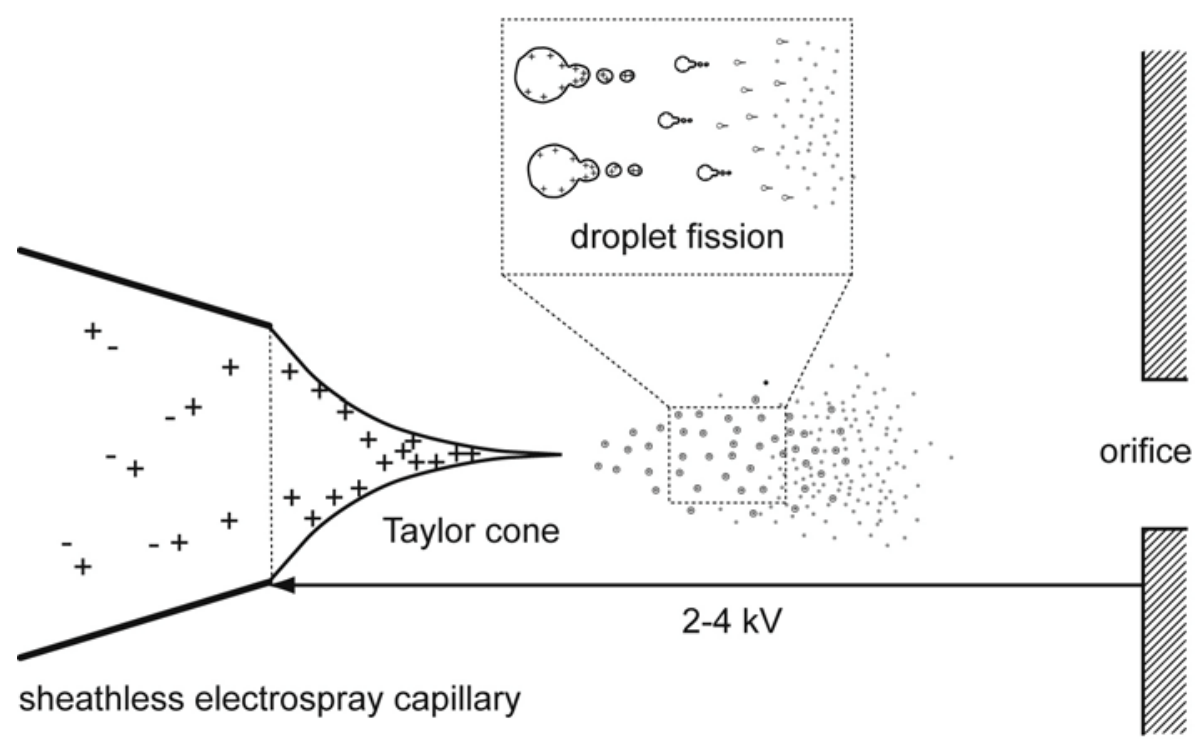

Figure 7. Application of a strong electric field separates charges in the solution and liquid of opposite net charge is pulled out into a Taylor cone. The liquid is distrupted where the Coulombic repulsion exceeds the surface tension, a process that is repeated recursively in smaller and smaller droplets as solvent evaporates.

In the experimental setup used in the experiments presented here, the electrostatic voltage was applied at the liquid end via a conductive outer coating on a fused silica capillary, tapered to a sharp tip [91, 92, 101]. The sample was pushed through a 30 $\mathrm{cm}, 25 \mu \mathrm{m}$ i.d. fused silica capillary by applying a pressure of $\sim 1.3 \mathrm{bar}$ at the sample end in a pressurized container (Figure 8). The flow rates in this system are 30-100 $\mathrm{nL} / \mathrm{min}$, or in or near the nanospray regime [100].

A micrograph of the two types of coated capillaries used and a commercial nanospray needle is shown in Figure 9. The inset shows an operating graphite-coated electrospray capillary. 


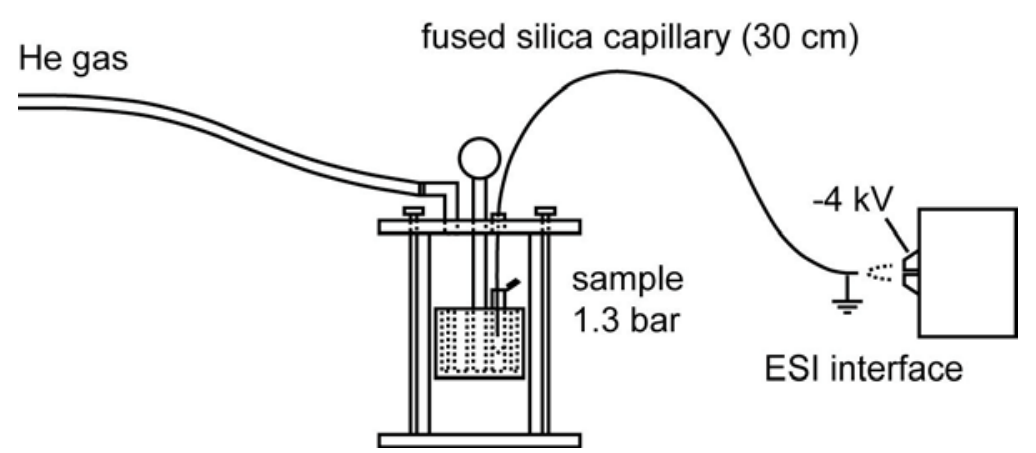

Figure 8. The home-built pressurized direct infusion electrospray apparatus. The sample is kept inside a pressurized container and pressure of $\sim 1.3 \mathrm{bar}$ is sufficient to push the sample through a $30 \mathrm{~cm} 25 \mu \mathrm{m}$ i.d. fused silica capillary. The electrospray end is coated with a conductive layer and kept at ground potential whereas a negative potential of $2-4 \mathrm{kV}$ is applied at the mass spectrometer orifice.

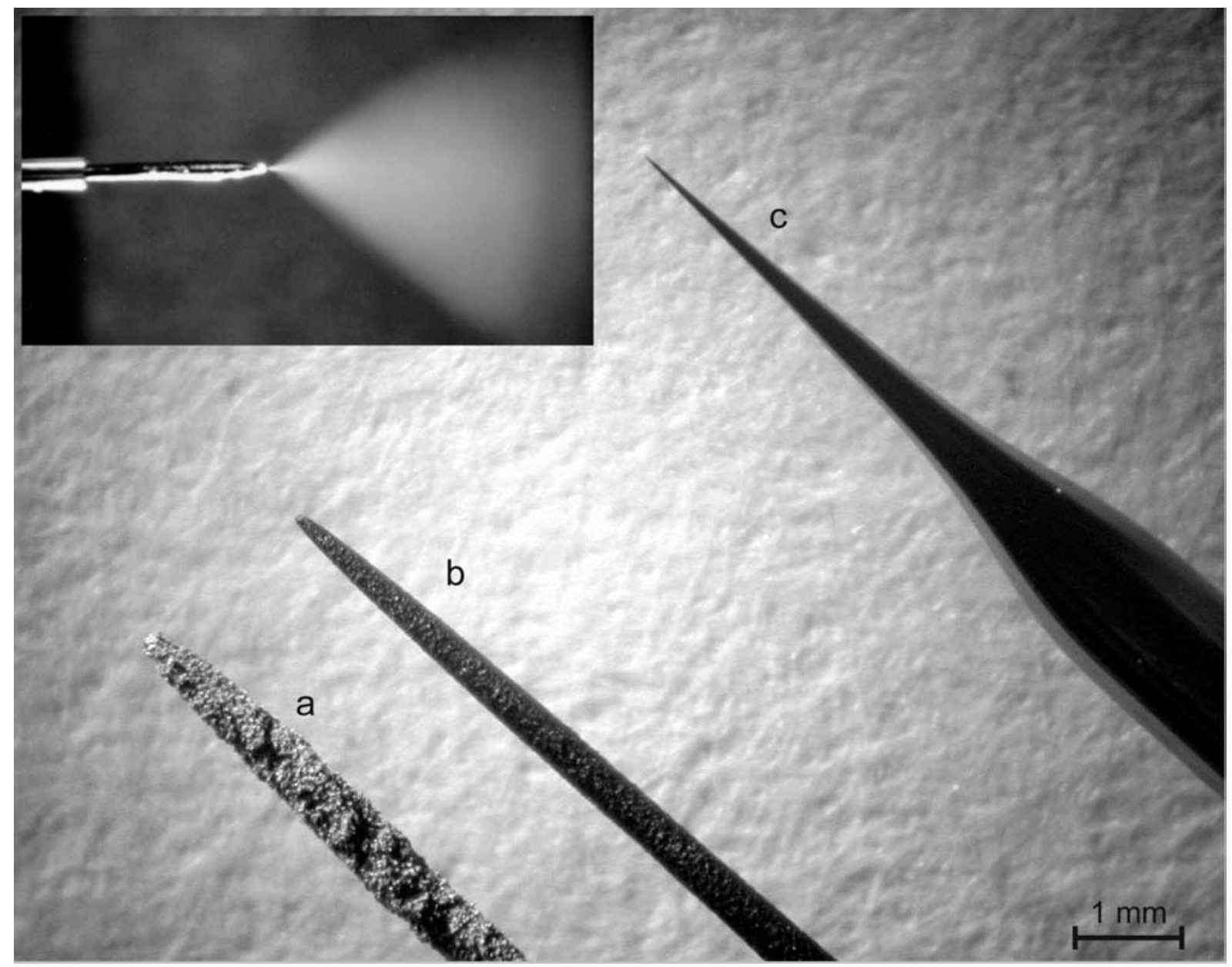

Figure 9. Micrograph of electrospray needles: gold/polyimide "fairy dust" (a) and graphite/polyimide "black dust" (b) coated fused silica capillaries and a New Objective PicoTip ${ }^{\mathrm{TM}}$ metal-coated nanospray needle (c). The inset shows a spraying graphite-coated capillary (inset picture courtesy of M. Wetterhall). 


\subsubsection{Fourier Transform Ion Cyclotron Resonance Mass Spectrometry}

\section{Ion Cyclotron Resonance}

An ion moving in the presence of a spatially uniform magnetic field, $\boldsymbol{B}$, is subject to a force $\boldsymbol{F}$,

$$
\boldsymbol{F}=m \frac{d \boldsymbol{v}}{d t}=z \boldsymbol{v} \times \boldsymbol{B}
$$

where $m, z$, and $v$ are the mass, charge and velocity of the ion, respectively.

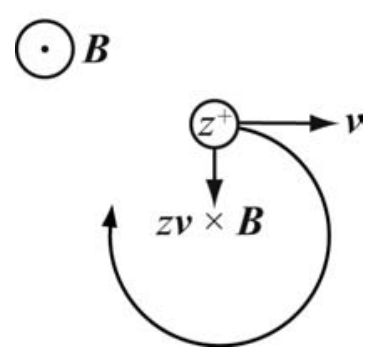

Figure 10. The force and resulting motion of a positive ion of charge $z$, in a magetic field $\boldsymbol{B}$ (direction out of the paper).

If $v_{\perp}$ is the velocity component perpendicular to $\boldsymbol{B}$ and $B_{0}$ the magnetic flux density, then the angular acceleration is this velocity squared divided by the radius of the planar motion, $r$, and

$$
\frac{m v_{\perp}^{2}}{r}=z v_{\perp} B_{0}
$$

The angular velocity $\omega$ around $\boldsymbol{B}$ is $v_{\perp} / r$ and substituting $v_{\perp}$ in Eq. 3,

$$
m \omega^{2} r=z \omega r B_{0}
$$

or

$$
\omega=\frac{z B_{0}}{m}
$$

Equation 5 is also known as the cyclotron equation, and $\omega$ the unperturbed ion cyclotron frequency. Note that the cyclotron frequency is not dependent on the radius (or velocity) of the ion but on the magnetic field and the mass-to-charge ratio. If $B_{0}$ is stable and $\omega$ can be accurately determined, then $\mathrm{m} / z$ can also be 
determined with high accuracy. It turns out that these conditions can be met in practice.

To measure the angular frequency $\omega$ for an ion, the cyclotron motion is excited by applying a radiofrequency signal with the same frequency across two opposite electrodes. This produces a coherent cyclotron motion, i.e. all ions are in phase with another. The ions induce an image current also in two other electrodes, offset by $90^{\circ}$ from the first pair. After the excitation frequency is turned off this image current is recorded. A mass spectrum is obtained by scanning the excitation frequency and plotting the response, the ion cyclotron resonance, as a function of mass-to-charge ratio according to Eq. 5.

In reality, the picture is more complicated due to static electric fields from the trapping electrodes (in front of and behind the plane in Figure 11) that cause a lower frequency magnetron motion to be superimposed on the cyclotron motion. However, measurements are conducted in such a way that the contribution from this magnetron motion is cancelled out.

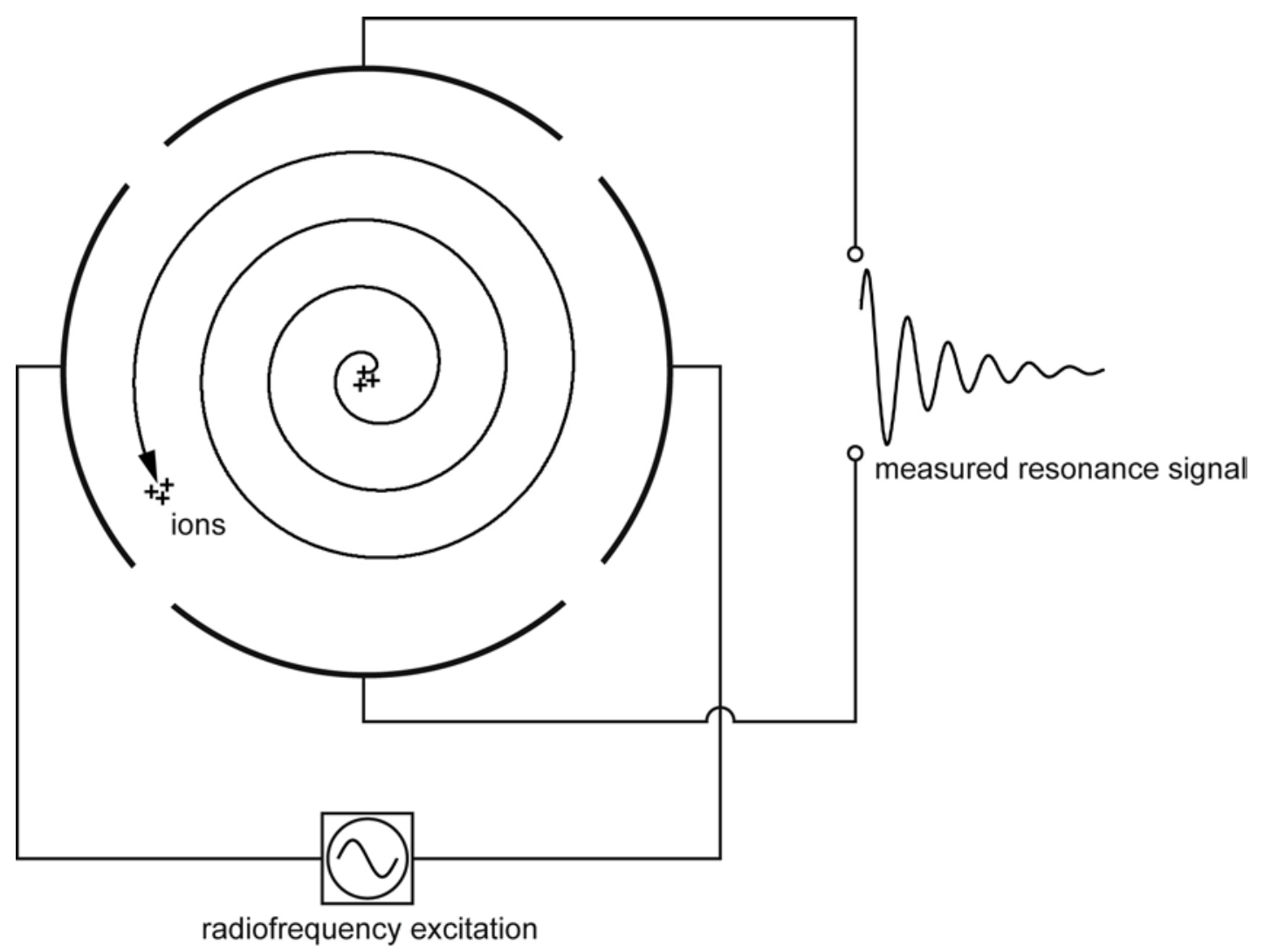

Figure 11. An external radiofrequency pulse applied across two electrodes (right and left) excites the cyclotron motion of resonating ions. These ions then induce an image current in two detector plates (top and bottom) that can be detected. The response as a function of applied frequency is converted to a mass spectrum by Eq. 5 . 


\section{Fourier Transform Spectroscopy}

Before computers and rapid analog-to-digital converters were generally available, most types of spectroscopies [whether optical, infrared (IR), Raman, nuclear magnetic resonance (NMR), electron spin resonance (ESR) or ion cyclotron resonance (ICR)] were operated in scanning mode, this means either (or both) the excitation frequency or the magnetic field was scanned and only a single resonant frequency recorded at any given time during the experiment. The detectors were undiscriminating toward signals at different frequencies, and the frequencies had to be separated before the detector. This problem was first solved two centuries ago by the French mathematician Fourier [102]. The Fourier transform (FT) relates a time domain signal, $f(t)$, to the frequency spectrum, $f(v)$ as

$$
f(v)=\mathrm{F}[f(t)]=\int_{-\infty}^{\infty} f(t) e^{-2 \pi i v t} d t
$$

In FT spectroscopies, energy (signal) is recorded as a function of time, converted to digital form and stored in a computer. The (discrete) signal sampled from time $t=0$ to time $t=T$ is then converted to a frequency domain spectrum in the computer, typically by the Fast Fourier transform (FFT) algorithm [103]. The discrete version of the Fourier transform can be written (omitting a scale factor):

$$
f\left(v_{n}\right)=\sum_{k=0}^{N-1} f_{k} e^{-2 \pi i n k / N}
$$

where

$$
f_{k}=f\left(t_{k}\right), t_{k}=\frac{k T}{N}, k=0, \ldots, N-1
$$

and

$$
v_{n}=\frac{n}{T}
$$

The transform (Eq. 7) has a real (absorption) and an imaginary (dispersion) component. If all $f\left(v_{n}\right)$ were in phase we could extract the absorption spectrum from the measured signal, but due to a frequency-dependent phase shift it is often more convenient to look at the phase-independent magnitude spectrum, $M\left(v_{n}\right)$ :

$$
M\left(v_{n}\right)=\sqrt{\operatorname{Re}\left(f\left(v_{n}\right)\right)^{2}+\operatorname{Im}\left(f\left(v_{n}\right)\right)^{2}}
$$


In some cases, the phase shift can be compensated for and the absorption spectrum retrieved [104]. The magnitude-mode spectrum is a factor $\sqrt{3}$ broader than the absorption-mode spectrum for a purely Lorentzian line [105]. In all cases, except where explicitly stated in Paper I, the spectra analyzed or displayed are the magnitude spectra.

For an excellent introduction to FT spectroscopy see "Fourier Transforms in NMR, Optical and Mass Spectrometry" by Marshall and Verdun [105].

The Fourier transform had already been applied to NMR and IR spectroscopy before it was successfully coupled to ion cyclotron resonance by Comisarow and Marshall in 1974 [39, 40, 106]. FTICR and FTNMR are homologous techniques and they have "a broad range of conceptual, physical, experimental, and data reduction characteristics" in common [41].

The practical advantages of FTICR over scanning-mode ICR are significant. The signal-to-noise ratio and acquisition speed increase dramatically because all frequencies are detected all the time. This is also known as the multichannel or Fellgett's advantage in Fourier transform methods. The speed increases a factor of 10000 and the sensitivity a factor 100 [43].

\section{The Bruker 9.4 T Fourier Transform Ion Cyclotron Resonance Mass Spectrometer}

A general layout of the instrument is shown in Figure 12. A $160 \mathrm{~mm}$ bore $9.4 \mathrm{~T}$ central-field, passively shielded, superconducting $\mathrm{Nb}_{3} \mathrm{Sn}$ magnet (Magnex Scientific Ltd., Oxford, U.K.) is cooled in a cryosystem by liquid He to $4.2 \mathrm{~K}$. The horizontal bore of the magnet is aligned with a metal frame supporting a vacuum system, ion sources and a gas inlet system on tracks. From the main vacuum chamber a titanium tube leads into the center of the magnet where it ends with a flange holding and INFINITY ${ }^{\mathrm{TM}}$ cell. The vacuum system is a differentially pumped ultra-high vacuum system capable of sustaining a base pressure of below $4 \times 10^{-10}$ mbar using turbomolecular pumps backed by mechanical rough pumps.

The instrument is controlled by and data is retrieved and analyzed on a UNIX or Windows 2000 workstation. The instrumentation includes a pulse-shaping system for generation of frequency shots, correlated frequency sweeps, on-resonance and sustained off-resonance irradiation (SORI) for collision-induced dissociation (CID) experiments [107, 108], preamplifier and electronics for direct and heterodyne mode detection. Outside the cell is an electron gun for internal electron impact (EI) ionization and chemical ionization (CI) of volatile substances and the same gun can also be used for electron capture dissociation (ECD) [49, 109, 110].

The ESI source (Analytica, Branford, CT, U.S.A.) is equipped with an inlet glass capillary $(15 \mathrm{~cm}$ in length, an inner diameter of $0.5 \mathrm{~mm}$ and platinum capping at both 
ends). The electrospray apparatus, needles and capillaries are described in section 2.1.5. A further improvement to the electrospray source was the addition of a computer-controlled shutter [111]. This shutter essentially closes the spectrometer, and no more ions are accumulated in the hexapole ion trap. This allowed a controlled investigation of multipole-storage assisted dissociation (MSAD) [112, 113]. The flexibility of the XMASS software permitted compilation of experimental pulse programs controlling not only this shutter but also the internal electron gun used in ECD experiments [Papers II and III].

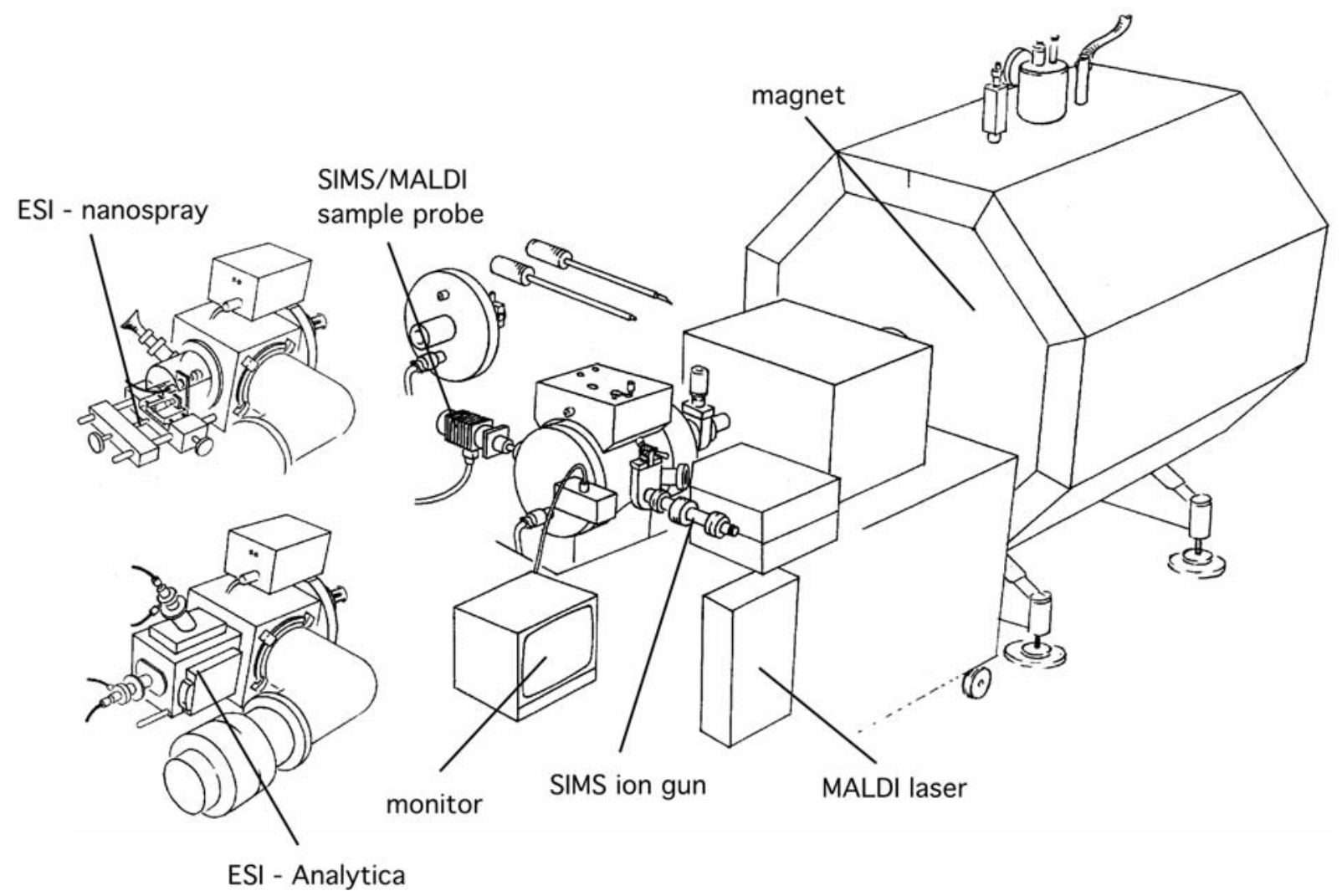

Figure 12. General layout of the Bruker $9.4 \mathrm{~T}$ FTICR mass spectrometer with interchangeable ion sources (Figure courtesy of G. Baykut). The experiments presented in this thesis were performed using either of the ESI sources.

For SORI and other experiments that require introduction of gas, two computer controlled fast valves for gas inlet are provided in this instrument. By opening an inlet valve connecting the cell and a volume of collision gas, like $\mathrm{Ar}$ or $\mathrm{Xe}$, at a pressure of 5 mbar, for $\sim 10 \mathrm{~ms}$, the pressure in the cell is raised to a level suitable for SORI experiments $\left(\sim 10^{-7} \mathrm{mbar}\right)$.

This instrument and its performance are described in detail in Paper I. Another 9.4 T FTICR instrument has also been described by Senko et al. [114]. 


\subsubsection{Data Analysis}

\section{Mass Spectrometry, Peptide Mass Fingerprinting and Information}

Mass spectrometry measures the ratio of mass to electric charge, $\mathrm{m} / \mathrm{z}$. Larger molecules, such as peptides, frequently become multiply charged in electrospray ionization. This means that one molecule can appear at different $m / z$ in a mass spectrum, each corresponding to a different $z$. The first step after the transformation of the time-domain signal is therefore to deconvolute or reduce [115] the mass spectrum to retrieve the individual masses.

The mass of a protein is not well defined in the sense that each protein molecule has the same mass. The natural abundances of heavier isotopes, such as ${ }^{13} \mathrm{C}$ and ${ }^{34} \mathrm{~S}$, contribute to an isotopic distribution characteristic for each molecule. The mass difference between isotopic peaks is around $1.00 \mathrm{Da}$ and the difference in $\mathrm{m} / \mathrm{z}$ around $1.00 / z$. This simple information can be used to find the charge state of a particular cluster of peaks.

There are several algorithms available to deconvolute mass spectra. The simplest methods use only information on the $\mathrm{m} / \mathrm{z}$ of peaks, to find charge states, or isotopic distributions, and remove them from the list of peaks being processed. If the isotopic distributions are known or can be estimated a more thorough approach can be taken, where a model for the isotopic distribution of a species of such mass (give or take a few mass units) is fitted to the experimental data [115-118]. A program was written to deconvolute mass spectra. This program, ESIMSA, was made freely available on the Internet.

The isotopic distributions themselves contain potentially valuable information. One such case is isotope-labeling experiments, where differentially labeled samples and controls are analyzed in the same spectrum, for instance using so-called isotopecoded affinity tags [119]. Another example is the study of protein structure and dynamics using hydrogen/deuterium exchange (HDX) where information in isotopic distributions can be used to extract information on the isotopic states of exchanging hydrogens [120] [Paper IX]. Software for extracting this information, AUTOHD, was written and also made available over the Internet.

In addition to the mass degeneracy due to isotopes, the mass of a protein is further degenerated as a function of variability in sequence, e.g. different splice forms or post-translational processing or modifications.

Instead of using the mass of the whole protein for identification, the protein can be cleaved or fragmented into smaller pieces with well-defined masses. The standard method is enzymatic digestion using trypsin. This enzyme cleaves specifically Cterminally of the basic residues arginine and lysine, except for $\mathrm{N}$-terminally of proline. The measured peptide masses from a tryptic digest are compared with calculated sets of masses for different protein sequences or libraries of mass spectra 
in a database, an approach called peptide mass fingerprinting (PMF) [15]. To aid protein identification, these peptides can be fragmented in vacuo to generate short sequence tags [21]. Sequences of 5-6 amino acids in length are often specific for a certain protein in the database. The sequence tag approach is more error-tolerant and can identify peptides with unpredicted post-translational modifications or errors in the database sequence.

To get an idea of the statistical significance for a certain identification it is appropriate to compare with random peptide mass matches from sequences derived from an unrelated organism. The random matches from the S. cerevisiae proteome can be used to calculate the probability (or risk) for a random match (false positive) when identifying a human protein and thus calculate the significance [121]. The biologist may object that $H$. Sapiens and S. cerevisiae are related organisms, but the evolutionary relationship must be much closer and protein sequence homologies near $100 \%$ to generate significant cross-talk in peptide mass fingerprinting, i.e. common tryptic peptides in distantly related human and yeast proteins. As is shown in Paper IV, peptide mass fingerprinting can distinguish between myoglobin from horse and zebra, differing in only one residue, i.e. having sequence homology $>99 \%$.

There are other means to discriminate between true and random matches. For instance, the pattern of matching peptides in the sequence may also differ between true and random matches. In general, true matches have non-random distributions of peptides in the protein sequence (Figure 13). The non-randomness of the distribution can be quantified, for instance by an adaptation of the runs test [122]. In the test the distributions of the lengths of contiguous peptide spatial runs in the protein sequence are compared with those calculated for random matches and the likelihood of a measured peptide distribution occuring at random. The random distributions can be simulated or estimated from data from unrelated proteins.

Another way of quantifying this one-dimensional pattern is to look at the distributions of peptides with zero, one or two close neighbors in the sequence, here simply called the connectivity in a peptide map [Paper V].

This choice of spatial pattern descriptors of peptide maps is supported by the empirical notion that true peptide matches are often contiguous. This pattern also appears as a factor in the Bayesian model used in the ProFound algorithm [123]. 


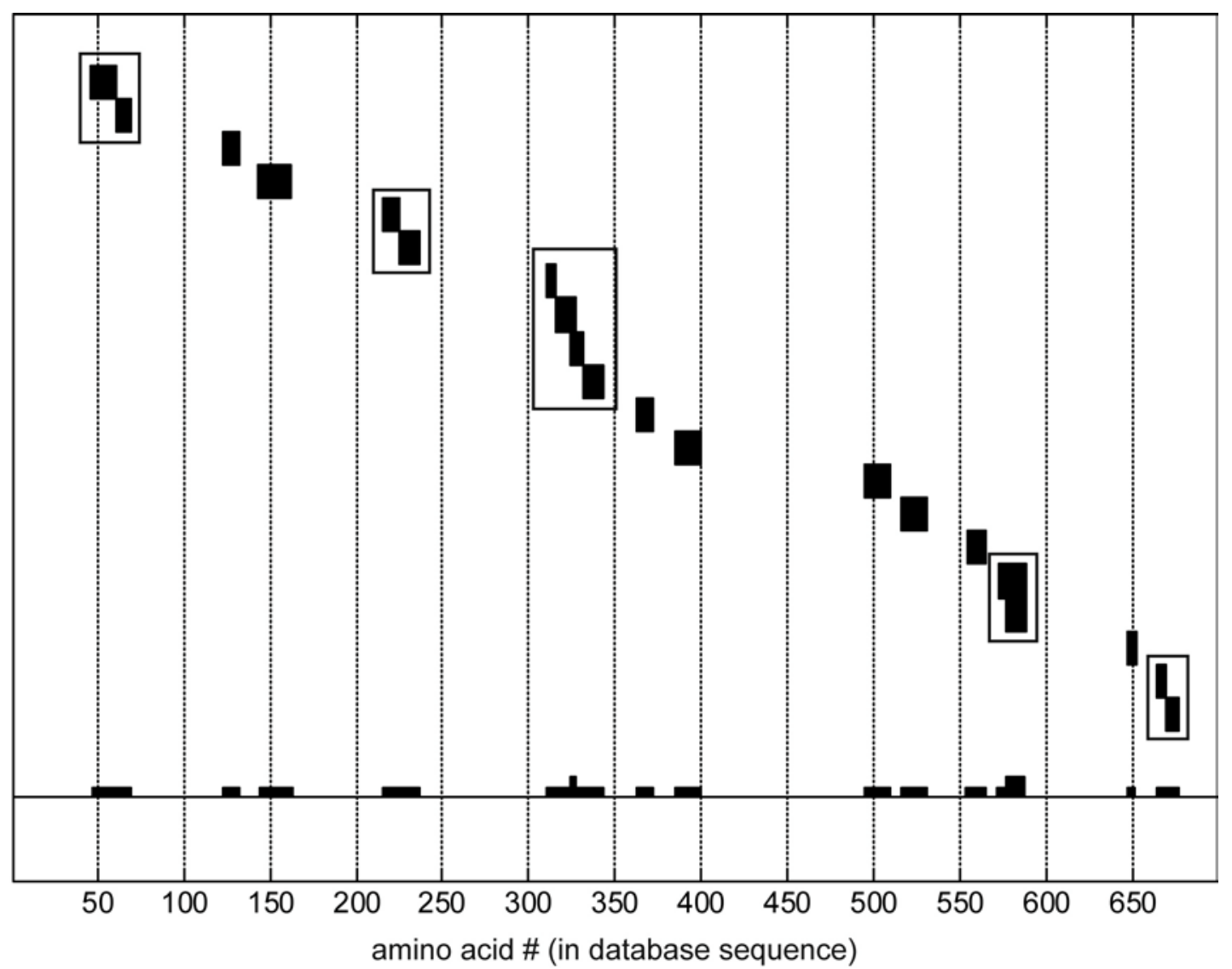

Figure 13. Non-random distribution of tryptic peptides in a peptide mass fingerprint. Regions of contiguous matching peptides are indicated. The pattern, or non-randomness, can be used to further discriminate between random and true matches in peptide mass fingerprinting.

Two-dimensional spectra, whether from liquid chromatography or capillary electrophoresis or any other type of separation, contain more information than the masses and intensities alone. The chromatographic retention or electrophoretic migration time contains information on the physiochemical properties of the peptides, such as hydrophobicity in RPC and size and charge in standard capillary zone electrophoresis (CZE). A model of chromatographic retention [124-128] or electrophoretic migration [129-138] can be fitted to experimental data from known proteins. These models are then used to predict the retention time for candidate peptides in a database. The candidates can then be ranked based by combining deviation of calculated mass from measured mass and predicted retention from measured retention by calculating a total $\chi^{2}$ value for all candidates within a certain mass interval.

Hydrophobicity is one of the most important physicochemical characteristics of amino acids and probably the most poorly defined term. Cornette et al. has reviewed and compared 37 different hydrophobicity scales [139]. 
To illustrate the use of a predictor of retention, a simple model of retention in reversed phase, also discussed by Hodges and co-workers [125-128], can be adapted to the chromatographic separations used here. Peptides from abundant proteins in complex mixtures can be used as internal standards to calculate a "retention coefficient" for each amino acid according to

$$
T_{\text {retention }}=\sum_{i=1}^{20} N_{i} R C_{i}+T_{0}
$$

where $R C_{i}$ are the retention coefficients for the 20 amino acids and there are $N_{i}$ amino acids $i$. The $R C_{i}$ values could be expected to correlate with hydrophobicity of the amino acid side-chains in RPC. The $R C_{i}$ and $T_{0}$ can be fitted to experimental data, retention times $T_{\text {retention, }}$ for a large number of peptides ( $\left.>20\right)$. Eq. 11 also allows for a linear dependence of retention time on peptide size, as a constant term added to each $R C_{i}$. In addition to a sufficiently large number of peptides in the predictor training set to avoid overfitting, each amino acid should also be represented by several peptides in this training set.

Most models of electrophoretic mobility of peptides are non-linear functions of peptide charge and molecular weight [136]. The molecular weight is easily calculated for each peptide candidate, and the charge, or distribution of charges, is estimated from measured $\mathrm{pK}_{\mathrm{a}}$ values of amino acids in $\mathrm{N}$ and $\mathrm{C}$-termini and side chain $\mathrm{pK}$ values. The sum of the electrophoretic mobility and electroosmotic flow at a certain electric field determines the electrophoretic migration.

\section{An Alternative Mass Spectrometric Approach to Proteomics?}

The methodology presented in this thesis scrambles the information by digesting all proteins simultaneously, separating these by direct infusion or a suitable liquid separation method (LC or CE) coupled to FTICR mass spectrometry (Figure 14) and identifies the proteins by highly accurate mass measurement and possibly the complementary types of information from ECD, patterns in tryptic digestion, retention time or electrophoretic mobility discussed above. To illustrate the concept behind this approach to protein identification it is useful to compare with a more established method in proteomics today. This method is based on separation by twodimensional SDS-PAGE, automated spot picking, tryptic digestion and protein identification by peptide mass fingerprinting or sequence tags generated by MS/MS [CID or post-source decay (PSD)] [22, 23].

These two methods should be regarded as complementary, each having benefits and disadvantages over the other. 
A

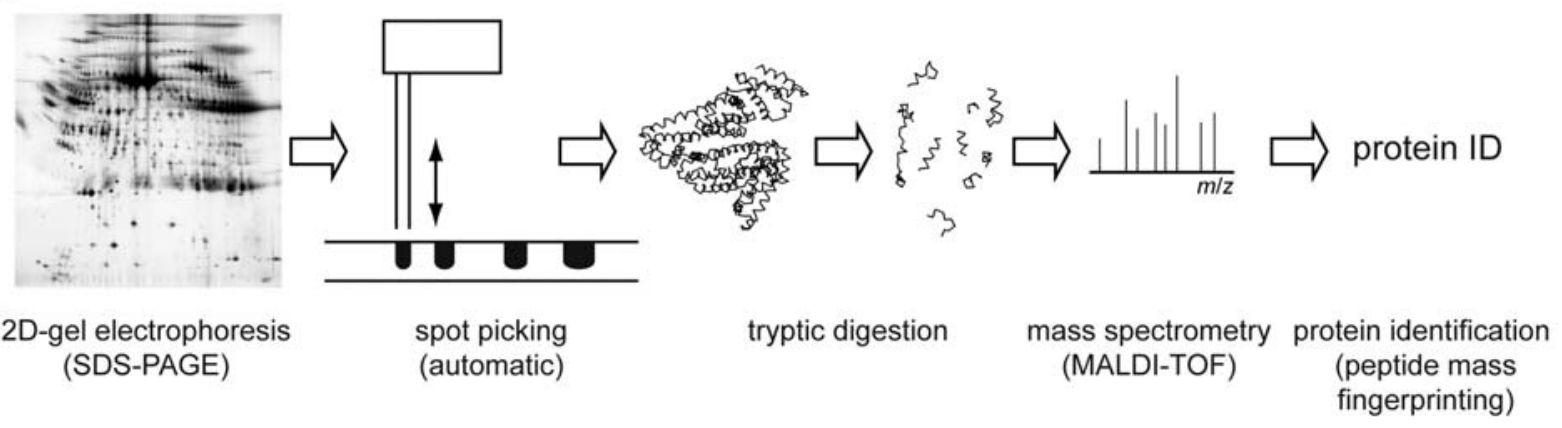

B

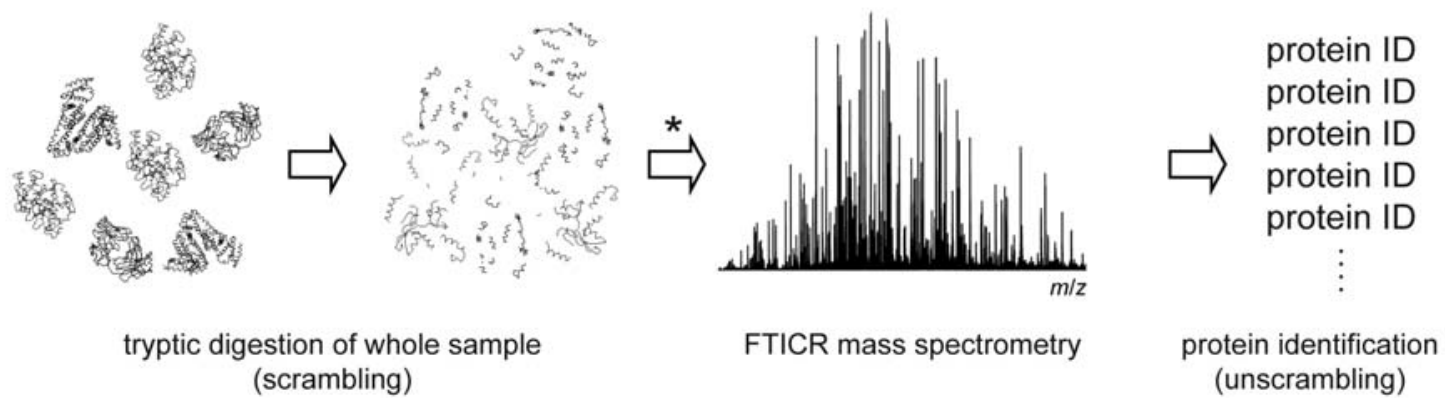

Figure 14. The picture shows two different approaches to proteomics involving mass spectrometry. The established technique $(\mathbf{A})$ is based on 2D-gel electrophoresis, spot picking and tryptic digestion before mass spectrometry (typically MALDI-TOF) and protein identification by peptide mass fingerprinting using one of several available algorithms, such as MASCOT [140], ProFound [123, 141] or MS-Fit [142]. The second approach (B), presented in detail in this thesis, begins by digesting all components in the sample at once, then separate the scrambled peptides by FTICR mass spectrometry and retrieve a list of identified proteins by unscrambling the available information. For complex mixtures, a liquid separation method such as LC or CE can be inserted at the *. A similar approach has also been used by Smith et al. $[143,144]$ in the analysis of bacterial and yeast proteomes. 


\subsection{Results and Discussion}

\subsubsection{Direct Infusion Electrospray lonization}

A general problem in proteomics is the identification of proteins in biological samples, that is, not only detecting a specific protein, but any protein that may be present in the sample. The standard approach today is to separate and visualize the proteins by $2 \mathrm{D}$ polyacrylamide gel electrophoresis $[13,145]$. The $2 \mathrm{D}$ image provides little information on the identity of the proteins, but the protein expression can be profiled and compared. Selected spots on the gel can be excised and analyzed by mass spectrometry, e.g. by digestion with trypsin $[15,20]$ or tryptic digestion followed by MS/MS [21, 22, 24].

2D-PAGE has inherent limitations in speed and dynamic range [143] and is biased against what proteins can be detected [146]. Hydrophobic analytes, such as membrane proteins, pose severe challenges in two-dimensional electrophoresis [147149]. These can be partially circumvented using strategies based on liquid chromatography or capillary electrophoresis $[143,146]$.

Before resorting to liquid separation techniques it is of interest to estimate how many proteins that can be identified by tryptic digestion and direct infusion into the mass spectrometer. This is not only a convenient figure-of-merit to compare mass spectrometers or experimental protocols, but have real importance, as gel spots are often heterogeneous [25] and SDS-PAGE is denaturing and does not preserve protein complexes. To identify proteins in a purified multi-protein complex with peptide mass fingerprinting, it is also of value to know how large complexes can be characterized by direct infusion of a total tryptic digest. First, three proteins, equine cytochrome $c(12 \mathrm{kDa})$, equine myoglobin $(17 \mathrm{kDa})$ and bovine serum albumin $(66$ $\mathrm{kDa}$ ), were digested, pooled together and electrosprayed into the mass spectrometer. The mass spectrum (Figure 15) contains about 1300 peaks, which could be reduced to 330 unique masses [paper IV]. A general database search (containing sequences from all species) finds the three proteins from the correct species. Ingendoh and coworkers later performed similar experiments using MALDI and a 7 T FTICR instrument with similar success [150]. Three or four proteins are by no means a limit for what can be analyzed through direct infusion FTICR mass spectrometry, which will be shown in this chapter. In general, the organism and tissue or cell type are all known, and the databases used for searching for matches with peptide mass fingerprints are more specific and thus smaller.

Another use for direct infusion of multi-protein tryptic digests is as a first rapid screen of the most abundant proteins in a complex biological sample. We have demonstrated this possibility by analyzing the total tryptic digests of proteins in four human body fluids of clinical interest, plasma, cerebrospinal fluid (CSF), urine, and saliva [paper V]. The protein profiles are known to be similar in plasma, CSF and 
urine, and the most abundant proteins are also found with the highest significances (lowest probabilities for random match) [paper V]. At most about 10 significant matches are found by direct infusion of the digested body fluids (in saliva, typically only salivary amylase could be found by direct infusion).

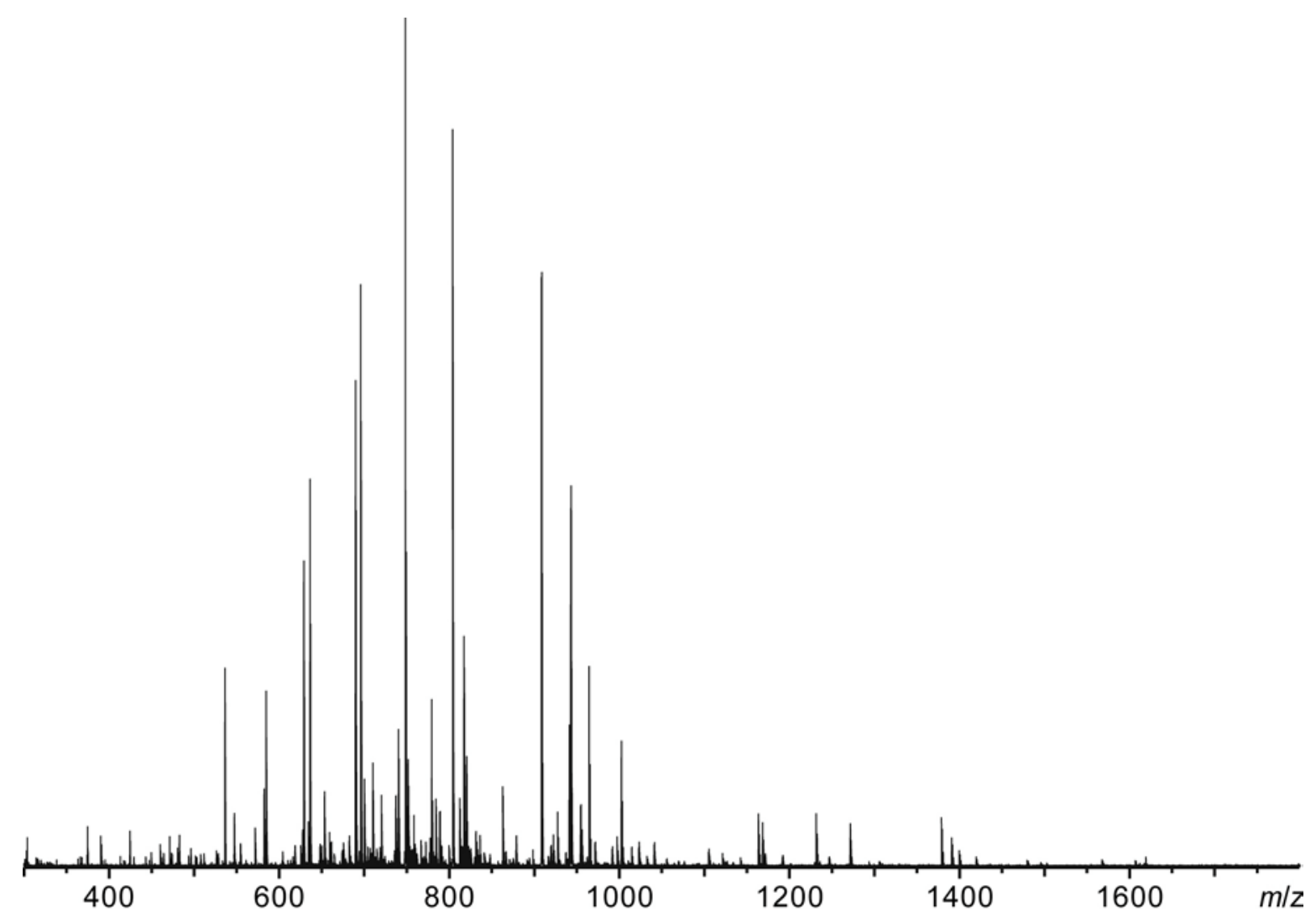

Figure 15. FTICR mass spectrum of a mixture of tryptic digests of cytochrome $c$, myoglobin and albumin. A total of 1294 peaks could be reduced to 573 isotopic clusters and 330 unique masses. Database search in full non-redundant OWL 31.4 database containing protein sequences from all available organisms identified the correct proteins from the correct species. For this spectrum, 2048 scans were accumulated and $512 \mathrm{~K}$ data points acquired.

The tryptic digestion had been carried out to near completion, meaning only a small number of missed cleavage sites in the proteins. Most peptides were found between $\mathrm{m} / \mathrm{z} 600$ and 1000 (Figure 15). The region $\mathrm{m} / \mathrm{z} 800-900$ of this spectrum is shown in Figure 16 to illustrate the spectral peak density. The unit for mass-tocharge ratio is called thomson, denoted Th, where $1 \mathrm{Th}=1 \mathrm{Da} / 1$ elementary charge. The resolving power of the $9.4 \mathrm{~T}$ FTICR instrument is sufficient to resolve peptides with mTh differences, for example, an albumin and a myoglobin tryptic peptide with a mass-to-charge difference 0.0045 Th could be resolved in this routinely acquired broadband spectrum without special tuning (Figure 17). 


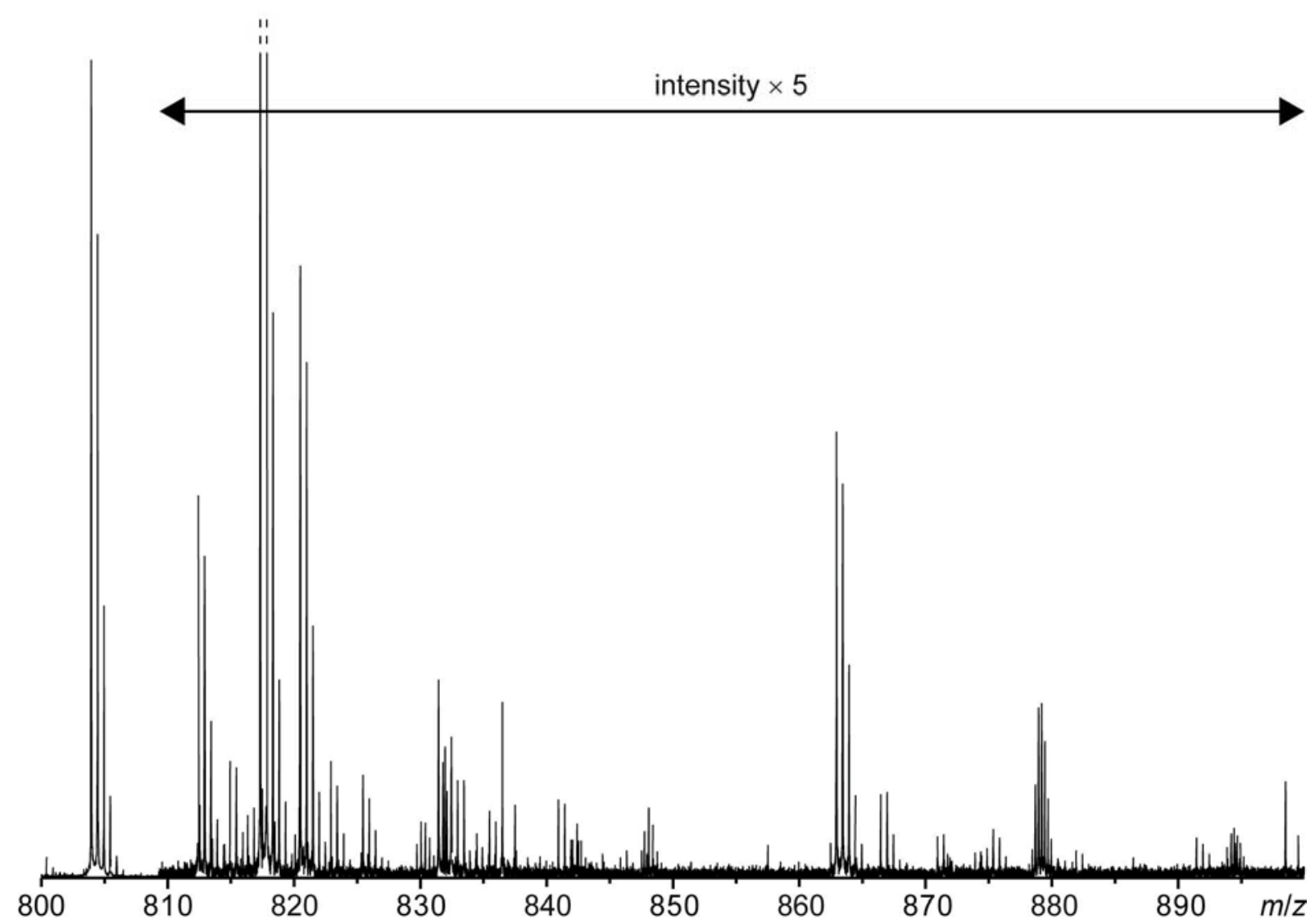

Figure 16. Magnification of the region 800-900 Th of the FTICR mass spectrum in Figure 15 illustrating the peak density ( 1 peak/Th).

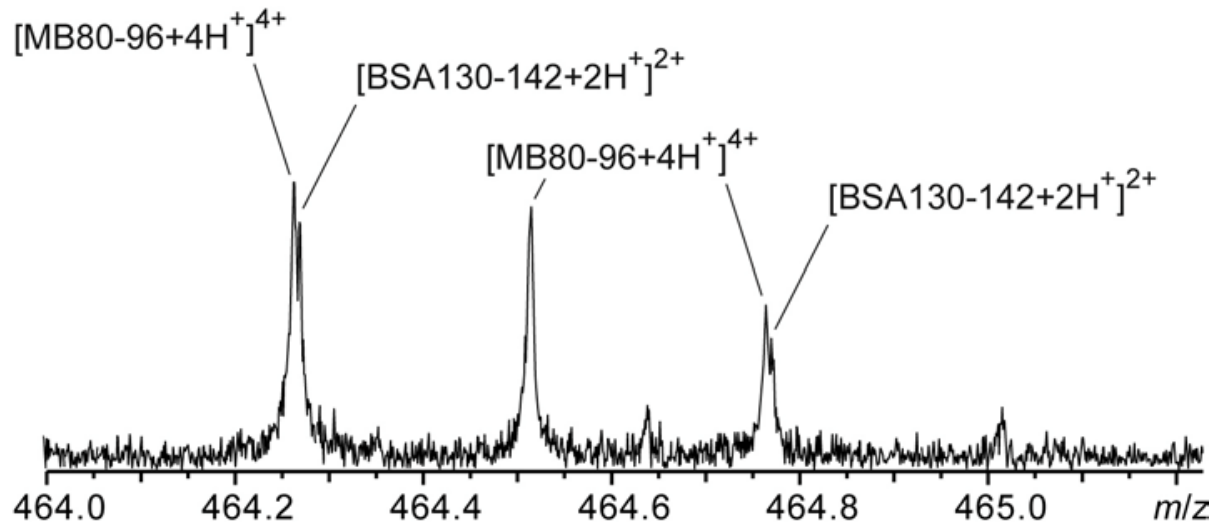

Figure 17. Magnification of the region 464-465 Th of the FTICR mass spectrum above, showing partially resolved isotopic peaks from quadruply charged horse myoglobin (MB) 80-96 (CHHEAELKPLAQSHATK), 464.2464 Th (calc.) (monoisotopic), 464.2445 Th (exp.) and doubly charged bovine serum albumin (BSA) 136-142 (YLYEIAR), 464.2509 Th (calc.), 464.2504 Th (exp.). 
The results from analysis of the three-protein mixture shows that at least a small number of proteins can be identified simultaneously with direct infusion and FTICR mass spectrometry. A biological protein extract is far more complex than this threeprotein mixture, illustrated by the resulting spectrum of a plasma tryptic digest in Figure 18.

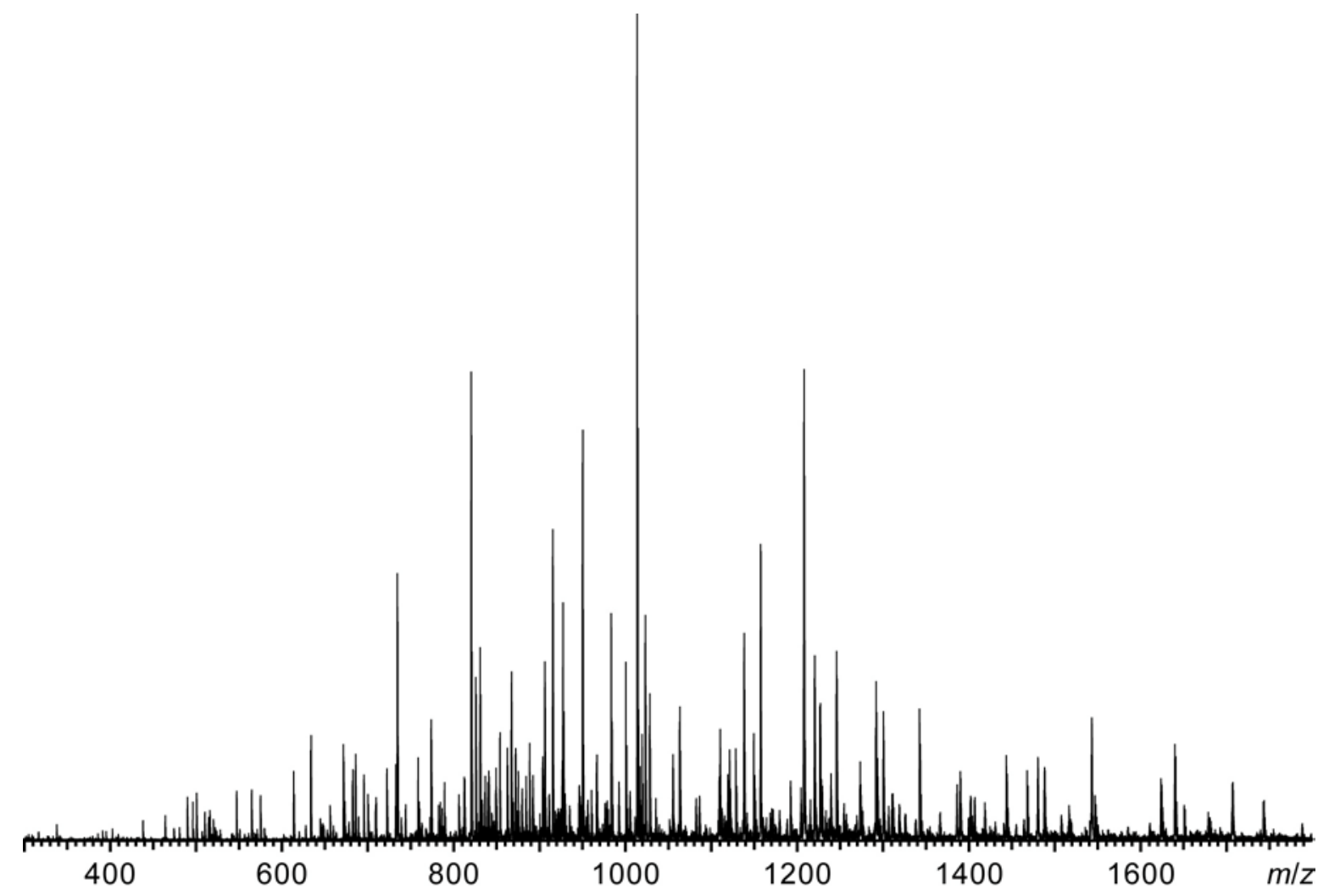

Figure 18. "World-record" FTICR mass spectrum of a human plasma tryptic digest containing about 5500 peaks that could be reduced to 1300 unique peptide masses. Direct database searches in MASCOT or ProFound returned only the most abundant protein, serum albumin, but subsequent analysis identified a number of the more abundant proteins with high statistical significances [paper V].

To illustrate the spectral peak density and compare this with the three-protein mixture, the same region 800-900 Th is shown in Figure 19. In the range 600-1000 Th the peak density is $\sim 5$ peaks/Th. Figure 20 shows a further magnification into the most dense region and the isotopic clusters putatively identified as human serum albumin (HSA) fragments by the computer software (ESIMSA+DATACOMP). Despite the broadband resolving power of the FTICR mass spectrometer, this sample is so complex that there is no baseline for most of the spectrum. 


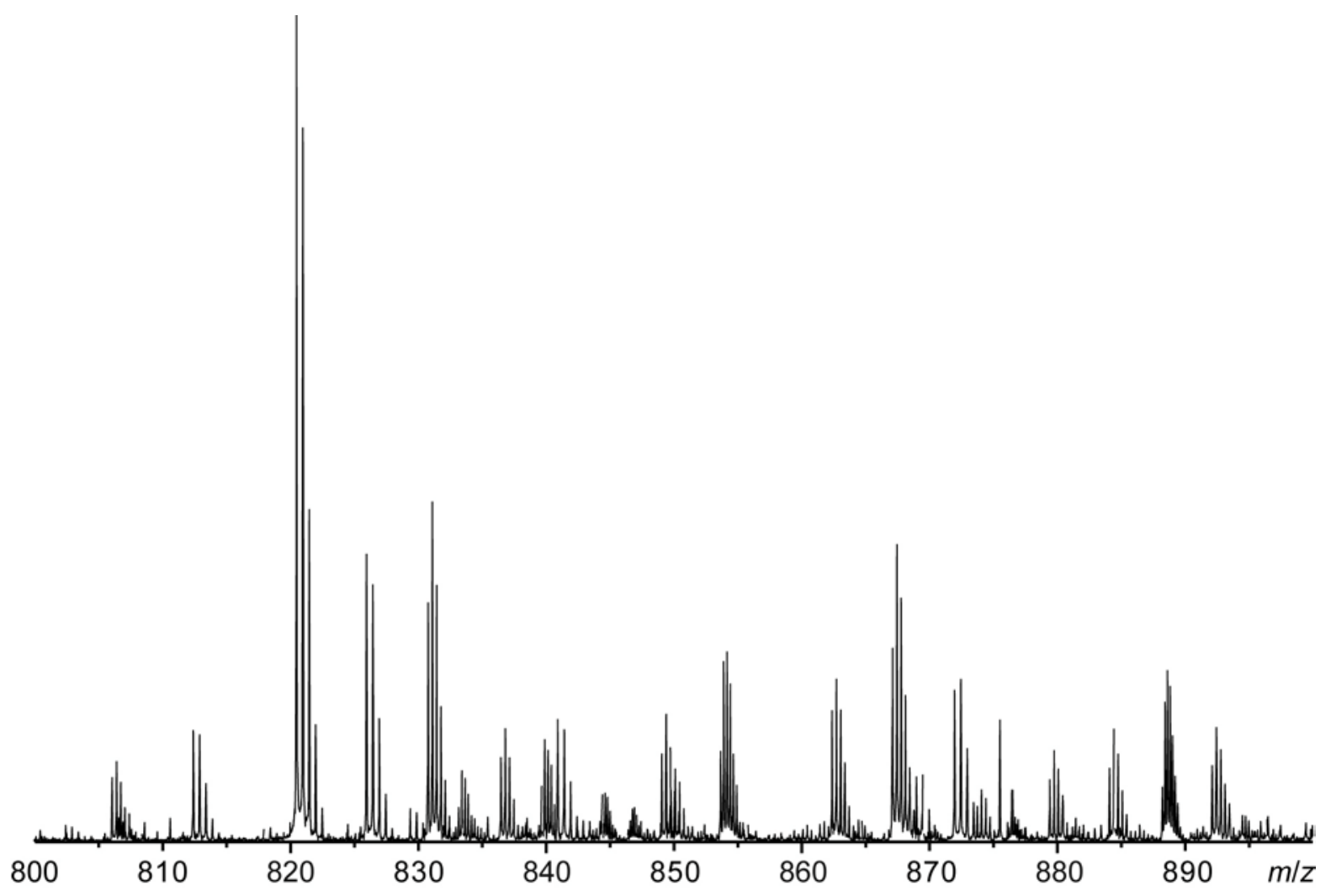

Figure 19. Magnification of the region $800-900$ Th of the FTICR mass spectrum in Figure 18 illustrating the peak density ( 5 peaks/Th).

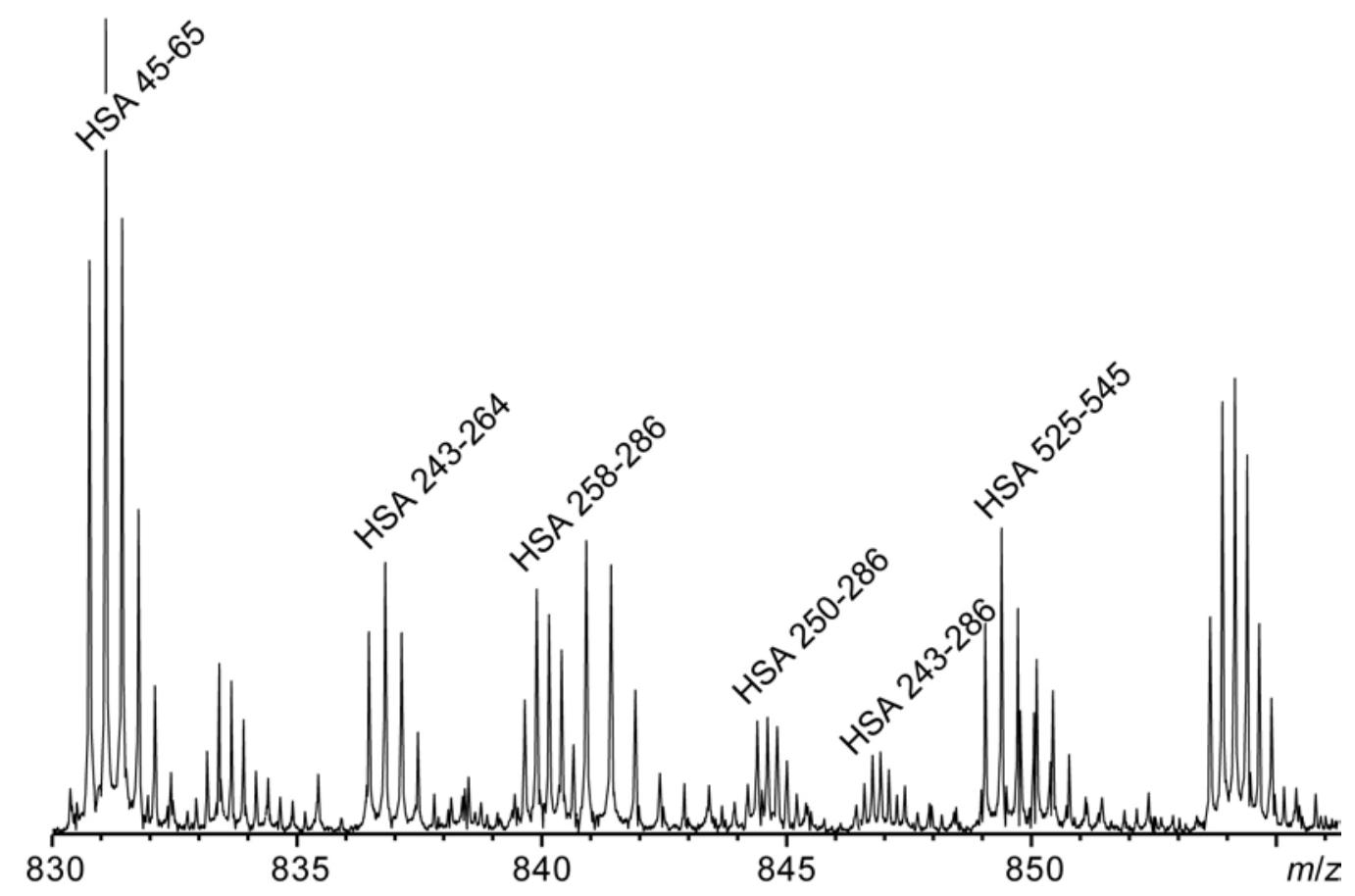

Figure 20. Magnification of the region 830-856 Th of the FTICR mass spectrum of the human plasma tryptic digest showing identified human serum albumin (HSA) fragments. This sample was too complex to resolve all peaks to the baseline in the 9.4 T FTICR mass spectrometer. 
Accurate mass determination is paramount in peptide mass fingerprinting and mass spectrometric protein identification [151-153].

The mass accuracy can be estimated by looking at the mass measurement error distribution for the most abundant protein in plasma, human serum albumin (HSA) (Figure 21).

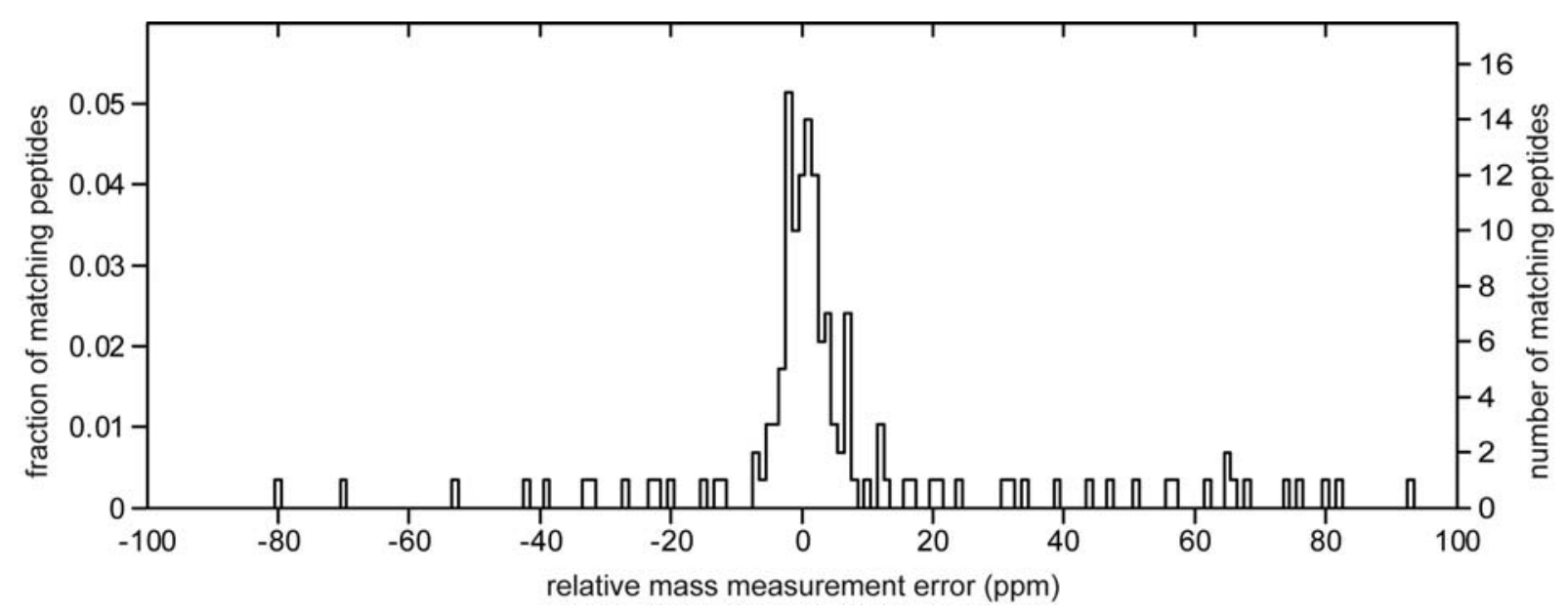

Figure 21. Relative mass measurement error distribution for human serum albumin (HSA) in plasma in the mass spectra above.

The centered distribution in Figure 21 is mainly the result of true matches whereas the matching peptides outside $\pm 10 \mathrm{ppm}$ are due to false matches. The true matches are drawn from a much more narrow distribution than the false matches. This distribution is the signal to be detected in peptide mass fingerprinting. The absolute number of matching peptides within any chosen cut-off (e.g. $\pm 10 \mathrm{ppm}$ ) does not suffice for protein identification. Instead, this number should be compared with the expected number of random matches given the experimental data and error cut-off. This comparison can be done by taking the ratio of the likelihood of the measured distribution being drawn from a random matching distribution and the likelihood of being drawn from a convolution of a random and true matching distribution. The ratio of convoluted signal (true matches) and background (false matches) should be large enough to discriminate between true and false matches.

The distribution of matching peptides in the database sequence of HSA $( \pm 10 \mathrm{ppm})$ can be illustrated by a "sequence coverage" plot (Figure 22). Note that the first 24 amino acids constitute signal and propeptides and are not expected in the released form of HSA. 


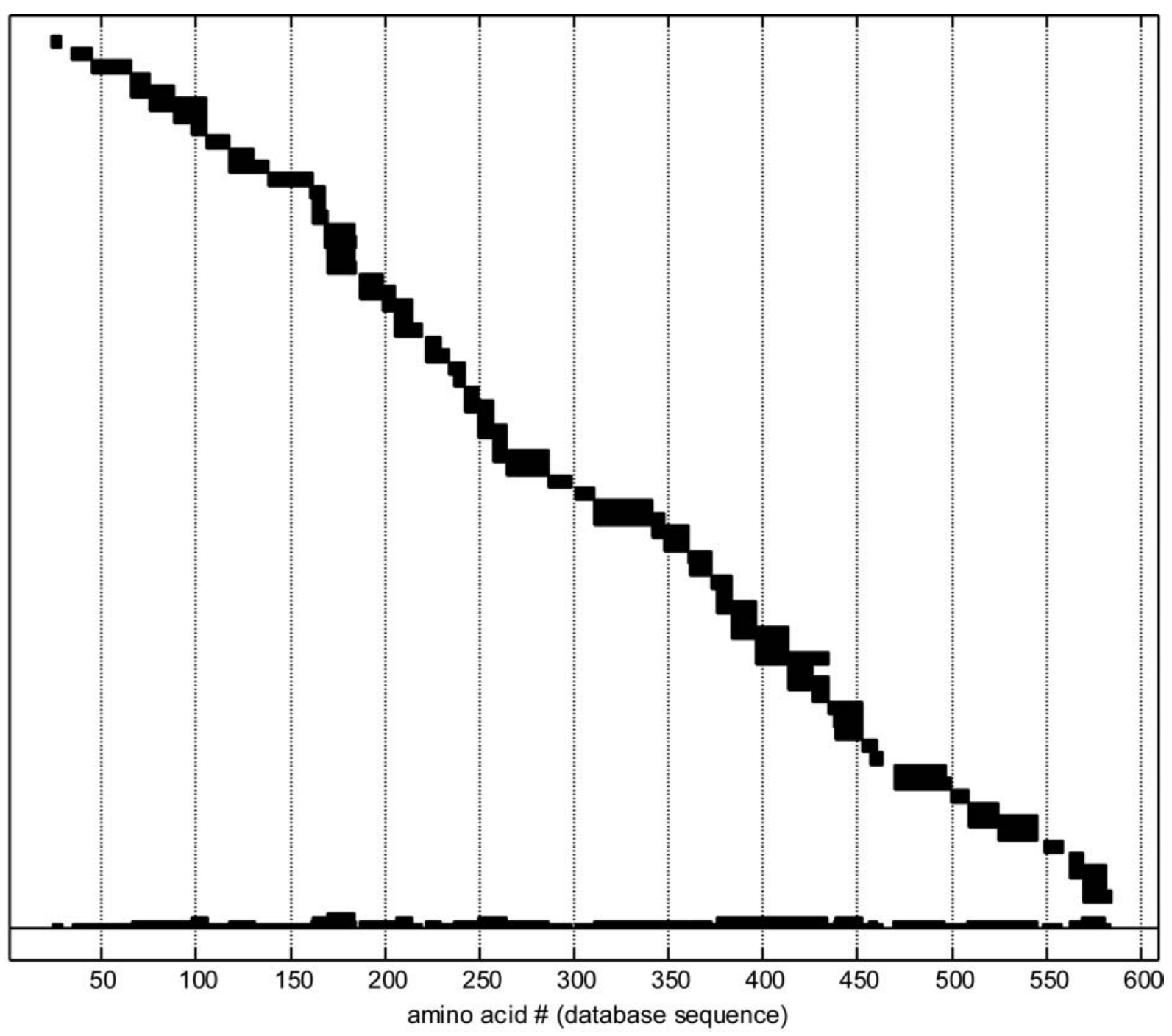

Figure 22. Distribution of 70 matching peptides within $10 \mathrm{ppm}$, covering $92 \%$ of the mature protein sequence, of human serum albumin (HSA) in a human plasma tryptic digest. Residues 1-18 and 19-24 are signal peptide and propeptide and not expected to show up in this graph. The bottom line is the degree of sequence coverage by overlapping peptides.

The likelihood ratios for mass measurement errors and peptide connectivity of 150 body fluid proteins in an a priori selected database were compared to $4861 \mathrm{~S}$. cerevisiae proteins as negative controls [Paper V]. Table 2 shows the matching proteins and their statistical significances calculated by comparison with the yeast sequences in four analyzed body fluids. A small number of the most abundant proteins could be identified already in the direct infusion spectra.

Although not that many proteins could be routinely identified in whole body fluid tryptic digests, the method could nonetheless be used as an initial screening of biological samples in general to identify the most abundant proteins. Further optimization is possible; one option would be to remove the highly abundant HSA, 
essentially doubling the relative abundance of all other proteins (except a few that are bound to HSA).

Table 2. Matches between the 150 sequences in the a priori selected database, BFPDB (for body fluid protein database) and direct infusion ESI-FTICR mass spectra of four body fluid tryptic digests run under identical conditions (a different plasma digest from shown spectra). Sequences in boldface would be $\geq 99 \%$ significant; others are 95 $99 \%$ significant when tested alone. At most $1-2$ sequences of those $\geq 99 \%$ could be false matches.

\begin{tabular}{llll}
\hline \multicolumn{1}{c}{ PlaSma } & \multicolumn{1}{c}{ Cerebrospinal fluid } & \multicolumn{1}{c}{ Saliva } & Urine \\
\hline \hline SERUM ALBUMIN & SERUM ALBUMIN & AMYLASE ALPHA 1A & \multicolumn{1}{c}{ SERUM ALBUMIN } \\
IMMUNOGLOBULIN G & TRANSFERRIN & APOLIPOPROTEIN A-IV & UROMODULIN \\
IMMUNOGLOBULIN A & CYSTATIN C & FIBRINOGEN ALPHA & HAPTOGLOBIN \\
FIBRINOGEN ALPHA & IMMUNOGLOBULIN G & COMPLEMENT FACTOR B & CYTOKERATIN \\
TRANSFERRIN & PERLECAN & COMPLEMENT FACTOR 9 & AMBP PROTEIN \\
\hline PLASMA KALLIKREIN & ALPHA-1-ANTITRYPSIN & IMMUNOGLOBULIN G & ALPHA-1-MICROGLOBULIN \\
COMPLEMENT FACTOR C4 & COMPLEMENT FACTOR C4 & COMPLEMENT C3 & EPIDERMAL GROWTH FACTOR \\
HAPTOGLOBIN & PROSTAGLANDIN D SYNTHASE & VITRONECTIN & APOLIPOPROTEIN D \\
CYSTATIN C & ALPHA-2-GLYCOPROTEIN 1 & & COMPLEMENT COMPONENT C4 \\
& HAPTOGLOBIN & & ALPHA-1-ACID GLYCOPROTEIN 1 \\
& FIBULIN 1 ISOFORM D & PROTEIN Z \\
& ACTIN GAMMA & PROSTAGLANDIN D2 SYNTHASE \\
& ALPHA-1-ANTICHYMOTRYPSIN & ALPHA-2-HS GLYCOPROTEIN \\
\hline
\end{tabular}

\subsubsection{Liquid Separations and Mass Spectrometry}

Coupling of liquid separations such as LC [154-156] or CE [94, 143, 157-161] to FTICR mass spectrometry significantly increases the capacity for analyzing complex samples. Primarily, this can be assigned to the reduced ion suppression and increased dynamic range compared with direct infusion. Belov, Gorshkov, Smith and co-workers have further increased the dynamic range by loading the FTICR analyzer cell after selection in a quadrupole ion trap, called "active dynamic range expansion" [162-164]. Smith et al. have also used this quadrupole to induce fragmentation to generate MS/MS type data [165]. A suitable figure-of-merit to compare direct infusion and different on- and off-line separations and mass spectrometry is how much information can be obtained in a given time and/or with a given amount of sample. The simplicity and reliability of direct infusion and the time needed to reequilibrate LC columns and CE capillaries between each run should also be taken into account (or alternatively, several LC or CE systems could be coupled to the same mass spectrometer). Figure 23 shows an LC-FTICR mass chromatogram and a CEFTICR electropherogram of CSF tryptic digests. 

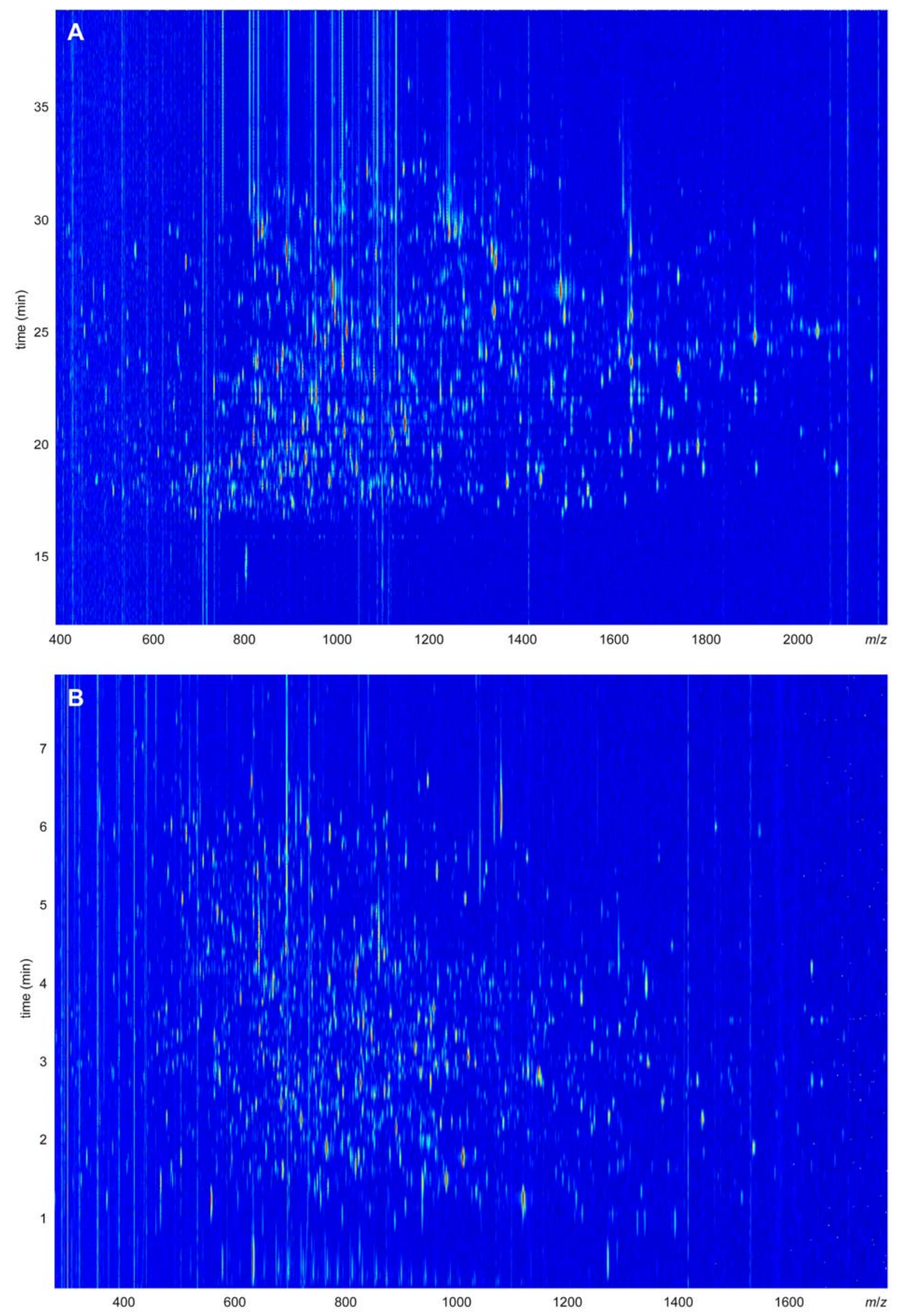
Figure 23 (color panel, opposite side). LC-FTICR (A) and CE-FTICR (B) analysis of cerebrospinal fluid tryptic digests. LC and CE data was acquired with skillful assistance of M. Ramström and M. Wetterhall respectively. Peaks were picked automatically by an AURA macro run in XMASS. The macro performed timedomain convolution with squared sine functions of period equal to the sampling time followed by peak picking using the function supplied with the XMASS software and centroid fitting to each peak. The generated peak report files were merged and analyzed by ESIMSA and DATACOMP. The logarithmically scaled intensities (color) and the plots were generated by sifting out $4 / 5$ (A) or $9 / 10$ (B) of the data points (keeping the maximum in each interval) using an AWK [166] script before plotting in MATLAB.

The total number of data points in 2D datasets such as those illustrated in Figure 23 is the number of data points in the $\mathrm{m} / \mathrm{z}$ domain times the number of spectra acquired, i.e. $\sim 128$ kbyte- 512 kbyte times $256-512$ spectra $=32-256$ Mbyte raw data generated in each run.

When searching the a priori defined body fluid protein database, a significantly larger number of proteins could be identified compared to the direct infusion spectra of CSF tryptic digests (Table 3). This comparison with direct infusion experiments demonstrates that separation methods enhance the ability of FTICR mass spectrometry to analyze complex biological samples, even given the relatively modest performance of the LC and CE equipment used here. Figure 24 shows the distributions of likelihood-ratio based scores for the 150 sequences in the a priori defined database and the 4861 sequences in the yeast database.

Here, all identifications have been made on mass measurement errors (standard peptide mass fingerprinting) and a probabilistic notion of the non-randomness of the distribution of tryptic peptides in the sequence coverage, i.e. the amount of overlap and contiguity of these peptides. 
Table 3. Proteins identified by mass measurement error and peptide connectivity in a cerebrospinal fluid digest by direct infusion, liquid chromatography and capillary electrophoresis electrospray ionization Fourier transform ion cyclotron resonance mass spectrometry from a 150-sequence a priori selected database. Proteins in boldface were $\geq 99 \%$ significant, others $95-99 \%$ significant. At most $1-2$ of the proteins on the $99 \%$ significance level can be expected to be random matches and 4-6 in the 95-99\% interval (redundant sequences not shown in table).

\begin{tabular}{|c|c|c|}
\hline direct infusion & LC-FTICR & CE-FTICR \\
\hline $\begin{array}{l}\text { SERUM ALBUMIN } \\
\text { TRANSFERRIN } \\
\text { CYSTATIN C } \\
\text { IMMUNOGLOBULIN G } \\
\text { PERLECAN } \\
\text { ALPHA-1-ANTITRYPSIN } \\
\text { COMPLEMENT COMPONENT C4 } \\
\text { PROSTAGLANDIN D SYNTHASE } \\
\text { ALPHA-2-GLYCOPROTEIN } 1 \\
\text { HAPTOGLOBIN } \\
\text { FIBULIN } 1 \text { ISOFORM D } \\
\text { ACTIN GAMMA } \\
\text { ALPHA-1-ANTICHYMOTRYPSIN }\end{array}$ & 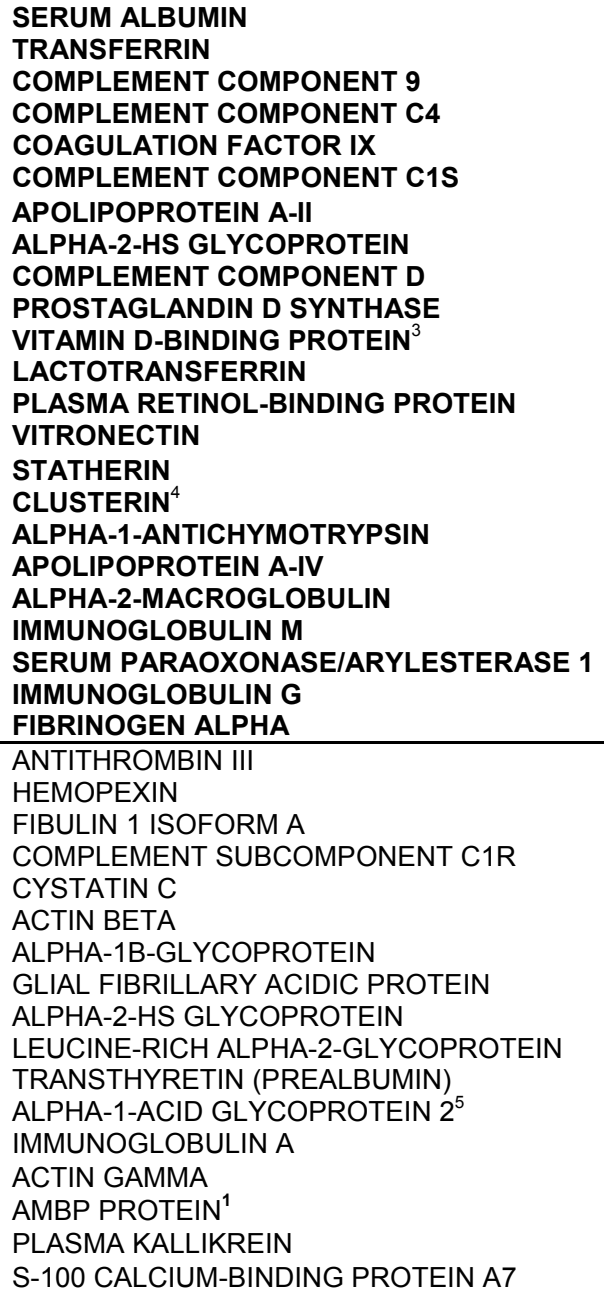 & $\begin{array}{l}\text { SERUM ALBUMIN } \\
\text { IMMUNOGLOBULIN G } \\
\text { TRANSFERRIN } \\
\text { TRANSTHYRETIN (PREALBUMIN) } \\
\text { AMBP PROTEIN }{ }^{1} \\
\text { PLASMA KALLIKREIN } \\
\text { UROMODULIN }{ }^{2} \\
\text { VITAMIN D-BINDING PROTEIN }{ }^{3} \\
\text { HEMOPEXIN } \\
\text { IMMUNOGLOBULIN M } \\
\text { FIBULIN } 1 \text { ISOFORM A } \\
\text { ALPHA-1B-GLYCOPROTEIN } \\
\text { APOLIPOPROTEIN A-IV } \\
\text { ALPHA-2-MACROGLOBULIN } \\
\text { PROTEIN Z } \\
\text { ALPHA-2-HS GLYCOPROTEIN } \\
\text { COAGULATION FACTOR XI } \\
\text { FIBRINOGEN ALPHA CHAIN } \\
\text { ALPHA-1-ANTITRYPSIN } \\
\text { COMPLEMENT COMPONENT C4 } \\
\text { FACTOR IX } \\
\text { COMPLEMENT FACTOR } 9 \\
\text { FIBRINOGEN GAMMA CHAIN } \\
\text { APOLIPOPROTEIN C-III } \\
\text { CLUSTERIN }{ }^{4} \\
\text { CYSTATIN C } \\
\text { CYTOKERATIN } \\
\text { PROTEIN SAP1 } \\
\text { ALPHA-2-HS GLYCOPROTEIN } \\
\text { ALPHA-1-ACID GLYCOPROTEIN } 2^{5}\end{array}$ \\
\hline
\end{tabular}

${ }^{1}$ CONTAINS ALPHA-1-MICROGLOBULIN (PROTEIN HC) AND INTER-ALPHA-TRYPSIN INHIBITOR LIGHT CHAIN (BIKUNIN) ${ }^{2}$ TAMM-HORSFALL URINARY GLYCOPROTEIN

${ }^{3} \mathrm{DBP}$ (GC-GLOBULIN)

${ }^{4}$ COMPLEMENT-ASSOCIATED PROTEIN SP-40,40) (COMPLEMENT CYTOLYSIS INHIBITOR) (CLI) (NA1 AND NA2)

(APOLIPOPROTEIN J) (APO-J) (TRPM-2)

${ }^{5}$ AGP 2 (OROSOMUCOID 2) 


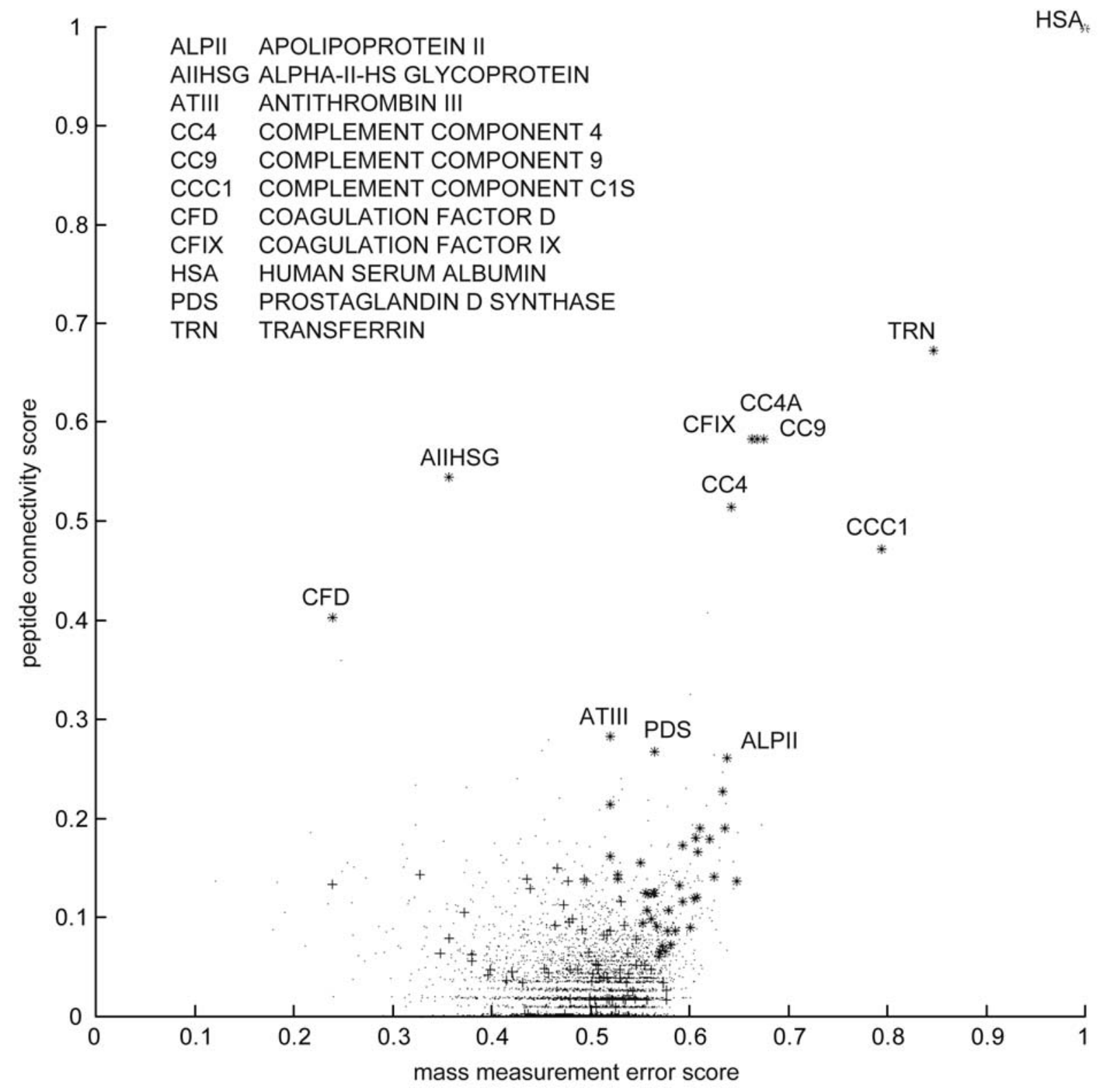

Figure 24. Distribution of mass measurement errors and peptide connectivity likelihood scores for 150 body fluid proteins $\left(+,{ }^{*}\right)$ in an LC-FTICR mass spectra of CSF compared to $4861 \mathrm{~S}$. cerevisiae sequences (·). The LC-FTICR dataset contained 70204 peaks, which could be reduced to 16296 isotopic clusters and 6551 unique masses. Asterisks ( $\left.{ }^{*}\right)$ denote $95 \%$ significant matches.

In addition to the accurate mass measurement and distribution of peptides in the protein sequence, containing information on the non-random behaviour of trypsin, protein structure, post-translational modifications and database sequence errors, there is also information on the physiochemical properties of the individual peptides. This is primarily hydrophobicity in reversed-phase chromatography [124-128] and size and charge in capillary zone electrophoresis [129-138]. A predictor of retention time according to Eq. 11 was "trained" by least squares fit to 103 measured retention 
times for tryptic peptides of serum albumin and transferrin in CSF [Paper VII]. HSA contains only one tryptophan residue and should not be used alone to train a predictor based on amino acid composition, especially since tryptophan is also one of the most hydrophobic residues. Table 4 show the retention coefficients found by fitting to Eq. 11. In this separation, the $\mathrm{pH}$ of the mobile phases was $\sim 3$. The $\mathrm{pH}$ has been shown to be very important in reversed-phase chromatographic retention and electrophoretic migration of peptides [138, 167].

Table 4. Retention coefficients in mass spectrum numbers (\#) and minutes for the 20 amino acids derived from tryptic peptides of human serum albumin and transferrin in a CSF tryptic digest analyzed by reversed-phase LC-FTICR mass spectrometry and acidic $(\mathrm{pH} \sim 3)$ mobile phases [Paper VII]. As expected, these have a positive correlation with hydrophobicity.

\begin{tabular}{lll}
\hline \multicolumn{1}{c}{ amino acid } & retention coefficient (\#) & retention coefficient (min) \\
\hline \hline arginine (Arg or R) & -4.02 & -0.76 \\
serine (Ser or S) & -3.75 & -0.71 \\
lysine (Lys or K) & -3.47 & -0.66 \\
asparagine (Asn or N) & -2.87 & -0.54 \\
glutamic acid (Glu or E) & -1.39 & -0.26 \\
aspartic acid (Asp or D) & 0.23 & 0.04 \\
glycine (Gly or G) & 1.53 & 0.29 \\
threonine (Thr or T) & 1.94 & 0.37 \\
alanine (Ala or A) & 2.18 & 0.41 \\
histidine (His or H) & 3.00 & 0.57 \\
proline (Pro or P) & 5.10 & 0.97 \\
methionine (Met or M) & 5.19 & 0.98 \\
glutamine (Gln or Q) & 5.37 & 1.02 \\
cystein (Cys or C) & 6.98 & 1.32 \\
leucine (Leu or L) & 12.04 & 2.28 \\
valine (Val or V) & 12.88 & 2.44 \\
phenylalanine (Phe or F) & 14.13 & 2.68 \\
isoleucine (Ile or I) & 14.24 & 2.70 \\
tyrosine (Tyr or Y) & 14.67 & 2.78 \\
tryptophan (Trp or W) & 24.69 & 4.68 \\
(T) & $(25.17)$ & $(4.77)$ \\
\hline
\end{tabular}

Figure 25 shows the correlation between predicted and measured retention for the 103 peptides of serum albumin and transferrin in the LC-FTICR mass spectra identified by accurate mass measurement alone. This is contrasted with the correlation between predicted retention for 622 peptides from 100 yeast proteins showing only a weak correlation to the measured retention for the randomly matching peptides in CSF (Figure 25 B). This weak correlation is due to a correlation between peptide size and retention time. 
In itself, the information on retention time is not sufficient to identify proteins in complex mixtures, but it is complementary to the mass measurement and peptide connectivity and can hence be used to resolve ambiguities and increase the significance of protein matches in LC-MS of whole sample tryptic digests. The same approach could also be applied in CE-MS experiments.
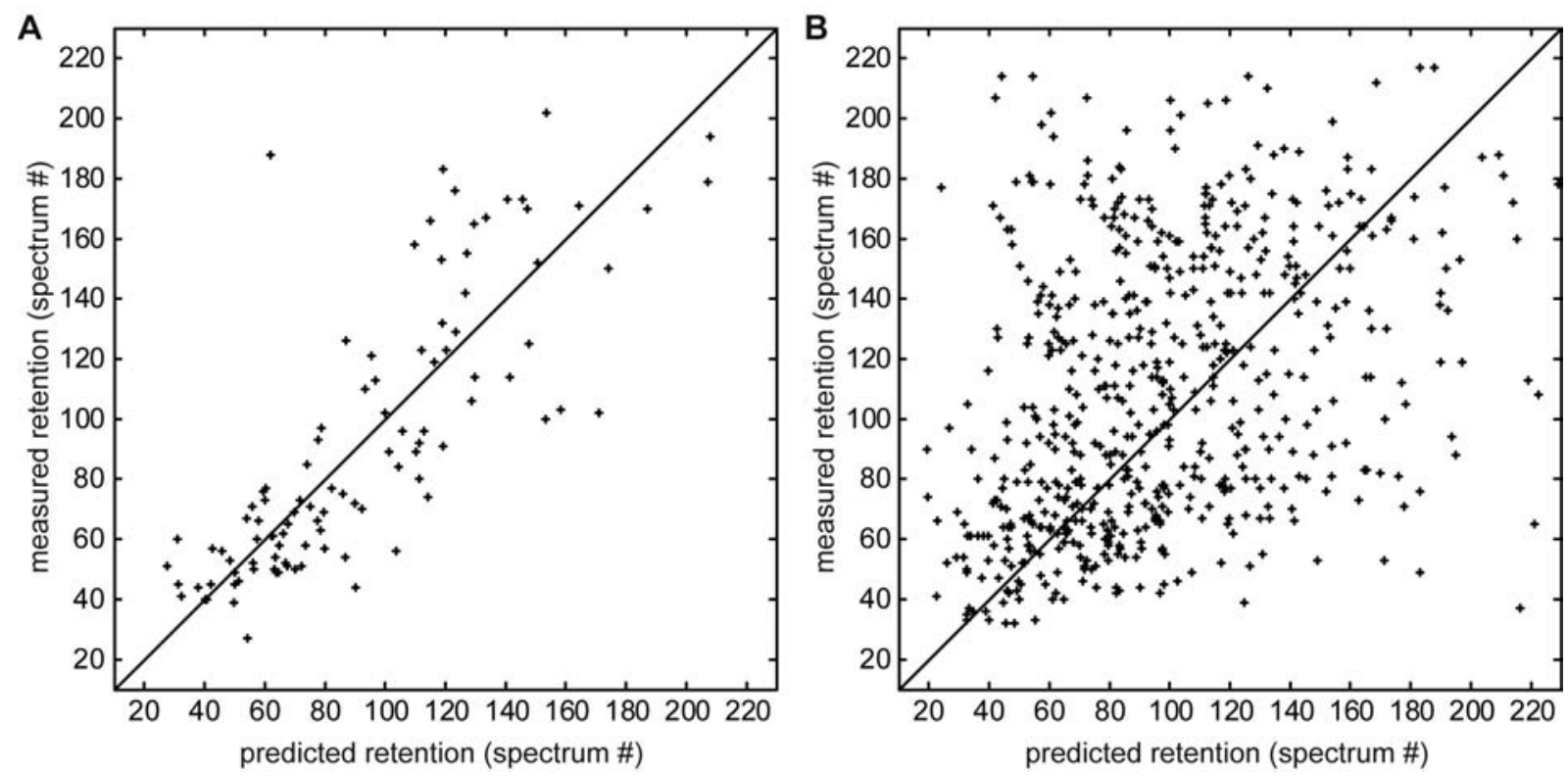

Figure 25. Correlation between predicted and observed retention for HSA and transferrin tryptic peptides (A) and random matches from 100 yeast proteins (B). No increase of the relative prediction error with peptide size was observed for this predictor. This could however be expected to limit the performance of improved predictors as larger peptides have more possibilities for intramolecular interactions and secondary structure that are likely to influence chromatographic behavior. The most prominent outlier in A, HSA 66-75 (LVNEVTEFAK), is conceivably a random (false) match.

Combining information from retention/migration time prediction, accurate mass measurements and non-randomness of matching peptides in peptide mass fingerprints in a total $\chi^{2}$-score improves the significances of found proteins and the number of proteins identified with a sufficient statistical significance. This predictor is based on a very simple model of retention and the accuracy could be expected to improve if more advanced features are incorporated. One such improvement would be to use a secondary structure predictor (a review was recently published by Rost [168]) to estimate the number of intramolecular hydrogen bonds and solvent accessibility to amino acid side-chains. These are likely to play an important role for peptide behavior in reversed-phase chromatography. 
Computer software was written that combined analysis of raw data with peptide mass fingerprinting and database searches. The raw data analysis consisted of apodization by time-domain convolution of a gaussian or a half-period sine function, automated peak picking and deconvolution to unique masses and their retention times, i.e. maxima for all selected ion chromatograms). In the LC-FTICR mass chromatogram discussed here, 70204 peaks were found and reduced to 16296 isotopic clusters and 6551 unique peptide masses. The whole process took a few seconds on a standard PC and matching to protein databases took about $1 \mathrm{~s} / 100$ sequences. 


\section{CHARACTERIZATION OF PEPTIDES AND PROTEINS}

\subsection{Methods}

The Bruker FTICR instrument was originally equipped to perform SORI-CID experiments. So-called capillary/skimmer (or nozzle/skimmer) fragmentation could also be easily achieved by altering the capillary and/or skimmer potential. Electron capture dissociation was initially performed using the filament for internal (in-cell) electron ionization supplied with the instrument. This filament was later replaced by a large-area $\left(78 \mathrm{~mm}^{2}\right)$, indirectly heated, cathode of dense porous tungsten impregnated with a barium calcium aluminate emission mix. This cathode produces a wider and more homogeneous electron beam, greatly simplifying ECD experiments. The electron beam has a $28 \mathrm{~mm}^{2}$ cross-section in the cell (limited only by the entrance to the cell) overlapping with ions stored in the cell. A more complete description on this cathode, its mounting into the instrument and characteristics have been published by Tsybin et al. [110]. In the experiments described here, the cathode heating current was 2.2-2.3 A and the irradiation time 100-250 ms.

Electrospray ionization was described in 2.1.5 and the FTICR mass spectrometer in 2.1.6. ECD was combined with liquid chromatography by simply alternatively acquiring normal (precursor) and ECD (precursor+fragments) spectra (Figure 26). More details on this experiment are found in Paper III.

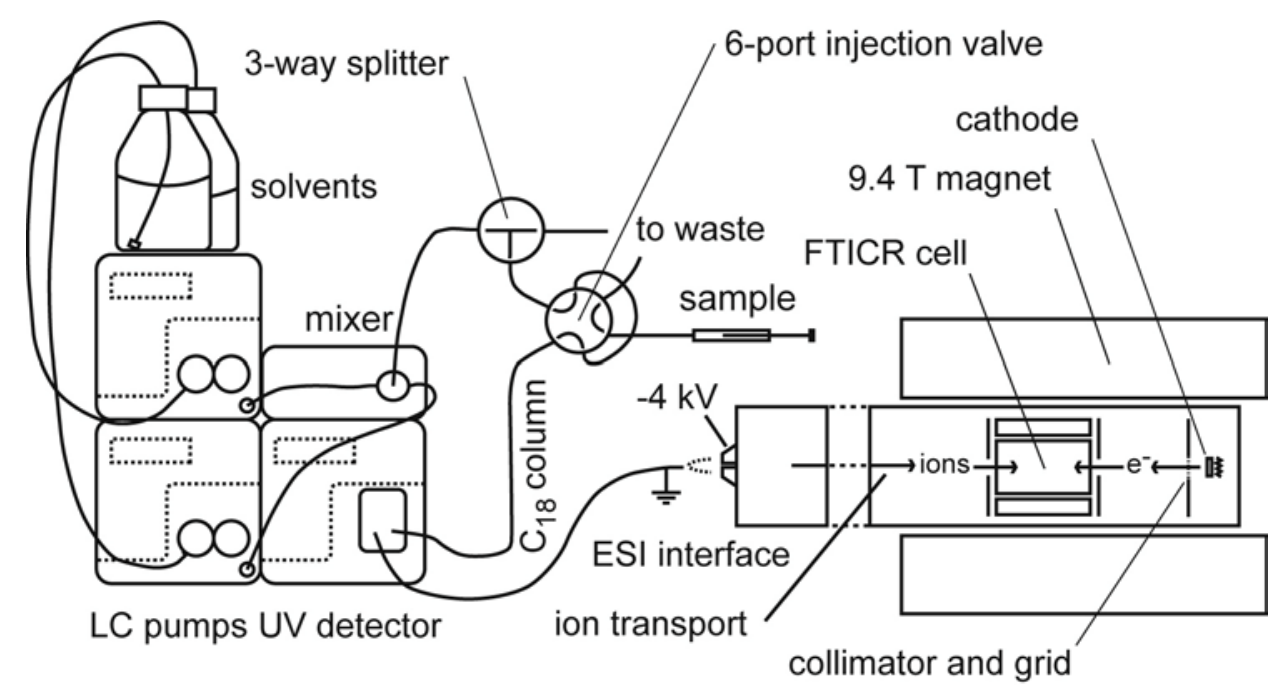

Figure 26. The experimetnal setup combining liquid chromatography and electron capture dissociation and FTICR mass spectrometry. The electron beam was pulsed by changing the extraction grid potential, alternating between acquiring precursor and fragment spectra. 


\subsection{Results and Discussion}

In addition to the identification of proteins made by comparison with genomederived sequences in a database, biochemists are frequently interested in learning about the post-translational modifications of proteins, as these are often important for structure and biological functions. Electron capture dissociation and mass spectrometry have been shown to be the methods of choice for characterizing such covalent post-translational modifications as O-glycosylations [51] and phosphorylations [53, 57, 61]. These modifications, if unpredicted, cause tryptic peptide fragment masses to differ from those calculated from DNA sequences. Measured peptide masses can also be different from those predicted due to errors or polymorphisms (differences between individuals) in the DNA sequence, frame shifts or alternative splicing.

A small neuropeptide, substance $P$, could be completely sequenced in a matter of seconds [Paper II]. With the improved electron source it was possible to observe ECD fragments on the millisecond time-scale for several small peptides [110]. ECD also preserves labile modifications, such as tyrosine sulfates, here shown on a fragment of the protein hirudin (Figure 27). These groups are easily lost in collision induced dissociation, and hence can not be localized within the peptide. 


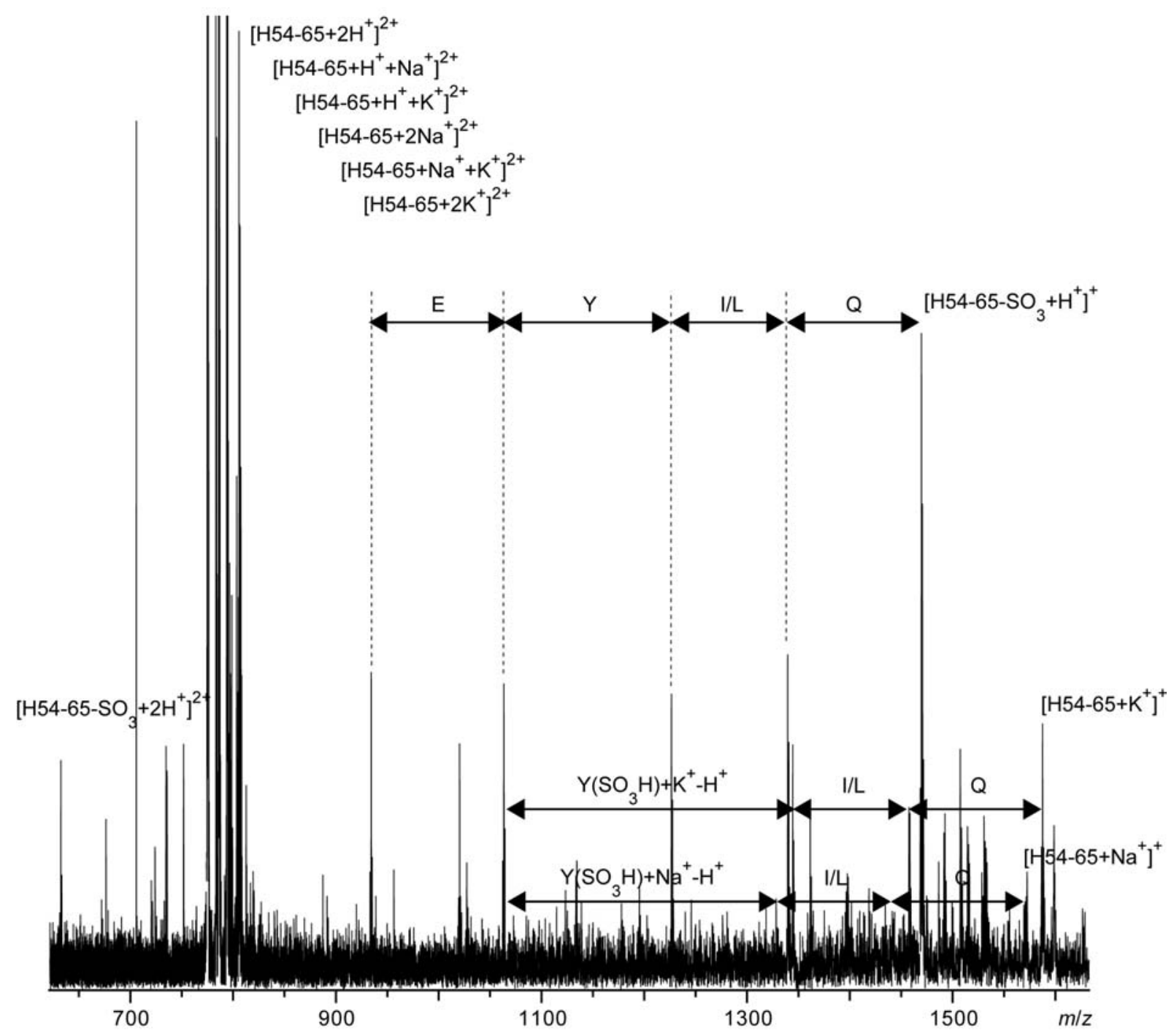

Figure 27. Electron capture dissociation of tyrosine-sulfated fragment 54-65 of hirudin (GDFEEIPEEYLQ). Alkali metal ions are associated with the sulfate and appear to stabilize the modification in ECD experiments. Hirudin is a potent anticoagulant from the bloodsucking leech, Hirudo medicinalis [169]. Electron capture dissociation characterization of tyrosine sulphate has not been reported previously. The peptide was kindly provided by M. Danfelter.

The high-rate of fragmentation using the new, large-area cathode enables coupling of ECD on-line with liquid separation techniques. Proof-of-principle experiments combining LC and ECD with FTICR mass spectrometry were performed [Paper III]. A BSA tryptic digest was separated on a RPC column and analyzed with ESI-FTICR and ECD (Figure 28).

Neither chromatographic separation nor conditions for ECD were optimized in this experiment, and it is likely that further improvement of the technique will increase the number and completeness of sequence tags generated from a protein tryptic digest. If two different enzymes are used, for instance trypsin (cleaving the peptide 
bond on the C-terminal side of Arg and Lys) and Glu-C (C-terminal side of Glu), overlapping peptides can be generated. If these overlap sufficiently, LC-ECD-FTICR could be used to sequence and characterize large proteins de novo, similar to shotgun genome sequencing [170] but on a much smaller scale. This has also been called the "bottom up" approach as compared to the "top down" approach [171].

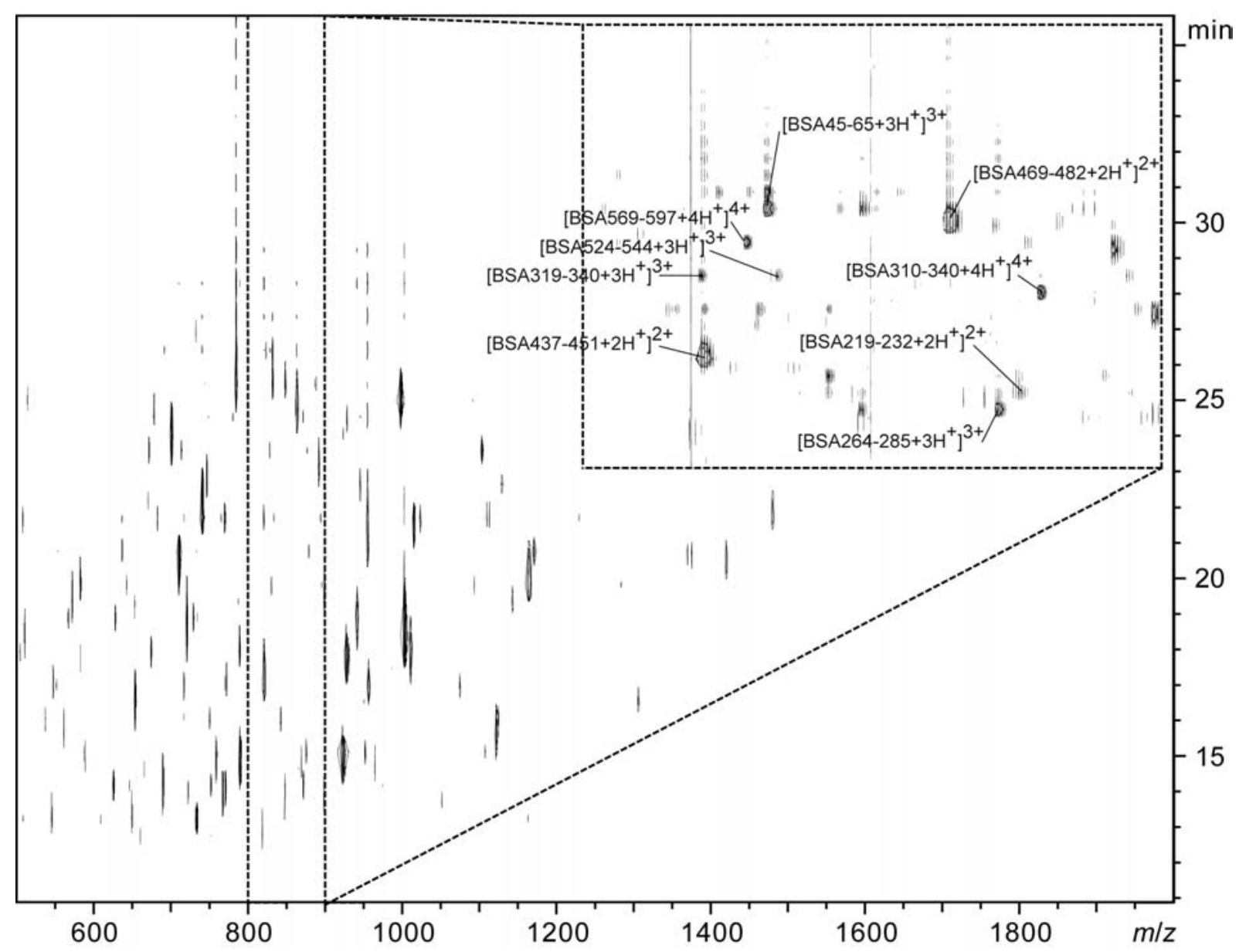

Figure 28. Contour plot of LC-ECD-FTICR mass spectra of a BSA tryptic digest. The inset shows the region 800-900 Th with the most abundant peaks identified. The effect of alternatively acquiring spectra with and without electrons is seen in the alternating intensities in the tails of the most abundant peaks.

Figure 29 shows the distributions of tryptic peptides and 13 complete and partial sequences of these peptides generated by ECD. Any one of these sequence tags is sufficient to identify the protein. 


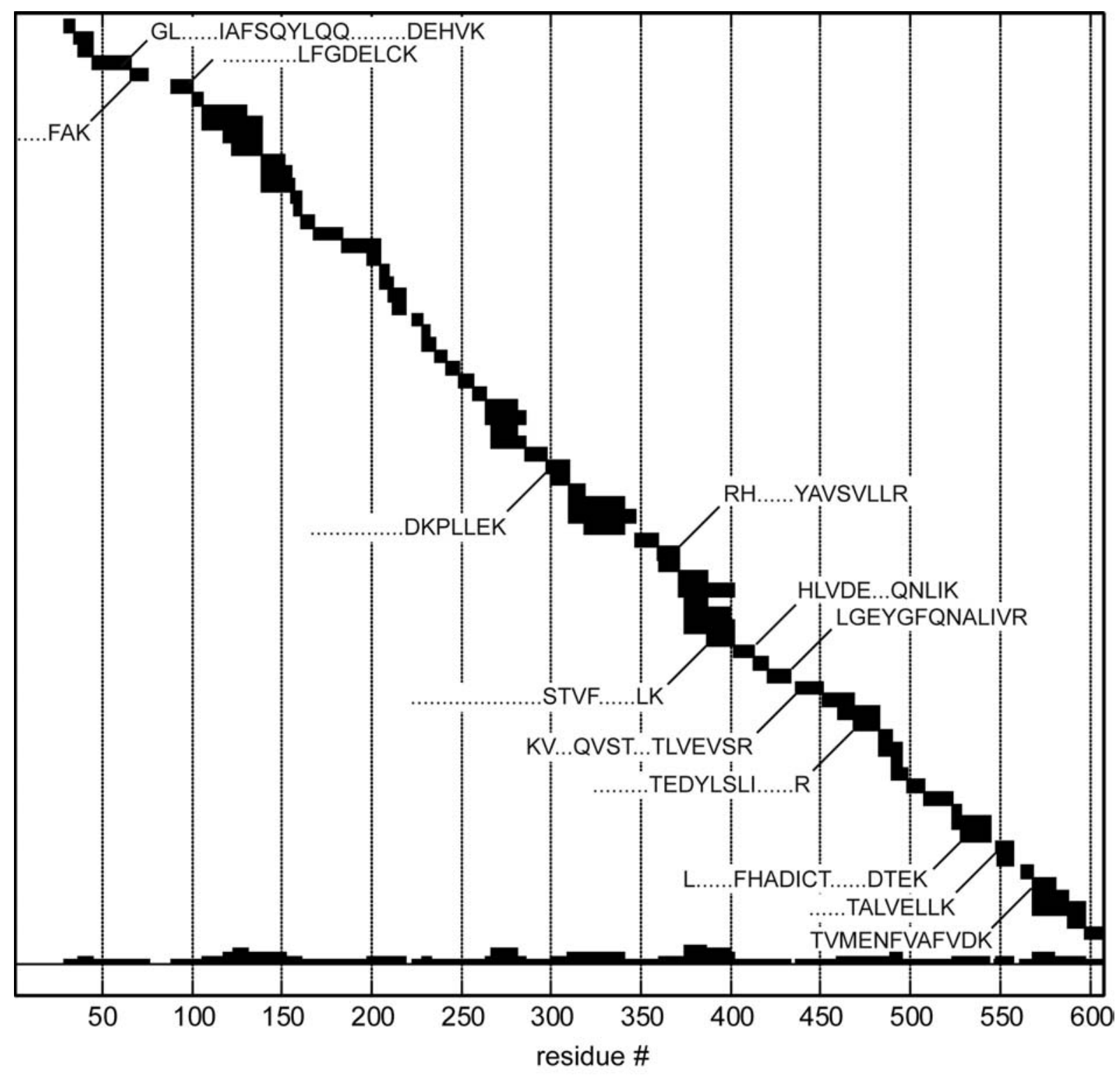

Figure 29. Tryptic peptides from bovine serum albumin, BSA, in an LC-FTICR mass chromatogram with sequence tags generated by on-line electron capture dissociation. Each sequence tag was sufficient to uniquely identify the protein and species in a Mascot sequence query using the measured precursor ion mass and the sequence tag [140].

Recent improvements include a data-dependent ECD, where electron energy and pulse duration depends on the $\mathrm{m} / \mathrm{z}$ and intensities of the tryptic fragments eluting from the column. The combination of ECD and LC in the characterization of larger proteins would be particularly useful in the presence of labile post-translational modifications such as those discussed here. In theory, all such modifications could be localized down to the amino acid residue and mass determined even in a large protein, assuming that a proteolytic enzyme or a combination of enzymes can cleave the protein into suitably large fragments for ECD. 


\section{PEPTIDE AND PROTEIN STRUCTURE AND INTERACTIONS}

\subsection{Methods}

Electrospray ionization mass spectrometry is a powerful tool in the study of biomolecular structure and interactions [172]. Protein/ligand complexes [108, 173], water clusters [174] and protein-bound water [173], intact ribosomes [78, 79] and even viral particles [80] have recently been successfully analyzed by mass spectrometric techniques. For an extensive review on non-covalent interactions and electrospray mass spectrometry, see Przybylski and Glocker [175]. The methods used in the studies of peptide structure and interactions differ from those generally used for peptide and protein electrospray mass spectrometry in some important aspects. Standard electrospray solvents with $50 \% \mathrm{MeOH}$ or $\mathrm{ACN}$ are replaced by $\mathrm{H}_{2} \mathrm{O}$ or a weak aqueous buffer. When studying non-covalent complexes, the conditions for electrospray and transfer of ions to the FTICR cell should also be such that the complexes survive to be measured.

In the Bruker FTICR instrument, the most important parameters are the capillary/skimmer potentials and the hexapole storage time. By varying these, the amount of non-covalent complexes surviving could be influenced. Higher capillary/skimmer voltage induces fragmentation by energetic collisions with residual gas molecules. The shorter the hexapole storage time, the more non-covalent complexes and clusters survive into the mass analyzer. The exact electrospray solvent compositions can be found in the method sections of papers VIII and IX. The graphite/polyimide coated fused silica capillaries [92, 101] were used for the experiments presented here. For a description of the electrospray interface and the FTICR mass spectrometer, see 2.1.5 and 2.1.6.

Non-covalently associated oligomers of peptides and proteins can be successfully studied by electrospray ionization mass spectrometry. At millimolar concentrations such aggregates can be formed in the electrospray process [176], however, certain peptides are known to self-associate in solution also at much lower concentrations, and these aggregates can also be studied by electrospray ionization. Here two types of such peptides, A $\beta$-peptides, forming the amyloid plaques intrinsic to Alzheimer's disease pathogenesis, and two tripeptides GPG and ALG shown to inhibit formation of HIV capsids in vitro $[177,178]$ are used to illustrate the applicability of ESI-FTICR mass spectrometry to the study of non-covalent interactions between biomolecules.

Another way mass spectrometry can be used to probe secondary and higher order structures is by measuring structure-dependent deuterium incorporation into peptides. A new approach to the analysis of such hydrogen/deuterium exchange (HDX) mass spectra will also be discussed in this chapter. 


\subsection{Results and Discussion}

\subsubsection{Amyloid $\beta$-Peptides, Structure and Aggregation}

The applicability of FTICR mass spectrometry to specific biological problems is illustrated by an investigation of early events in the oligomerization of the amyloid $\beta$-peptide (A $\beta$ ). The amyloid $\beta$-peptide is a $39-43$ amino acid long peptide derived from a larger transmembrane protein, the amyloid precursor protein (APP). A $\beta$ is the central component of neuritic plaques in the Alzheimer's disease (AD) brain. A large number of studies have focused on the structure, aggregational properties and fibril formation [179-183], and neurotoxicity [184, 185] of $A \beta$ peptides and their roles in AD.

$\mathrm{A} \beta$ peptides have a methionine residue in position 35. Oxidation of this methionine to methionine sulfoxide [Met35(O)] has been detected in samples extracted from post-mortem AD plaques [186]. Few studies have explored the consequences of Met35 oxidation on peptide chemical characteristics or biological actions. There are, however, some intriguing findings and some contradicting reports. Substituting the Met35 in synthetic A $\beta 1-42$ with Met35(O) results in enhanced $A \beta 1-42$ mediated cellular toxicity $[187,188]$. Whether these actions are a consequence of attenuated [189] or accelerated [188] fibril formation remains to be determined. $A \beta(1-$ $40)$ Met35(O) is less prone to aggregation and fibril formation compared to $A \beta(1-40)$, shown in circular dichroism studies [190]. This is also reflected by inhibition of conformational switching of $\mathrm{A} \beta(1-40) \mathrm{Met} 35(\mathrm{O})$ from random coil to $\beta$-sheet, observed using millimolar peptide concentrations and NMR [190]. The inhibited aggregation can, however, be overcome by increasing the concentration of $A \beta(1$ 40)Met35(O). Peptide fibril formation is a complex multi-step reaction involving the transitional formation of numerous oligomeric [191] and protofibrillar [192, 193] A $\beta$ species. Clarification of what steps in the oligomerization cascade underlie the affected aggregation rate of $\mathrm{A} \beta(1-40) \mathrm{Met} 35(\mathrm{O})$ would therefore increase our understanding of fibrillization and of the forces determining peptide structural changes. This could in turn be important for understanding the toxicities of different $\mathrm{A} \beta$ species.

This study was aimed at investigating the consequences of Met35 oxidation on the formation of small $A \beta$ peptide oligomers and also to attempt to find oxidation mediated rate limiting steps in the fibrillization cascade of the Met35(O) modified $\mathrm{A} \beta(1-40)$ peptide using ESI-FTICR mass spectrometry. Electrospray ionization mass spectrometry has previously been used to detect and characterize A $\beta$ peptides in vitro [194] as well as in vivo [195]. Using gentle ESI conditions, small aggregates of $A \beta(1-40)$ in water can be transferred to the gas phase and detected, making it possible to monitor aggregation of $A \beta(1-40)$ over time [194]. The oligomer distribution detected by ESI mass spectrometry [194] is similar to that approached in the short irradiation time limit of photo induced cross-linking experiments [196]. 
One advantage in using the high resolving power of a $9.4 \mathrm{~T}$ FTICR instrument is that homo- and heterooligomers of $A \beta(1-40)$ and $A \beta(1-40)$ Met $35(O)$ can easily be resolved. Furthermore, the sensitivity of the technique allows aggregation kinetics to be studied using nano- and micromolar concentrations of $\mathrm{A} \beta$, more closely resembling the in vivo situation [197].

The oxidation of Met35 was verified using nozzle/skimmer CID (Figure 30). The figure shows the C-terminal sequence of $A \beta(1-40) \operatorname{Met} 35(\mathrm{O})$ read from a series of quadruply charged $b$-ions [198] from the quadruply charged parent ion [A $\beta(1-$ 40)Met35(O) $\left.+4 \mathrm{H}^{+}\right]^{4+}$ resulting from collision induced dissociation in the capillary/ skimmer region. The $b$-ions covering residues 3-40 could be identified in this spectrum.

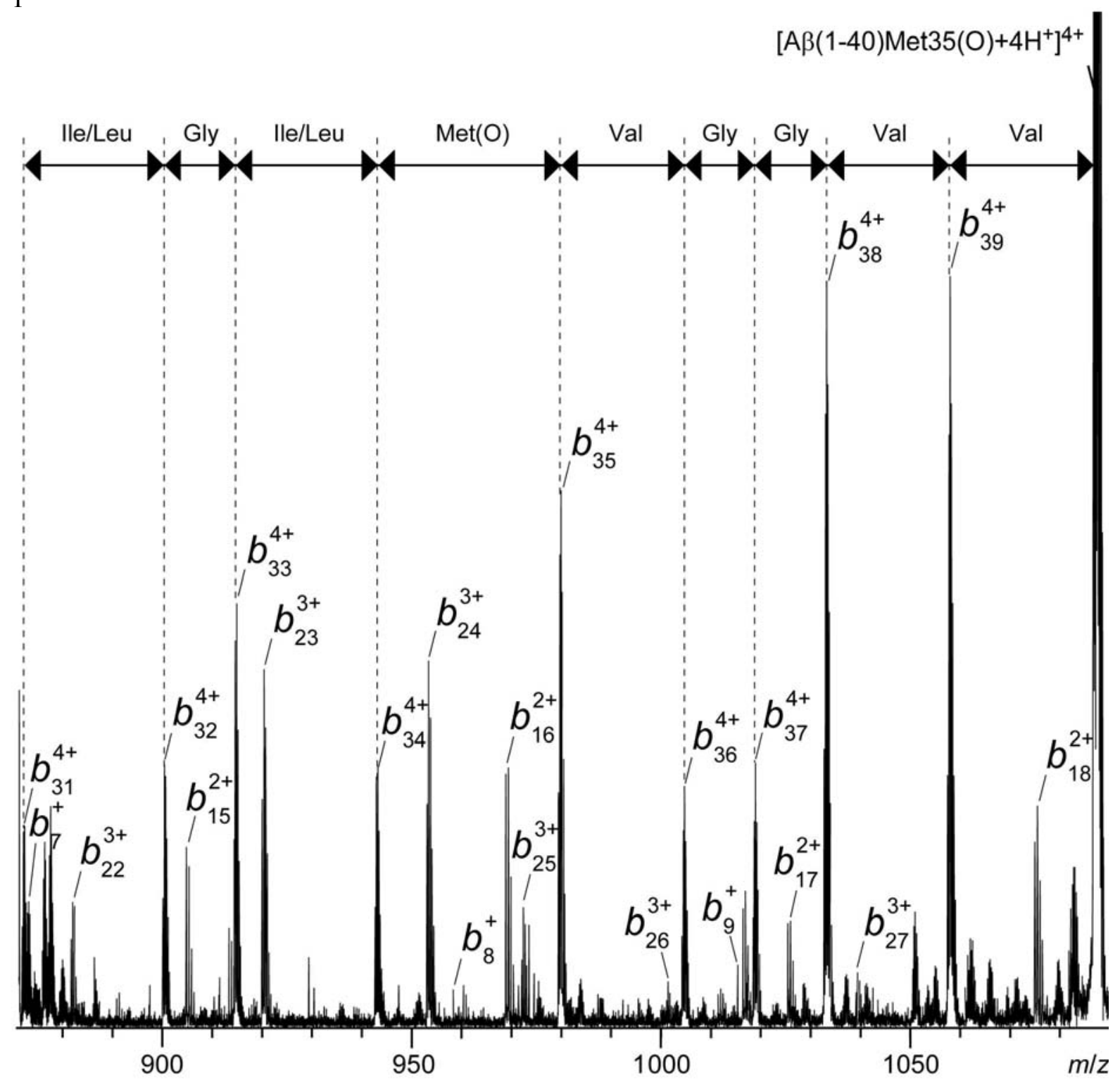

Figure 30. The C-terminal part of the sequence of $A \beta(1-40)$ Met35(O) can be read as a ladder of quadruply charged $b$-ions starting from the quadruply charged A $\beta(1-40) \operatorname{Met} 35(O)$. 
The mass difference measured between the most intense isotopic peaks and corresponding to the methionine residue was found to be $147.0356 \mathrm{Da}$, within the experimental mass measurement error from the theoretical monoisotopic mass of $\operatorname{Met}(\mathrm{O})\left(\mathrm{C}_{5} \mathrm{H}_{9} \mathrm{NO}_{2} \mathrm{~S}\right)$ of 147.0354 Da. As a comparison, the mass difference corresponding to a phenylalanine residue $\left(\mathrm{C}_{9} \mathrm{H}_{9} \mathrm{NO}\right)$ in this position would be 147.0684 Da. The almost complete sequence coverage demonstrates the ability to identify modifications of $\mathrm{A} \beta$ peptides while studying aggregation kinetics using the FTICR mass spectrometer.

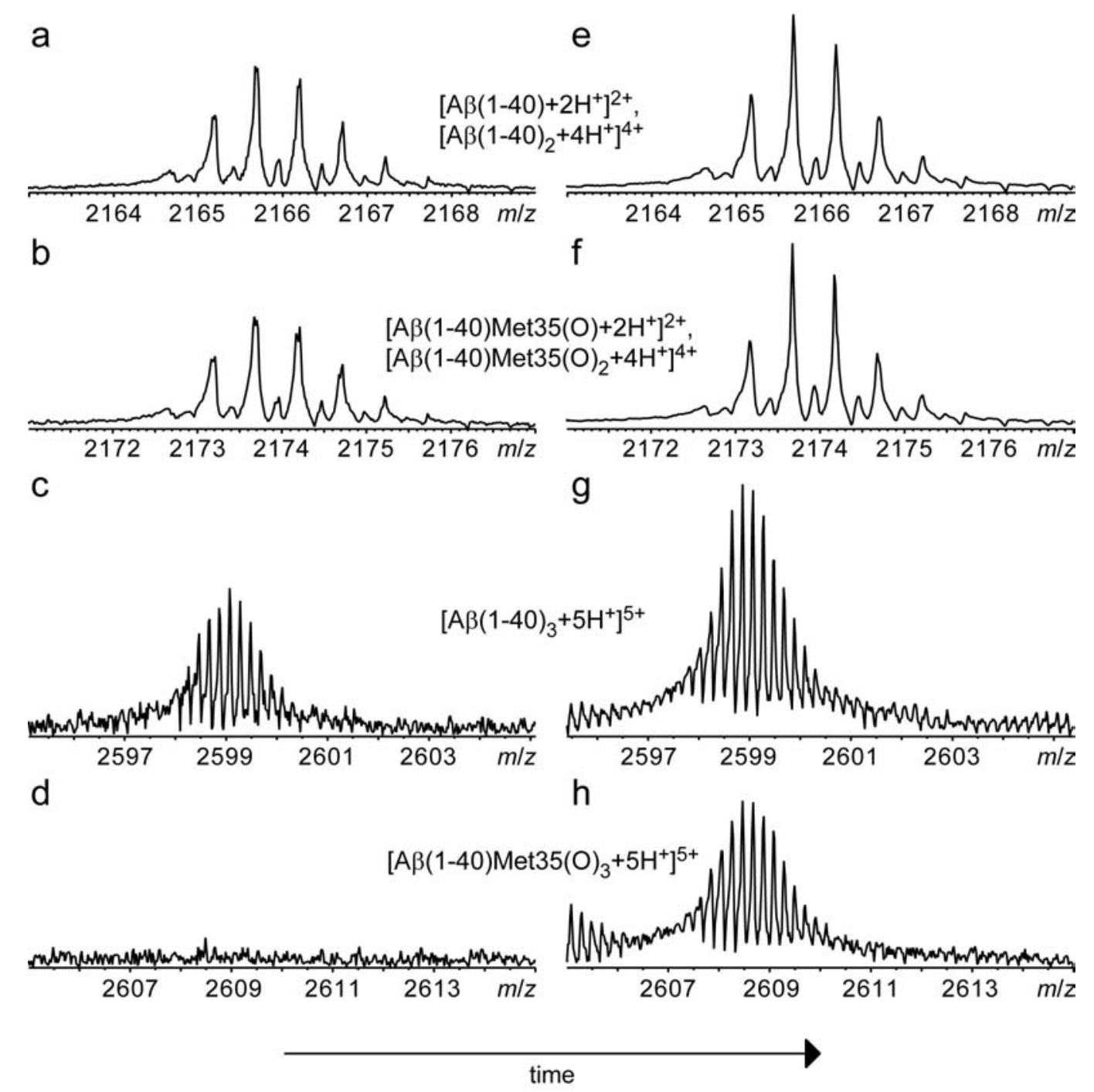

Figure 31. Oxidation of Met35 attenuates formation of trimers ( $d$ and $h$ ) (and tetramers) in $A \beta(1-40)$. The trimer signals converge after longer incubation ( $g$ and $h)$. The dimer intensities were very similar throughout the experiment $(a, b$, e, f).

The results show that $\mathrm{A} \beta(1-40) \mathrm{Met} 35(\mathrm{O})$ trimer and tetramer formation is significantly attenuated compared to $A \beta(1-40)$ (Figure 31). This in combination with 
the findings of others suggests that oxidation of Met35 inhibits a conformational switch in $A \beta(1-40)$ necessary for trimer but not dimer formation.

Random incorporation of $\mathrm{A} \beta(1-40)$ and $\mathrm{A} \beta(1-40) \mathrm{Met} 35(\mathrm{O})$ in homo- and heterooligomers could also be observed (Figure 32), indicating that oxidation of Met35 is of little or no importance in the formation of dimers. This is also consistent with the predicted structure of $A \beta(1-42)$ dimers where the Met35 side-chains are not located in the dimer interface. Slowing of the fibrillization process at this early step is likely to support prolonged solubility and clearance of $A \beta$ from brain and may reduce disease progression.

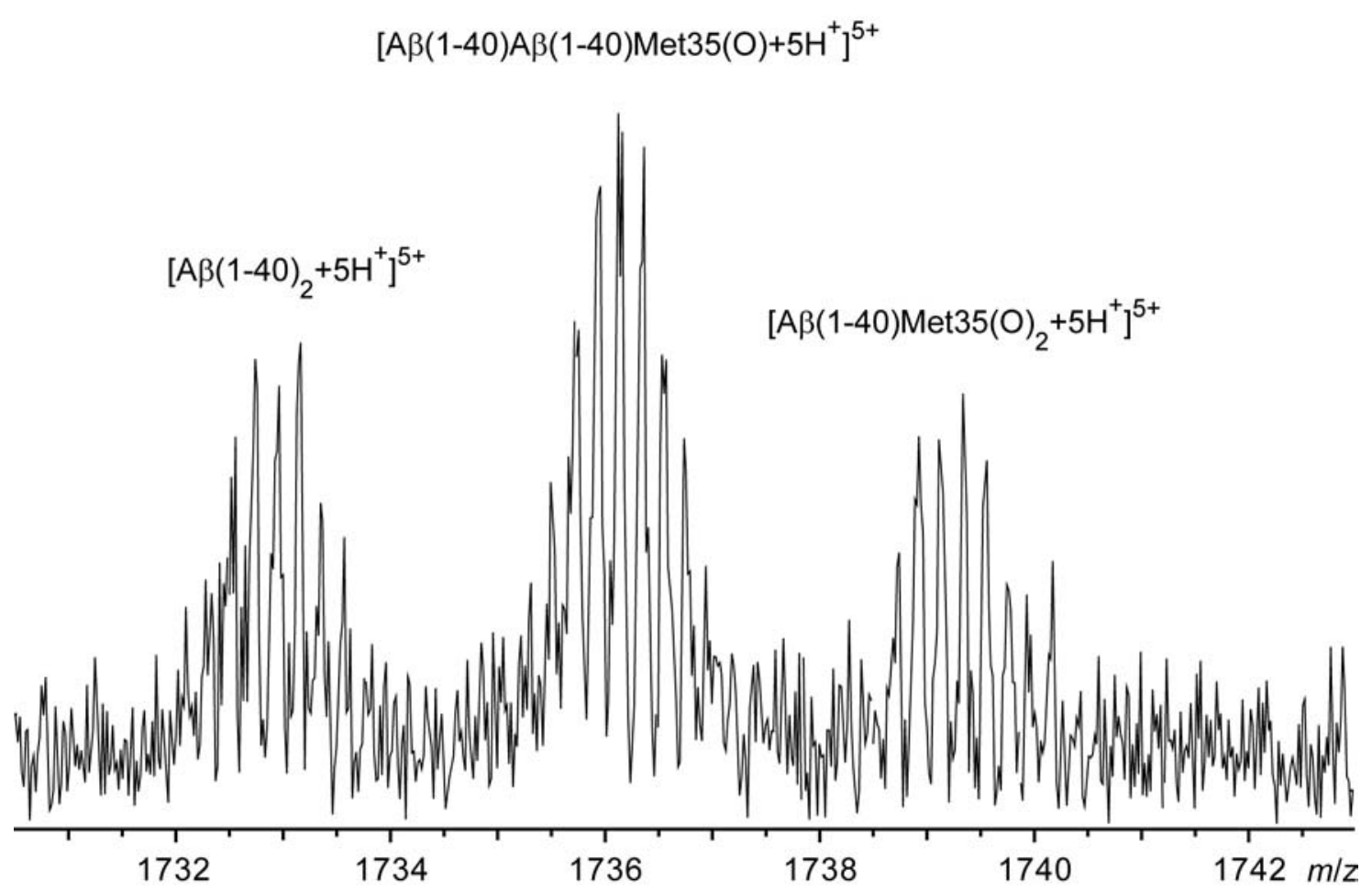

Figure 32. Random incorporation of $A \beta(1-40)$ and $A \beta(1-40)$ Met35(O) in homoand heterodimers after $12 \mathrm{~h}$ incubation illustrated by a nearly binomial distribution 1:2:1 of homo- and heterodimers in a 1:1 mixture of $A \beta(1-40)$ and A $\beta(1-40) \operatorname{Met} 35(\mathrm{O})$.

The "arctic" mutation in the APP gene is thought to cause AD by enhanced A $\beta$ protofibril formation in a family in northern Sweden [199]. The phenotype is the most similar to AD of all mutations in the A $\beta$ coding region of the APP gene. When analyzed by ESI-FTICR mass spectrometry, the arctic mutant $A \beta(1-40)$ peptide $[A \beta(1-$ 40)E22G] (Figure 33), shows similar random incorporation into dimers as wildtype A $\beta$ (Figure 34). 


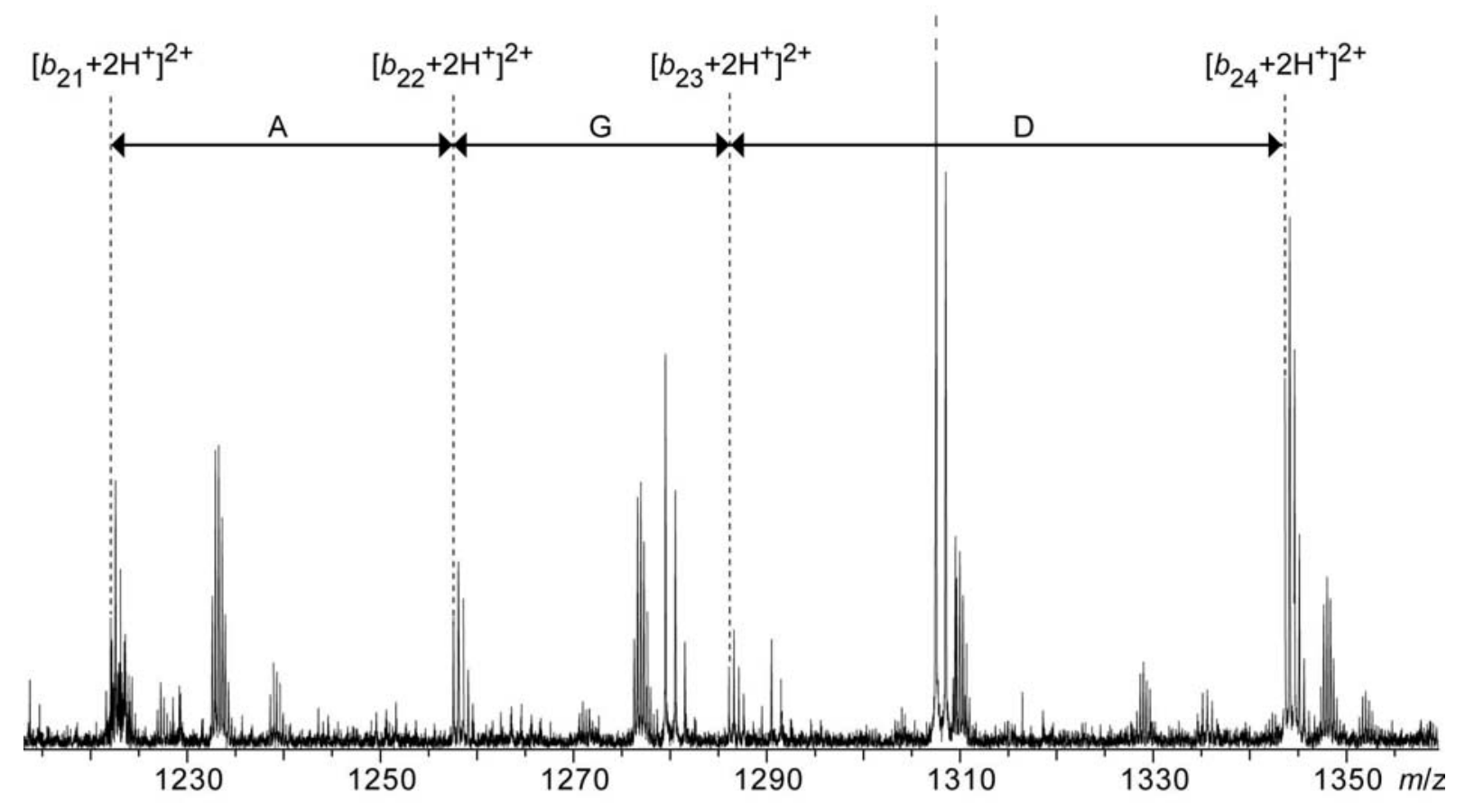

Figure 33. The arctic mutant peptide (E22G) [199] verified by nozzle/skimmer CID.

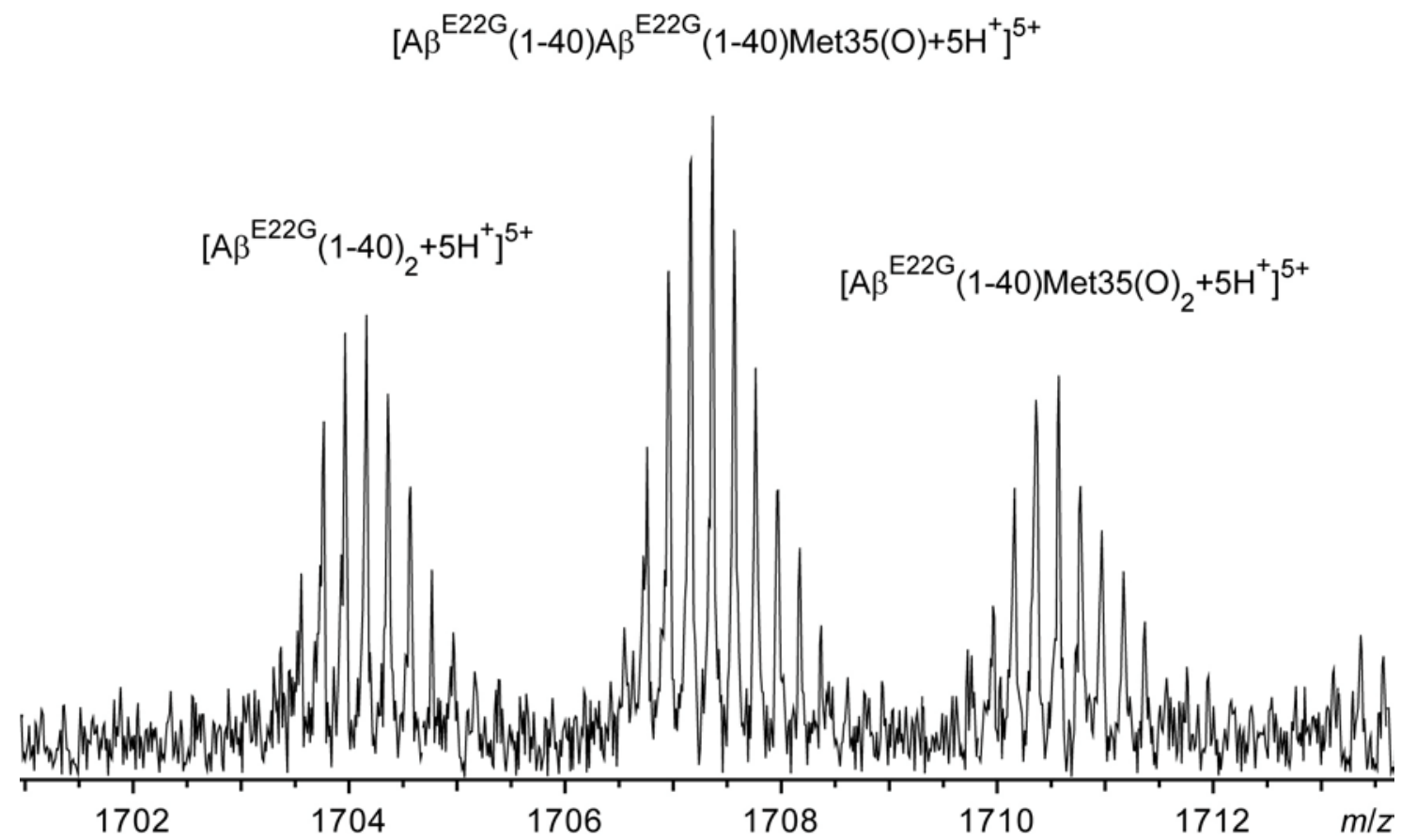

Figure 34. Random incorporation of $A \beta(1-40) E 22 G$ and $A \beta(1-40) E 22 G M e t 35(O)$ in homo- and heterodimers in a 1:1 mixture of oxidized and unoxidized peptide. Trimers showed a significant bias toward less oxidized species. 


\subsubsection{Non-Covalent Interaction between HIV-Inhibitory Tripeptides}

It was shown with electrospray ionization FTICR mass spectrometry that the tripeptides GPG and ALG, both with amidated and hydroxylated C-termini have oligomer distributions strongly biased toward dimers in a concentration range from low micromolar to millimolar. This is particularly interesting as the proposed mechanism of inhibition involves interaction with conserved GPG and ALG motifs in the HIV capsid protein p24 [177, 178]. Furthermore, it could be shown that dimers also form complexes with $\mathrm{Na}^{+}$and $\mathrm{K}^{+}$in micromolar concentrations, possibly by chelating the alkali ion in a "pocket" formed between the monomers in dimer structures from molecular dynamics and density functional theory by D. van der Spoel and J. Raber (unpublished results). Figure 35 shows mass spectra of protonated and potassiated dimers of GPG-OH and GPG-NH $\mathrm{N}_{2}$ with intensities scaled for clarity.
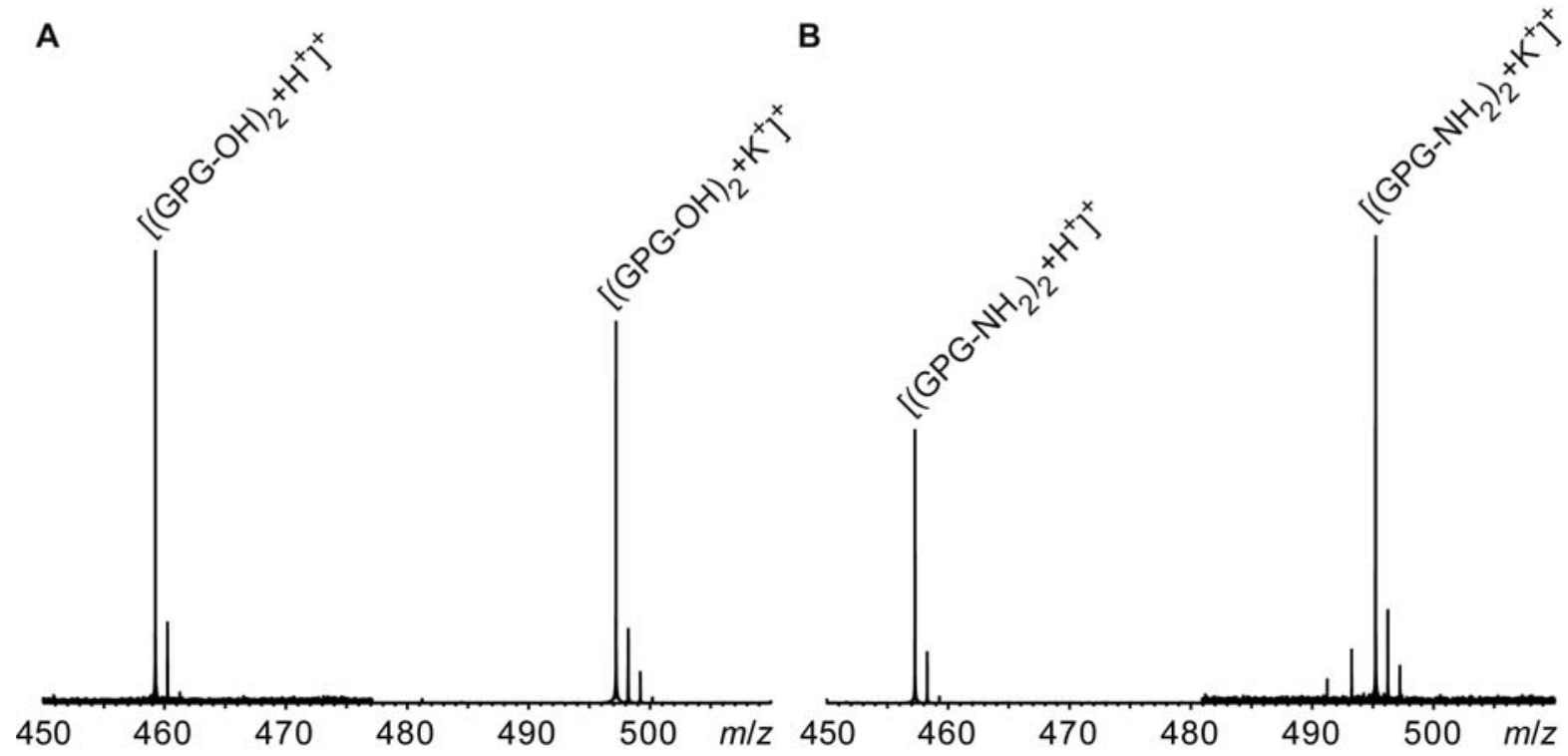

Figure 35. Protonated and potassiated dimers of GPG-OH (A) and GPG-NH $\mathrm{N}_{2}$ (B). Dimers were found to be preferentially formed, although weakly associated trimers and tetramers could be detected as well at millimolar concentrations.

One way of ascertaining relative stabilities of non-covalent complexes in the gas phase is by applying a variable amount of sustained off-resonance irradiation [108, 200]. The SORI frequency offset was $300 \mathrm{~Hz}$ from the monoisotopic peak and the irradiation power attenuation was varied between 28 and $42 \mathrm{~dB}$. The power attenuation $d B$ is defined as

$$
d B=20 \log \frac{V_{\max }}{V_{\text {applied }}}
$$

where $V_{\max }$ was $300 \mathrm{~V}$ (peak-to-peak). Argon was used as collision gas. 
The pressure in the FTICR was not known exactly but was precisely controlled by keeping the inlet reservoir pressure and the inlet time constant between measurements. The monoisotopic intensity was measured as a function of SORI attenuation. To eliminate any contribution from fluctuations in signal intensity due to the electrospray ionization or other external factors, the monoisotopic intensities were compared with the intensity of the first isotopic peak, unaffected by SORI of the monoisotopic species (if the frequency offset and bandwidth are small enough).

The results from SORI experiments of GPG dimers did not show any significant difference between the stabilities of protonated, sodiated and potassiated dimers as suggested from calculated structures with chelating alkali ions. There could be at least two explanations for this. The predicted structure could be incorrect or the difference in stability is too small to be detected by SORI in this experimental setup.

Figure 36 shows the ratio of monoisotopic species to the first isotopic species normalized to the native distribution, i.e. in absence of SORI, for sodiated and potassiated GPG-OH. Each dataset is the sum of 32 accumulated spectra and three such datasets were acquired for each attenuation and peptide, alternating between SORI of sodiated and potassiated dimers to avoid systematic errors caused by instrument drift.

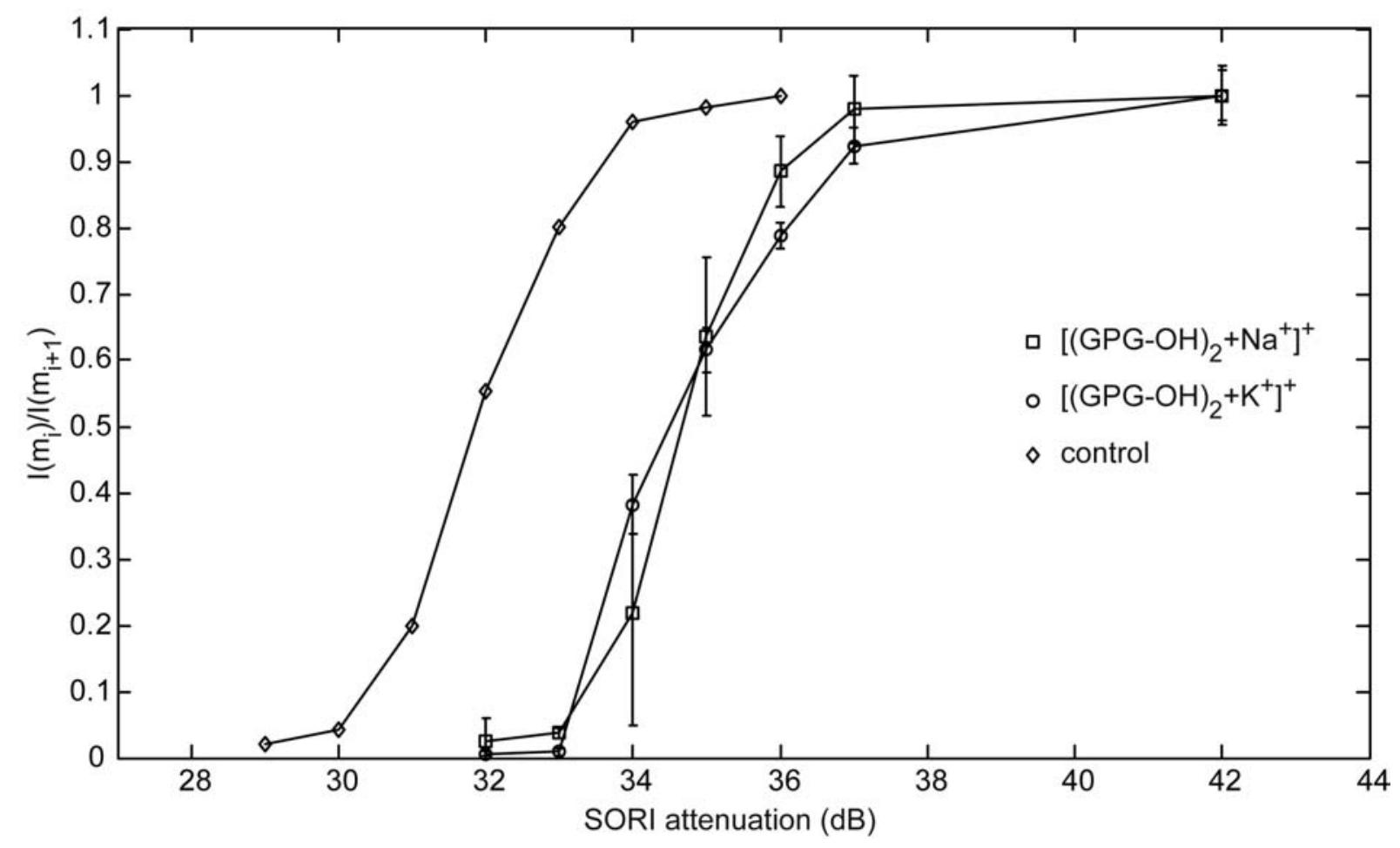

Figure 36. Dimer signals as functions of SORI amplitude. No significant difference in stability of complexes between GPG-OH dimers and $\mathrm{Na}^{+}$and $\mathrm{K}^{+}$ could be detected in these SORI experiments. 
These experiments are shown to illustrate another tool available in FTICR mass spectrometry - the possibility to study non-covalent associations of biomolecules and measure, at least in relative terms, the dissociation energies. Absolute measurements of gas-phase dissociation energies are possible, but require control and variation of vacuum system temperature and equilibrating trapped ions with the temperature of the system by infrared radiation [201, 202].

\subsubsection{Hydrogen/Deuterium Exchange Mass Spectrometry}

Hydrogen/deuterium exchange (HDX) experiments allow us to look at the stability and flexibility of a protein by monitoring the rate of exchange of amide hydrogens with the bulk solvent [203-208]. HDX can also be used to map intermolecular interaction interfaces [209]. This exchange rate depends on the intra- or intermolecular hydrogen bonding of the amide hydrogens and on the structural dynamics of the protein. Mass spectrometry can be used to detect the number of hydrogens exchanged for deuterium or vice versa by simply measuring the mass of the total peptide or protein and compare this with undeuterated controls.

The H/D exchange reaction can be quenched by lowering $\mathrm{pH}$ (or $\mathrm{pD}$ ) and temperature. The exchange rate has a minimum near $\mathrm{pH} 2.7$ [204]. To retrieve spatial information, the protein can be digested by a proteolytic enzyme. Pepsin is one such enzyme that function well at $\mathrm{pH} 2.7$ and $0^{\circ} \mathrm{C}$. The protein can also be fragmented in the gas phase by techniques such as CID or ECD, however the amide hydrogens may scramble and information may be lost, or more correctly, the amide deuterium distribution in the gas phase does not correlate with the distribution in liquid phase. These techniques can potentially give the exchange rates of individual amide hydrogens and information comparable with that obtained by HDX experiments in NMR. (NMR can also differentiate between $H$ and D, since D has integer spin and does not show up in ${ }^{1} \mathrm{H}-\mathrm{NMR}$.) The advantages of mass spectrometry over NMR in this context are a 10000-fold increase in sensitivity and a tenfold larger size of proteins that can be studied [207]. The speed and throughput is also much higher in MS than in NMR.

Figure 37 shows a peptic digest of sheep myoglobin after 1 min HDX. Note the width and shape of the isotopic distributions in this spectrum. These isotopic distributions are convolutions of the intrinsic isotopic distribution of the peptides and the distributions of incorporated deuterium. To extract information on the deuterium distributions, the experimentally obtained isotopic distributions can be fitted by a model that takes both the natural isotopic distribution and the incorporation of deuterium into account. At the same time, a combination of accurate mass measurement and goodness-of-fit for such a model can be used to identify peptic, CID, or ECD fragments in HDX mass spectra. This identification can also be done by 
comparison with undeuterated controls, but this does not allow for any change or drift in the conditions for peptic digestion or fragmentation. Paper IX shows that it is possible to combine the accurate mass determination and isotopic distributions in FTICR mass spectra to uniquely and correctly identify fragments, regardless of the amount of deuterium incorporation. The problem of fitting experimental and model isotopic distributions with respect to one or more free parameters in the model becomes computable when the isotopic distributions are calculated using the FFT method by Rockwood and van Orden [210, 211]. This method was further improved by extensive use of oversampling when calculating the transforms of the isotopic distributions, using integer mass modulo a small integer, typically 64 or 128, chosen to be larger than the width of the largest isotopic distribution to be calculated.

A computer program performing this task, AUTOHD, was made freely available on the Internet and has been used by several other groups working with HDX as a tool to study protein structure or folding.

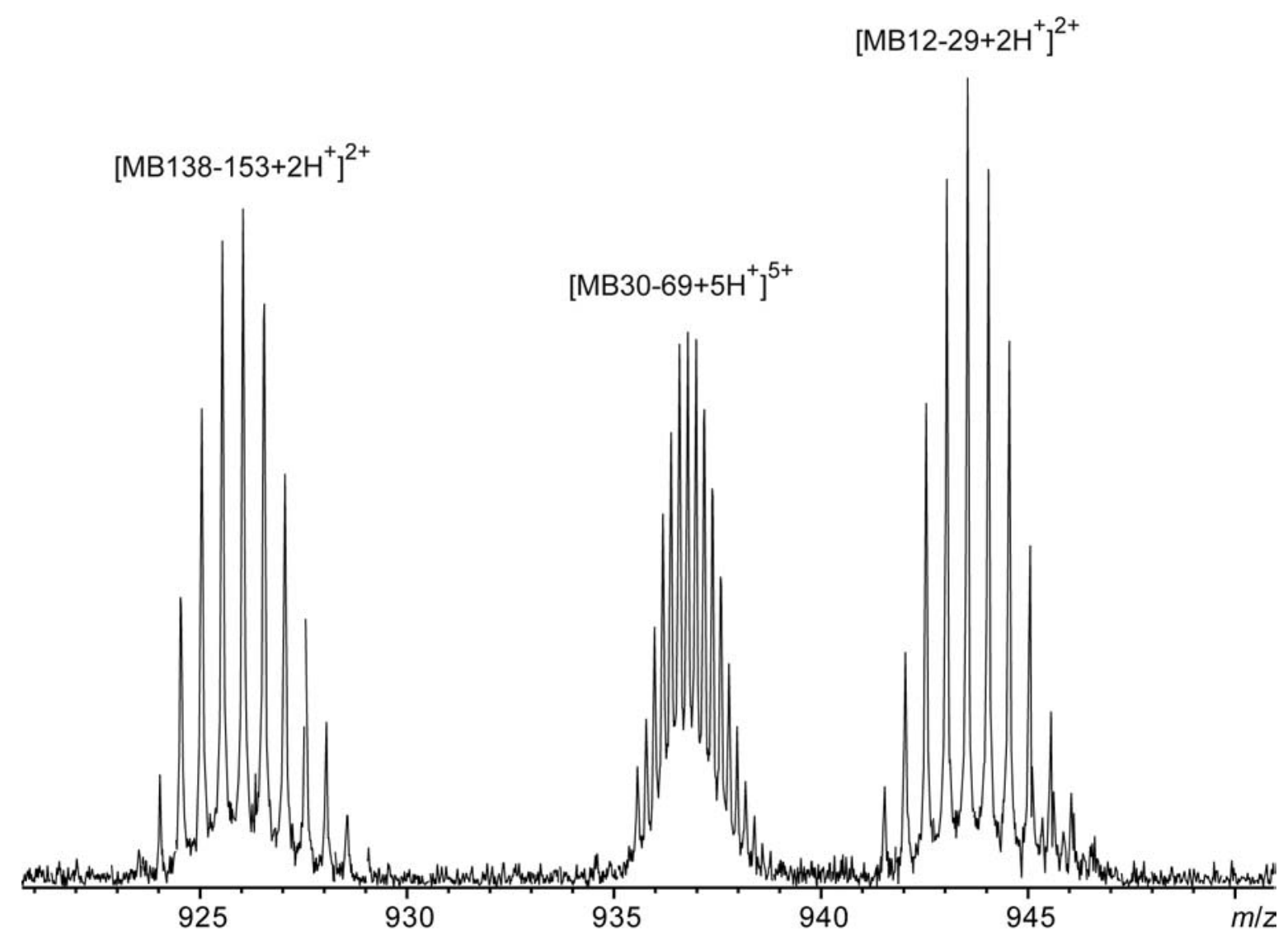

Figure 37. Part of sheep myoglobin (MB) FTICR mass spectrum after 1 min in $\mathrm{D}_{2} \mathrm{O}$ acquired by J. Buijs. The isotopic distributions contain information on the exchange rate constants and hence on the structural dynamics of the protein. 
Figure 38 shows typical output from AUTOHD applied to an FTICR mass spectrum of sheep myoglobin where the mass accuracy was not sufficient to identify the peptide. Virtually all peptic fragments could be correctly and uniquely identified in myoglobin spectra by this algorithm combining accurate mass determination and modeling of the amide deuterium exchange assuming one average probability for deuterium incorporation for all amide hydrogens in the peptide. What this algorithm does is to extract useful information from all measured data, not only averages over a large number of isotopic peaks. The information could be retrieved in the form of values of parameters in the model for amide deuterium incorporation fitted to experimental data. Alternatively, information could be used to choose between or discard structural-dependent models of deuterium incorporation. It is conceivable that a certain model may fit the average mass but not the isotopic distributions. Exchange of different amide hydrogens in proteins can be correlated [212], in which case the model will be more complicated and involve more parameters.

To summarize this chapter, we first note how versatile a tool FTICR mass spectrometry is in the study of peptides and proteins. The mass range and resolving power make it possible to study very small changes, for instance binding of a small ligand, in large proteins. While studying non-covalent interactions between peptides and smaller proteins, these can also be sequenced by methods such as electron capture dissociation or collision induced dissociation. This is useful if the peptide or protein also undergoes chemical modification. In FTICR mass spectrometry isotopic distributions are easily resolved. These distributions contain information that can be used in isotopic exchange studies [213, 214][Paper IX] or to determine oxidation states of metalloproteins [215][Paper IV]. 
A

$\mathrm{m} / \mathrm{z} 832.882[\mathrm{M}+5 \mathrm{H}+] 5+, \mathrm{M}=4164.408,18$ peaks found, maximum signal-to-background ratio $=167.6$

fragment minimum intensity $\chi^{2} \operatorname{argmin} \chi^{2}$ mass error (ppm) minimum total $\chi^{2} \quad 1-\alpha$

\begin{tabular}{llllll}
\hline$(62-99)$ & $1.45 \cdot 10^{2}$ & 0.076 & -0.8 & $1.45 \cdot 10^{2}$ & 1.000 \\
$(70-106)$ & $1.30 \cdot 10^{1}$ & 0.104 & -8.6 & $1.77 \cdot 10^{1}$ & 0.002 \\
$(10-46)$ & $6.16 \cdot 10^{2}$ & 0.315 & -31.1 & $6.76 \cdot 10^{2}$ & 1.000 \\
$(36-71)$ & $6.96 \cdot 10^{2}$ & 0.306 & -33.9 & $7.68 \cdot 10^{2}$ & 1.000 \\
$(47-84)$ & $1.42 \cdot 10^{3}$ & 0.349 & -1.4 & $1.41 \cdot 10^{3}$ & 1.000 \\
$(77-112)$ & $1.01 \cdot 10^{4}$ & 0.076 & 3.4 & $1.01 \cdot 10^{4}$ & 1.000 \\
$(76-111)$ & $1.01 \cdot 10^{4}$ & 0.076 & 3.4 & $1.01 \cdot 10^{4}$ & 1.000 \\
$(75-110)$ & $1.01 \cdot 10^{4}$ & 0.076 & 3.4 & $1.01 \cdot 10^{4}$ & 1.000 \\
$(34-69)$ & $9.78 \cdot 10^{3}$ & 0.206 & -16.6 & $9.80 \cdot 10^{3}$ & 1.000 \\
$(22-57)$ & $9.78 \cdot 10^{3}$ & 0.239 & -7.6 & $9.78 \cdot 10^{3}$ & 1.000 \\
$(91-127)$ & $9.78 \cdot 10^{3}$ & 0.305 & -6.5 & $9.78 \cdot 10^{3}$ & 1.000 \\
$(14-49)$ & $9.78 \cdot 10^{3}$ & 0.349 & -1.2 & $9.78 \cdot 10^{3}$ & 1.000 \\
$(31-65)$ & $1.10 \cdot 10^{5}$ & 0.349 & 2.5 & $1.10 \cdot 10^{5}$ & 1.000
\end{tabular}

B

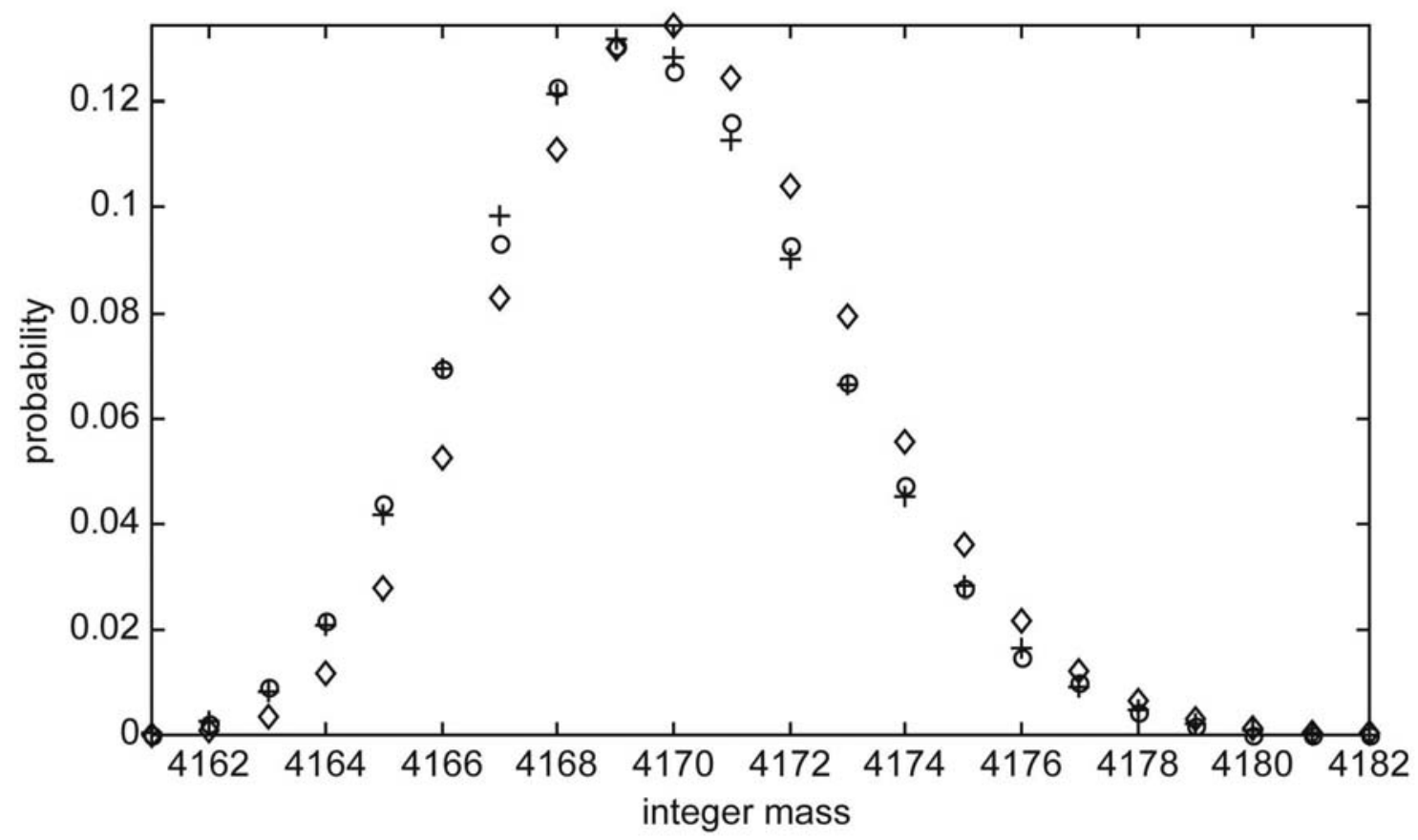

Figure 38. Output from computer program AUTOHD (A) fitting peptic fragment 70-106 of sheep myoglobin (crosses) to measured data (circles) (B). The second best fit was fragment 62-99 (diamonds). The bottom line is that isotopic distributions contain information on the exchange rate constants that can be extracted by algorithms such as this. The low value of $1-\alpha$ indicates that experimental errors were overestimated, however this does not compromise the performance of the algorithm. This approach works well for smaller proteins $(<50 \mathrm{kDa})$ [Paper IX]. 


\section{CONCLUSIONS}

The experiments and results presented in this thesis demonstrate that mass spectrometry, in particular Fourier transform ion cyclotron resonance mass spectrometry, is an extremely versatile and powerful tool in biology.

Further improvement of supporting liquid separations and in vacuo fragmentation techniques such as electron capture dissociation will increase the amount of information extracted from complex biological samples.

The results also illustrate that electrospray ionization can be successfully employed in the study of non-covalent complexes and their properties in liquid and gas phases. FTICR mass spectrometry is a competent tool in such analyses, providing several independent methods for obtaining sequence and structural information and for gasphase stability measurements.

I strongly believe that the potential of Fourier transform ion cyclotron resonance mass spectrometry has only begun to be realized in biochemistry and biology and that many new applications will be seen in the future. 


\section{ACKNOWLEDGEMENTS}

I am indebted to far more people than I can name, but first and foremost I greatly owe my supervisor, Per Håkansson for taking me on as a graduate student, letting a molecular biotechnologist loose in a physics laboratory. I appreciate all your kind and encouraging support and that you always took time to discuss ideas and answer my questions in an almost daily, and always unscheduled, manner. In particular, I am deeply grateful that you always let me follow my own leads and encouraged all my collaborative efforts; only making sure things were going forward. To be fair I should go on acknowledging you for several more pages, but since I know you think that would be a irresponsible waste of space (and time), I will acknowledge a few others who have also helped me in the course of my doctorate studies.

Starting the count in 1992, when I was first visiting the Ion Physics group for a sixweek summer project, I wish thank my supervisor Ann Brinkmalm (then Westman) for introducing me to mass spectrometry, but also Thomas Huth-Fehre, Arjan Quist and Curt Reimann and the rest of the people in the group in 1992. Jan Axelsson also belonged to the group in those days, and I remember you were trying to explain your experiments in the basement of old Teknikum to me. I also remember that Göran Possnert took time to show me the now "retired" tandem accelerator. I want to thank Jan for helping me getting started as a $\mathrm{PhD}$ student and for great travel company. Many thanks also to Jos Buijs, for all the nice work, the discussions during coffee breaks, lunches and parties, and for travel company to ASMS, ACMS and other events.

Jonas Bergquist has been my foremost collaborator outside the group during these years, and our work together has taught me a great deal on neuroscience and medicine, and I believe also on science in general, in the McMullin $S_{2}$ sense [216]. But most importantly, we have had a lot of fun in the lab - even when things did not go as expected. Thanks also for great travel company to ASMS, Society for Neuroscience and other meetings.

I also want to acknowledge the collaborations of Magnus Wetterhall, Klas Broo and Karin Markides at the Department of Analytical Chemistry. Thanks also to the Analytical Chemistry floorball team. Thanks to Hans Önnerud for great times inand outside the lab studying lignin and hemicellulose and Anita WestlindDanielsson and co-workers for great collaborations and discussions on $\mathrm{A} \beta$.

I want to acknowledge the scientific contributions, moral support and great company of fellow graduate students, visiting students or scholars or staff: Christian, Greger, Vassili, Kicki, Lotta, Nadia, Margareta, Youri, Mikael, Anna, Michael, AnneCatherine, Leif, Denny, Gamini, Ramal, Anne, Bogdan, Laurent, Raad, Doug and Yanwen. 
Johan Kjellberg, a great guy and incredible research engineer, deserves his own acknowledgement. Thanks for all the help! Thanks also to our secretary and partypingla \#1, Paula for all the help and assistance, company and fun. And thanks to the rest of the group for all the company during coffee breaks!

Thanks to Steve van Orden, Roland Jertz and Göhkan Baykut at Bruker Daltonics for all the help on the FTICR instrument and the XMASS software.

Thanks to Janos Hajdu for support and advice, Tove Sjögren, David van der Spoel, Johan Raber and all other people at BMC who helped me one way or another. Måns Ehrenberg and Johan Paulsson for everything I learned during my Master's project, Lars Larsson-Cohn, Henrik Brandén, Björn Larsson and Johan Rung for invaluable mathematical and theoretical advice and stimulating discussions. To Marta DabrioRamos and Per Andrén, Rebecka Klintenberg at SVA I can only apologize there never seemed to be enough time, but thanks for all the great discussions, travel company and hospitality.

Naturally, I cannot omit thanking the Ångström "Philosophy Club" for all entertaining discussions ("Digga Darwin, denne man som sammanhanget fann...") or my friends Andreas, Kin-Chun, Fredrik, Magnus, Jesper, Micke and Jörgen (and Lars and Björn again) for just being you.

On a more serious note I would also like to sincerely thank the generous funding from the Knut and Alice Wallenberg Foundation and travel grants from the Liljewalchs Foundation, the Helge Ax:son Johnson Foundation and the organizers of the $5^{\text {th }}$ International Symposium on Mass Spectrometry in the Health and Life Sciences: Molecular and Cellular Proteomics.

...och så tack till Mamma, Pappa, och Karin förstås - för allt. 


\section{REFERENCES}

1. F. H. C. Crick. On Protein Synthesis. in Symp Soc Exp Biol The Biological Replication of Macromolecules, XII. 1958.

2. F. H. C. Crick Nature 1970, 227, 561-563.

3. B. Alberts, A. Johnson, J. Lewis, M. Raff, K. Roberts and P. Walter, Molecular Biology of the Cell. 4 Ed. 2002: Garland Science Publishing.

4. R. D. Fleischmann, et al. Science 1995, 269, 496-512.

5. H. W. Mewes, et al. Nature 1997, 387, 7-65.

6. J. D. McPherson, et al. Nature 2001, 409, 934-941.

7. J. C. Venter, et al. Science 2001, 291, 1304-1351.

8. F. Sanger and E. O. P. Thompson Biochem J 1953, 53, 353-374.

9. M. O. Noordewier and P. V. Warren Trends Biotechnol 2001, 19, 412-415.

10. E. K. Lobenhofer, P. R. Bushel, C. A. Afshari and H. K. Hamadeh Environ Health Perspect 2001, 109, 881-891.

11. S. P. Gygi, Y. Rochon, B. R. Franza and R. Aebersold Mol Cell Biol 1999, 19, 17201730.

12. D. Stoll, M. F. Templin, M. Schrenk, P. C. Traub, C. F. Vohringer and T. O. Joos Front Biosci 2002, 7, C13-C32.

13. P. H. O'Farrell J Biol Chem 1975, 250, 4007-4021.

14. J. Klose Humangenetik 1975, 26, 231-243.

15. M. Mann, P. Hojrup and P. Roepstorff Biol Mass Spectrom 1993, 22, 338-345.

16. P. James, M. Quadroni, E. Carafoli and G. Gonnet Biochem Biophys Res Commun 1993, 195, 58-64.

17. W. J. Henzel, T. M. Billeci, J. T. Stults, S. C. Wong, C. Grimley and C. Watanabe Proc Natl Acad Sci U S A 1993, 90, 5011-5015.

18. D. J. C. Pappin, P. Hojrup and A. J. Bleasby Curr Biol 1993, 3, 327-332.

19. J. R. Yates, 3rd, S. Speicher, P. R. Griffin and T. Hunkapiller Anal Biochem 1993, 214, 397-408.

20. S. D. Patterson and R. Aebersold Electrophoresis 1995, 16, 1791-1814.

21. M. Mann and M. Wilm Anal Chem 1994, 66, 4390-4399.

22. A. Shevchenko, et al. Proc Natl Acad Sci U S A 1996, 93, 14440-14445.

23. O. N. Jensen, M. R. Larsen and P. Roepstorff Proteins 1998, Suppl, 74-89.

24. O. N. Jensen, M. Wilm, A. Shevchenko and M. Mann Methods Mol Biol 1999, 112, 571-588.

25. O. N. Jensen, A. V. Podtelejnikov and M. Mann Anal Chem 1997, 69, 4741-4750.

26. Y. Ho, et al. Nature 2002, 415, 180-183.

27. A. Shevchenko, D. Schaft, A. Roguev, W. W. M. P. Pijnappel, A. F. Stewart and A. Shevchenko Mol Cell Proteom 2002, 1,

28. T. J. Nelson, P. S. Backlund Jr, A. L. Yergey and D. L. Alkon Mol Cell Proteom 2002, 1,

29. J. J. Thomson Phil Mag 1897, 44, 295. 
30. E. O. Lawrence and M. S. Livingston Phys Rev 1932, 40, 19-35.

31. F. M. Penning Physica (Utrecht) 1936, III, 873-894.

32. http://www.chemheritage.org/ASMS/timeline.html The ASMS 50th Anniversary Volume History of Mass Sprectrometry Timeline.

33. W. E. Stephens Phys Rev 1946, 69, 691.

34. A. E. Cameron and D. F. Eggers Rev Sci Instrum 1948, 19, 605-607.

35. W. Paul and H. Steinwedel Z Naturforsch 1953, 8a, 448-450.

36. J. A. Hipple, H. Sommer and H. A. Thomas Phys Rev 1949, 76, 1877-1878.

37. H. Sommer, H. A. Thomas and J. A. Hipple Phys Rev 1951, 82, 697-702.

38. T. A. Lehman and M. M. Bursey, Ion Cyclotron Resonance Spectrometry. 1976, New York: John Wiley \& Sons, Inc.

39. M. B. Comisarow and A. G. Marshall Chem Phys Lett 1974, 25, 282-283.

40. M. B. Comisarow and A. G. Marshall J Mass Spectrom 1996, 31, 581-585.

41. A. G. Marshall Acc Chem Res 1996, 29, 307-316.

42. A. G. Marshall and L. Schweikhard Int J Mass Spectrom Ion Processes 1992, 118/119, 37-70.

43. A. G. Marshall, C. L. Hendrickson and G. S. Jackson Mass Spectrom Rev 1998, 17, 1-35.

44. H. R. Morris, T. Paxton, M. Panico, R. McDowell and A. Dell J Protein Chem 1997, 16, 469-479.

45. A. Shevchenko, et al. Rapid Commun Mass Spectrom 1997, 11, 1015-1024.

46. A. Shevchenko, A. Loboda, W. Ens and K. G. Standing Anal Chem 2000, 72, 2132-2141.

47. K. F. Medzihradszky, et al. Anal Chem 2000, 72, 552-558.

48. R. N. Hayes and M. L. Gross Methods Enzymol 1990, 193, 237-263.

49. R. A. Zubarev, N. L. Kelleher and F. W. McLafferty J Am Chem Soc 1998, 120, 3265-3266.

50. N. L. Kelleher, et al. Anal Chem 1999, 71, 4250-4253.

51. E. Mirgorodskaya, P. Roepstorff and R. A. Zubarev Anal Chem 1999, 71, 44314436.

52. R. A. Zubarev, et al. Anal Chem 2000, 72, 563-573.

53. A. Stensballe, O. N. Jensen, J. V. Olsen, K. F. Haselmann and R. A. Zubarev Rapid Commun Mass Spectrom 2000, 14, 1793-1800.

54. D. M. Horn, Y. Ge and F. W. McLafferty Anal Chem 2000, 72, 4778-4784.

55. K. F. Haselmann, B. A. Budnik and R. A. Zubarev Rapid Commun Mass Spectrom 2000, 14, 2242-2246.

56. F. W. McLafferty, et al. J Am Soc Mass Spectrom 2001, 12, 245-249.

57. S. D. Shi, M. E. Hemling, S. A. Carr, D. M. Horn, I. Lindh and F. W. McLafferty Anal Chem 2001, 73, 19-22.

58. D. M. Horn, K. Breuker, A. J. Frank and F. W. McLafferty J Am Chem Soc 2001, 123, 9792-9799.

59. K. Håkansson, H. J. Cooper, M. R. Emmett, C. E. Costello, A. G. Marshall and C. L. Nilsson Anal Chem 2001, 73, 4530-4536. 
60. Y. Ge, et al. J Am Chem Soc 2002, 124, 672-678.

61. S. K. Sze, Y. Ge, H. Oh and F. W. McLafferty Proc Natl Acad Sci U S A 2002, 99, 1774-1779.

62. E. W. Müller Z Physik 1951, 131, 136-142.

63. M. G. Inghram and R. Gomer J Chem Phys 1954, 22, 1279-1280.

64. H. D. Beckey, Principles of Field Ionization and Field Desorption Mass Spectrometry. 1977, Oxford, UK: Pergamon Press.

65. M. S. B. Munson and F. H. Field J Am Chem Soc 1966, 88, 2621-2630.

66. http://www.cea.com/tutorial.htm Secondary Ion Mass Spectrometry Theory Tutorial.

67. R. D. Macfarlane and D. F. Torgerson Science 1976, 191, 920-925.

68. P. Håkansson, et al. J Am Chem Soc 1982, 104, 2948-2949.

69. M. A. Posthumus, P. G. Kistenmaker and H. L. Meuzelaar Anal Chem 1978, 50, 985-991.

70. M. Barber, R. S. Bordoli, R. D. Sedgwick and A. N. Tyler Nature 1981, 293, 270275.

71. M. A. Moseley, L. J. Deterding, K. B. Tomer and J. W. Jorgenson J Chromatogr 1989, 480, 197-209.

72. M. Karas and F. Hillenkamp Anal Chem 1988, 60, 2299-2301.

73. K. Tanaka, H. Waki, Y. Ido, S. Akita, Y. Yoshida and T. Yoshida Rapid Commun Mass Spectrom 1988, 2, 151-153.

74. M. Yamashita and J. B. Fenn J Phys Chem 1984, 88, 4451-4459.

75. M. L. Aleksandrov, L. N. Gall, V. N. Krasnov, V. I. Nikolaev, V. A. Pavlenko and V. A. Shkurov Dokl Akad Nauk SSSR 1984, 277, 379-383.

76. P. Kebarle and L. Tang Anal Chem 1993, 65, A972-A986.

77. A. Gomez and K. Tang Phys Fluids 1994, 6, 404-414.

78. D. R. Benjamin, C. V. Robinson, J. P. Hendrick, F. U. Hartl and C. M. Dobson Proc Natl Acad Sci U S A 1998, 95, 7391-7395.

79. A. A. Rostom, et al. Proc Natl Acad Sci U S A 2000, 97, 5185-5190.

80. G. Siuzdak, et al. Chem Biol 1996, 3, 45-48.

81. K. D. Henry, E. R. Williams, B. H. Wang, F. W. McLafferty, J. Shabanowitz and D. F. Hunt Proc Natl Acad Sci USA 1989, 86, 9075-9078.

82. M. L. Vestal Chem Rev 2001, 101, 361-375.

83. A. L. Burlingame, R. K. Boyd and S. J. Gaskell Anal Chem 1998, 70, 647R-716R.

84. T. Matsuo and Y. Seyama J Mass Spectrom 2000, 35, 114-130.

85. X. Geng and F. E. Regnier J Chromatogr 1984, 296, 15-30.

86. C. C. Stacey, et al. Rapid Commun Mass Spectrom 1994, 8, 513-516.

87. J. Frenz, W. S. Hancock, W. J. Henzel and C. Horváth, Reversed Phase Chromatography in Analytical Biotechnology of Proteins, in HPLC of Biological Macromolecules: Methods and Applications. 1990, Marcel Dekker: New York. pp. 145-177. 
88. R. D. Voyksner, Combining Liquid Chromatography with Electrospray Mass Spectrometry, in Electrospray Ionization Mass Spectrometry, R. B. Cole, Editor. 1997, John Wiley \& Sons: New York. pp. 323-341.

89. K. B. Tomer Chem Rev 2001, 101, 297-328.

90. D. R. Barnidge, S. Nilsson, K. E. Markides, H. Rapp and K. Hjort Rapid Commun Mass Spectrom 1999, 994-1002.

91. D. R. Barnidge, S. Nilsson and K. E. Markides Anal Chem 1999, 4115-4118.

92. S. Nilsson, M. Wetterhall, J. Bergquist, L. Nyholm and K. E. Markides Rapid Commun Mass Spectrom 2001, 15, 1997-2000.

93. J. A. Olivares, N. T. Nguyen, C. R. Yonker and R. D. Smith Anal Chem 1987, 59, 1230-1232.

94. J. C. Severs, S. A. Hofstadler, Z. Zhao, R. T. Senh and R. D. Smith Electrophoresis 1996, 17, 1808-1817.

95. J. P. E. Landers, Handbook of Capillary Electrophoresis. 2 Ed. 1997, Boca Raton: CRC Press.

96. J. F. Kelly, L. Ramaley and P. Thibault Anal Chem 1997, 69, 51-60.

97. J. Samskog, M. Wetterhall, S. Jacobsson and K. Markides J Mass Spectrom 2000, 35, 919-924.

98. L. Rayleigh Phil Mag Ser 5 1882, 14, 184-186.

99. T. Covey, in Biochemical and Biotechnological Applications of Electrospray Ionization Mass Spectrometry, A. P. Snyder, Editor. 1995, American Chemical Society: Washington D. C. pp. 21-59.

100. R. B. Cole J Mass Spectrom 2000, 35, 763-772.

101. M. Wetterhall, S. Nilsson, K. E. Markides and J. Bergquist Anal Chem 2002, 74, 239-245.

102. J. B. J. Fourier, Théorie analytique de la chaleur. 1822, Paris: Chez Firmin Didot, Père et Fils.

103. J. W. Cooley and J. W. Tukey Math Comp 1965, 19, 297-301.

104. B. A. Vining, R. E. Bossio and A. G. Marshall Anal Chem 1999, 71, 460-467.

105. A. G. Marshall and F. R. Verdun, Fourier Transforms in NMR, Optical, and Mass Spectrometry. 1990, New York: Elsevier.

106. M. B. Comisarow and A. G. Marshall, Fourier Transform Ion Cyclotron Resonance Spectroscopy Method and Apparatus. Patent US3937955. 1976, Nicolet Technology Corporation: United States.

107. R. B. Cody and B. S. Freiser Int J Mass Spectrom Ion Phys 1982, 41, 199-204.

108. J. Gao, Q. Wu, J. Carbeck, Q. P. Lei, R. D. Smith and G. M. Whitesides Biophys J 1999, 76, 3253-3260.

109. J. Axelsson, M. Palmblad, K. Håkansson and P. Håkansson Rapid Commun Mass Spectrom 1999, 13, 474-477.

110. Y. O. Tsybin, et al. Rapid Commun Mass Spectrom 2001, 15, 1849-1854.

111. J. Axelsson, K. Håkansson, M. Palmblad and P. Håkansson Rapid Commun Mass Spectrom 1999, 13, 1550. 
112. K. Sannes-Lowery, R. H. Griffey, G. H. Kruppa, J. P. Speir and S. A. Hofstadler Rapid Commun Mass Spectrom 1998, 12, 1957-1961.

113. K. Håkansson, J. Axelsson, M. Palmblad and P. Håkansson J Am Soc Mass Spectrom 2000, 11, 210-217.

114. M. W. Senko, et al. Rapid Commun Mass Spectrom 1996, 10, 1824-1828.

115. D. M. Horn, R. A. Zubarev and F. W. McLafferty J Am Soc Mass Spectrom 2000, 11, 320-332.

116. M. W. Senko, S. C. Beu and F. W. McLafferty J Am Soc Mass Spectrom 1995, 6, 229-233.

117. M. W. Senko, S. C. Beu and F. W. McLafferty J Am Soc Mass Spectrom 1995, 6, 5256.

118. Z. Zhang and A. G. Marshall J Am Soc Mass Spectrom 1998, 9, 225-233.

119. S. P. Gygi, B. Rist, S. A. Gerber, F. Turecek, M. H. Gelb and R. Aebersold Nat Biotechnol 1999, 17, 994-999.

120. Z. Zhang, S. Guan and A. G. Marshall J Am Soc Mass Spectrom 1997, 8, 659-670.

121. J. Eriksson, B. T. Chait and D. Fenyö Anal Chem 2000, 72, 999-1005.

122. J. Bradley, Distribution-free statistical tests. 1968, Prentice-Hall: Englewood Cliffs, NJ.

123. W. Zhang and B. T. Chait Anal Chem 2000, 72, 2482-2489.

124. J. L. Meek Proc Natl Acad Sci U S A 1980, 77, 1632-1636.

125. M. T. Hearn, M. I. Aguilar, C. T. Mant and R. S. Hodges J Chromatogr 1988, 438, 197-210.

126. R. S. Hodges, J. M. Parker, C. T. Mant and R. R. Sharma J Chromatogr 1988, 458, 147-167.

127. C. T. Mant, N. E. Zhou and R. S. Hodges J Chromatogr 1989, 476, 363-375.

128. C. T. Mant, T. W. Burke, N. E. Zhou, J. M. Parker and R. S. Hodges J Chromatogr $1989,485,365-382$.

129. P. D. Grossman, J. C. Colburn and H. H. Lauer Anal Biochem 1989, 179, 28-33.

130. T. A. van de Goor, P. S. Janssen, J. W. van Nispen, M. J. van Zeeland and F. M. Everaerts J Chromatogr 1991, 545, 379-389.

131. M. Castagnola, L. Cassiano, R. Rabino, D. V. Rossetti and F. A. Bassi J Chromatogr 1991, 572, 51-58.

132. M. Castagnola, et al. J Chromatogr B Biomed Appl 1994, 656, 87-97.

133. A. Cifuentes and H. Poppe J Chromatogr A 1994, 680, 321-340.

134. A. Cifuentes and H. Poppe Electrophoresis 1995, 16, 516-524.

135. I. Messana, D. V. Rossetti, L. Cassiano, F. Misiti, B. Giardina and M. Castagnola J Chromatogr B Biomed Sci Appl 1997, 699, 149-171.

136. A. Cifuentes and H. Poppe Electrophoresis 1997, 18, 2362-2376.

137. M. Castagnola, et al. Electrophoresis 1998, 19, 1728-1732.

138. M. Castagnola, et al. Electrophoresis 1998, 19, 2273-2277.

139. J. L. Cornette, K. B. Cease, H. Margalit, J. L. Spouge, J. A. Berzofsky and C. DeLisi J Mol Biol 1987, 195, 659-685.

140. http://www.matrixscience.com The Matrix Science homepage. 
141. http://www.proteometrics.com The ProteoMetrics homepage.

142. http://prospector.ucsf.edu The ProteinProspector homepage.

143. R. D. Smith, et al. Electrophoresis 2001, 22, 1652-1668.

144. R. D. Smith, et al. Omics 2002, 6, 61-90.

145. J. Klose and U. Kobalz Electrophoresis 1995, 16, 1034-1059.

146. S. P. Gygi, G. L. Corthals, Y. Zhang, Y. Rochon and R. Aebersold Proc Natl Acad Sci U S A 2000, 97, 9390-9395.

147. F. Penin, C. Godinot and D. C. Gautheron Biochim Biophys Acta 1984, 775, 239245.

148. J. Corbett and M. J. Dunn Methods Mol Biol 1993, 19, 219-227.

149. C. Pasquali, I. Fialka and L. A. Huber Electrophoresis 1997, 18, 2573-2581.

150. A. Ingendoh, M. Witt, J. Fuchser and G. Baykut. High Mass Accuracy MALDI FTICR MS for Protein Identification out of Mixtures of Enzymatic Digests. in 49th ASMS Conference on Mass Spectrometry and Allied Topics. 2001. Chicago, Il.

151. R. A. Zubarev, P. Håkansson and B. U. R. Sundqvist Anal Chem 1996, 68, 40604063.

152. C. Masselon, G. A. Anderson, R. Harkewicz, J. E. Bruce, L. Pasa-Tolic and R. D. Smith Anal Chem 2000, 72, 1918-1924.

153. T. P. Conrads, G. A. Anderson, T. D. Veenstra, L. Pasa-Tolic and R. D. Smith Anal Chem 2000, 72, 3349-3354.

154. Y. Shen, et al. Anal Chem 2001, 73, 3011-3021.

155. L. Li, et al. Anal Chem 2001, 73, 3312-3322.

156. T. L. Quenzer, M. R. Emmett, C. L. Hendrickson, P. H. Kelly and A. G. Marshall Anal Chem 2001, 73, 1721-1725.

157. S. A. Hofstadler, F. D. Swanek, D. C. Gale, A. G. Ewing and R. D. Smith Anal Chem 1995, 67, 1477-1480.

158. S. A. Hofstadler, J. C. Severs, R. D. Smith, F. D. Swanek and A. G. Ewing Rapid Commun Mass Spectrom 1996, 10, 919-922.

159. L. Yang, C. S. Lee, S. A. Hofstadler, L. Pasa-Tolic and R. D. Smith Anal Chem 1998, 70, 3235-3241.

160. P. K. Jensen, et al. Anal Chem 1999, 71, 2076-2084.

161. P. K. Jensen, et al. Electrophoresis 2000, 21, 1372-1380.

162. M. E. Belov, et al. Anal Chem 2001, 73, 253-261.

163. M. E. Belov, M. V. Gorshkov, K. Alving and R. D. Smith Rapid Commun Mass Spectrom 2001, 15, 1988-1996.

164. M. E. Belov, et al. Anal Chem 2001, 73, 5052-5060.

165. M. E. Belov, M. V. Gorshkov, H. R. Udseth and R. D. Smith J Am Soc Mass Spectrom 2001, 12, 1312-1319.

166. A. V. Aho, B. W. Kernighan and P. J. Weinberger, The AWK Programming Language. 1988: Addison-Wesley.

167. V. Sanz-Nebot, I. Toro, F. Benavente and J. Barbosa J Chromatogr A 2002, 942, 145-156.

168. B. Rost J Struct Biol 2001, 134, 204-218. 
169. R. P. Harvey, et al. Proc Natl Acad Sci U S A 1986, 83, 1084-1088.

170. J. C. Venter, M. D. Adams, G. G. Sutton, A. R. Kerlavage, H. O. Smith and M. Hunkapiller Science 1998, 280, 1540-1542.

171. N. L. Kelleher, H. Y. Lin, G. A. Valaskovic, D. J. Aaserud, E. K. Fridriksson and F. W. McLafferty J Am Chem Soc 1999, 121, 806-812.

172. J. E. Bruce, et al. Rapid Commun Mass Spectrom 1995, 9, 644-650.

173. A. M. Last and C. V. Robinson Curr Opin Chem Biol 1999, 3, 564-570.

174. S. W. Lee, H. Cox, W. A. Goddard and J. L. Beauchamp J Am Chem Soc 2000, 122, 9201-9205.

175. M. Przybylski and M. O. Glocker Angew Chem Int Ed Engl 1996, 35, 806-826.

176. C. K. Meng and J. B. Fenn Ord Mass Spectrom 1991, 26, 542-549.

177. J. Su, et al. J Hum Virol 2001, 4, 1-7.

178. J. Su, et al. J Hum Virol 2001, 4, 8-15.

179. J. T. Jarrett and P. T. Lansbury, Jr. Cell 1993, 73, 1055-1058.

180. P. T. J. Lansbury, et al. Nat Struct Biol 1995, 2, 990-998.

181. R. Kisilevsky and P. E. Fraser Crit Rev Biochem Mol Biol 1997, 32, 361-404.

182. D. B. Teplow Amyloid 1998, 5, 121-142.

183. T. H. Huang, D. S. Yang, P. E. Fraser and A. Chakrabartty J Biol Chem 2000, 275, 36436-36440.

184. L. L. Iversen, R. J. Mortishire-Smith, S. J. Pollack and M. S. Shearman Biochem J 1995, 311, 1-16.

185. T. Harkany, et al. Rev Neurosci 2000, 11, 329-382.

186. Y. M. Kuo, et al. J Biol Chem 2001, 276, 12991-12998.

187. C. J. Pike, A. J. Walencewicz-Wasserman, J. Kosmoski, D. H. Cribbs, C. G. Glabe and C. W. Cotman J Neurochem 1995, 64, 253-265.

188. B. Seilheimer, B. Bohrmann, L. Bondolfi, F. Muller, D. Stuber and H. Dobeli J Struct Biol 1997, 119, 59-71.

189. S. W. Snyder, et al. Biophys J 1994, 67, 1216-1228.

190. A. A. Watson, D. P. Fairlie and D. J. Craik Biochemistry 1998, 37, 12700-12706.

191. W. L. Klein, G. A. Krafft and C. E. Finch Trends Neurosci 2001, 24, 219-224.

192. D. M. Walsh, A. Lomakin, G. B. Benedek, M. M. Condron and D. B. Teplow J Biol Chem 1997, 272, 22364-22372.

193. J. D. Harper, S. S. Wong, C. M. Lieber and P. T. Lansbury Chem Biol 1997, 4, 119125.

194. X. G. Chen, S. K. Brining, V. Q. Nguyen and A. L. Yergey Faseb J 1997, 11, 817823.

195. T. E. Golde, C. B. Eckman and S. G. Younkin Biochim Biophys Acta 2000, 1502, 172-187.

196. G. Bitan, A. Lomakin and D. B. Teplow J Biol Chem 2001, 276, 35176-35184.

197. K. Sennvik, J. Fastbom, M. Blomberg, L. O. Wahlund, B. Winblad and E. Benedikz Neurosci Lett 2000, 278, 169-172.

198. P. Roepstorff and J. Fohlman Biol Mass Spectrom 1984, 11, 601.

199. C. Nilsberth, et al. Nat Neurosci 2001, 4, 887-893. 
200. R. D. Smith, J. E. Bruce, Q. Wu and Q. P. Lei Chem Soc Rev 1997, 26, 191-202.

201. R. M. A. Heeren and K. Vékey Rapid Commun Mass Spectrom 1998, 12, 1175-1181.

202. E. F. Strittmatter, P. D. Schnier, J. S. Klassen and E. R. Williams J Am Soc Mass Spectrom 1999, 10, 1095-1104.

203. G. Thevenon-Emeric, J. Kozlowski, Z. Zhang and D. L. Smith Anal Chem 1992, 64, 2456-2458.

204. Z. Zhang and D. L. Smith Protein Sci 1993, 2, 522-531.

205. D. L. Smith and Z. Q. Zhang Mass Spectrom Rev 1994, 13, 411-429.

206. Z. Zhang, C. B. Post and D. L. Smith Biochemistry 1996, 35, 779-791.

207. D. L. Smith, Y. Deng and Z. Zhang J Mass Spectrom 1997, 32, 135-146.

208. J. R. Engen and D. L. Smith Methods Mol Biol 2000, 146, 95-112.

209. J. G. Mandell, A. M. Falick and E. A. Komives Proc Natl Acad Sci USA 1998, 95, 14705-14710.

210. A. L. Rockwood Rapid Commun Mass Spectrom 1995, 9, 103-105.

211. A. L. Rockwood and S. L. Van Orden Anal Chem 1996, 68, 2027-2030.

212. C. B. Arrington and A. D. Robertson J Mol Biol 2000, 300, 221-232.

213. J. Buijs, K. Håkansson, C. Hagman, P. Håkansson and S. Oscarsson Rapid Commun Mass Spectrom 2000, 14, 1751-1756.

214. J. Buijs, C. Hagman, K. Håkansson, J. H. Richter, P. Håkansson and S. Oscarsson J Am Soc Mass Spectrom 2001, 12, 410-419.

215. F. He, C. L. Hendrickson and A. G. Marshall J Am Soc Mass Spectrom 2000, 11, $120-126$.

216. E. McMullin, The History and Philosophy of Science: A Taxonomy, in Historical \& Philosophical Perspectives of Science, R. Stuewer, Editor. 1970, University of Minnesota Press: Minneapolis. pp. 12-67. 